\title{
Comparative Study of Materials' Behaviour in Supercritical Water and Superheated Steam
}

by

\section{Peter McClure}

A thesis submitted to the Faculty of Graduate and Postdoctoral Affairs in partial fulfillment of the requirements for the degree of

\section{Master of Applied Science}

in

Sustainable Energy

Carleton University

Ottawa, Ontario

(C)2013

Peter McClure 
Library and Archives

Canada

Published Heritage

Branch

395 Wellington Street

Ottawa ON K1A ON4

Canada
Bibliothèque et

Archives Canada

Direction du

Patrimoine de l'édition

395 , rue Wellington

Ottawa ON K1A ON4

Canada
Your file Votre référence

ISBN: 978-0-494-94638-1

Our file Notre référence

ISBN: 978-0-494-94638-1
NOTICE:

The author has granted a nonexclusive license allowing Library and Archives Canada to reproduce, publish, archive, preserve, conserve, communicate to the public by telecommunication or on the Internet, loan, distrbute and sell theses worldwide, for commercial or noncommercial purposes, in microform, paper, electronic and/or any other formats.

The author retains copyright ownership and moral rights in this thesis. Neither the thesis nor substantial extracts from it may be printed or otherwise reproduced without the author's permission.
AVIS:

L'auteur a accordé une licence non exclusive permettant à la Bibliothèque et Archives Canada de reproduire, publier, archiver, sauvegarder, conserver, transmettre au public par télécommunication ou par l'Internet, prêter, distribuer et vendre des thèses partout dans le monde, à des fins commerciales ou autres, sur support microforme, papier, électronique et/ou autres formats.

L'auteur conserve la propriété du droit d'auteur et des droits moraux qui protege cette thèse. $\mathrm{Ni}$ la thèse ni des extraits substantiels de celle-ci ne doivent être imprimés ou autrement reproduits sans son autorisation.
In compliance with the Canadian Privacy Act some supporting forms may have been removed from this thesis.

While these forms may be included in the document page count, their removal does not represent any loss of content from the thesis.
Conformément à la loi canadienne sur la protection de la vie privée, quelques formulaires secondaires ont été enlevés de cette thèse.

Bien que ces formulaires aient inclus dans la pagination, il n'y aura aucun contenu manquant. 


\section{Abstract}

Advanced supercritical water cooled nuclear reactors require materials to survive a corrosive, high temperature fluid environment, in addition to radiation effects. This thesis details corrosion testing of A286 (iron-nickel based), AISI 310 stainless steel, and IN625 (nickel based) in supercritical water (29 MPa) and superheated steam (ambient pressure) at $650^{\circ} \mathrm{C}$ to understand effects of materials' composition and fluid pressure.

A superheated steam testing rig was designed and an autoclave was assembled. Samples were tested for 100,200 , and 300 hours, then analysed for weight gain and surface appearance; surface morphology and composition were determined through scanning electron microscope imaging and energy-dispersive $\mathrm{X}$-ray spectroscopy.

A286 demonstrated poor corrosion resistance due to low chromium content. AISI 310 and IN625 demonstrated similarly strong corrosion resistance in supercritical water through formation of adherent scales, but poor corrosion resistance in superheated steam due to scale spallation. Supercritical water and superheated steam corrosion behaviour were non-analogous. 


\section{Acknowledgements}

This thesis project was a challenging and rewarding undertaking, and there are a number of people I would like to thank for their assistance. This project was suggested by my supervisor Professor Xiao Huang, who has been a tremendous source of support and help throughout the entire process. Without Dr. Huang's guidance and advice this thesis would never have come together.

I would like to thank Fred Barrett for his technical support and assistance. He was instrumental in assembling the equipment needed for this project, and was always willing to help out when I got in over my head. I would also like to thank Dr. Jianqun Wang from the SEM laboratory at Carleton, who made sure I got great results as fast as possible.

I could not have finished this project without the help of Jessica Dubinsky, who was always there to support me when I needed it, and who has helped me tremendously in editing and preparing this report. I would also like to thank my family for their support throughout my entire academic career. I could not have gotten where I am now without all of your help. 


\section{Table of Contents}

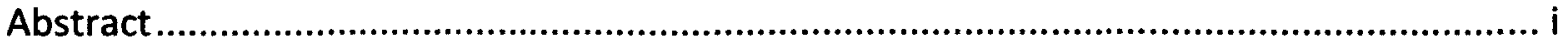

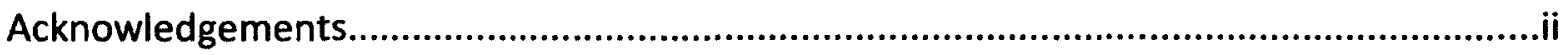

List of Figures ......................................................................................................... vi

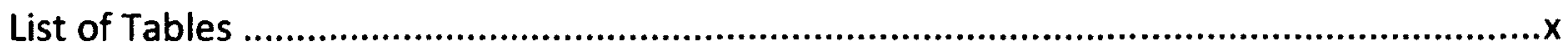

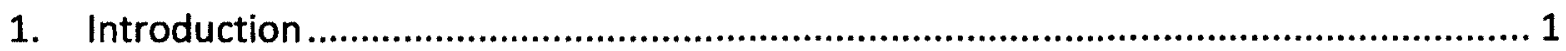

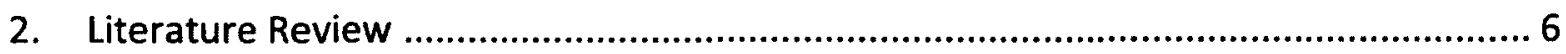

2.1. Oxidation and Corrosion in Supercritical Water ................................................ 6

2.1.1. Properties of Supercritical Water .........................................................

2.1.2. Corrosion Mechanisms and Factors........................................................ 11

2.2. Oxidation and Corrosion in Superheated Steam ............................................ 17

2.3. Candidate Materials for Supercritical Water Reactors ....................................... 20

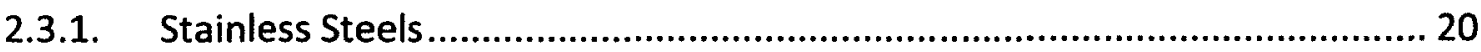

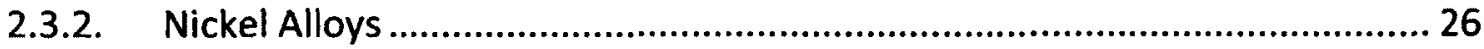

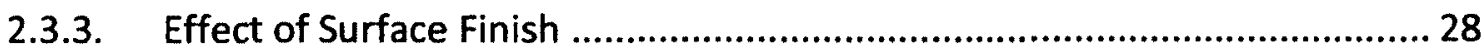

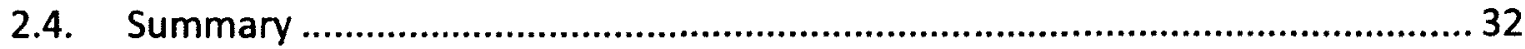

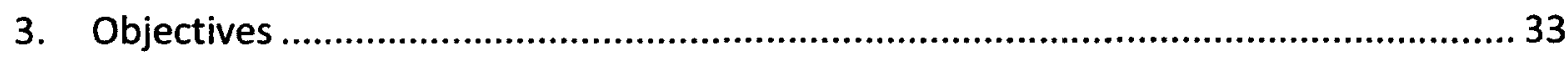

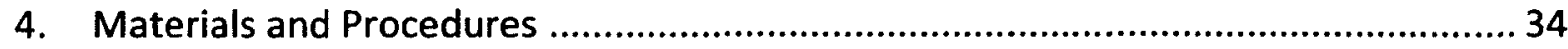

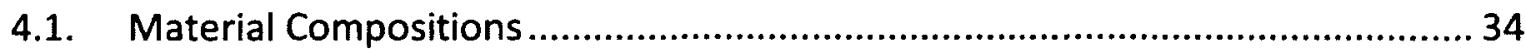




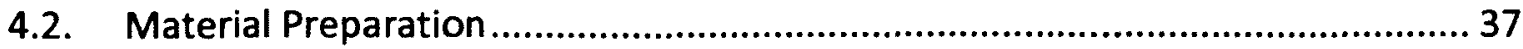

4.3. Superheated Steam Testing Rig …............................................................... 39

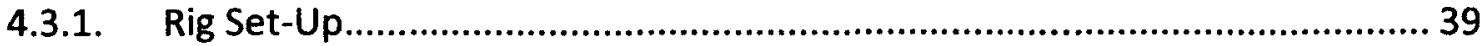

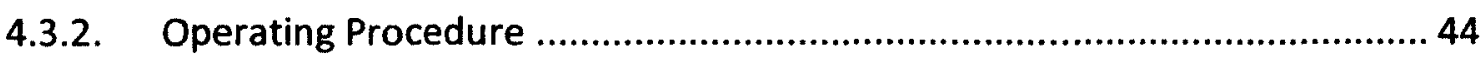

4.4. Supercritical Water Testing Autoclave ...........................................................46

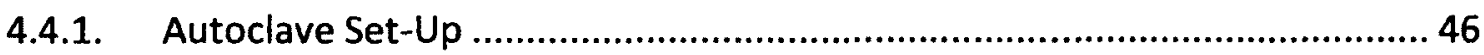

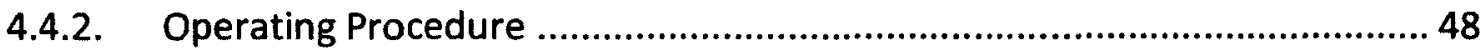

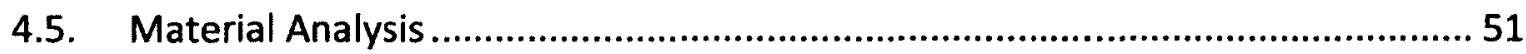

4.5.1. Visual Inspection .................................................................................... 51

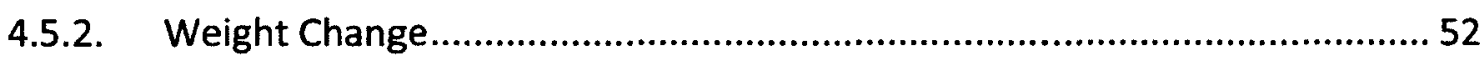

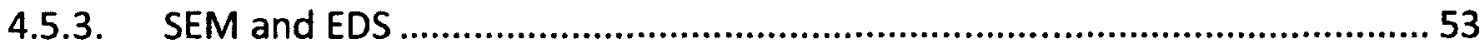

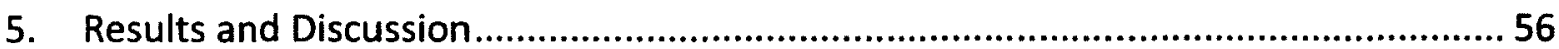

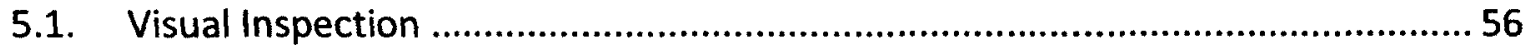

5.1.1. Supercritical Water Exposed Samples ……..............................................56

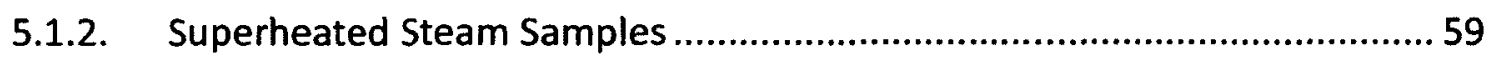

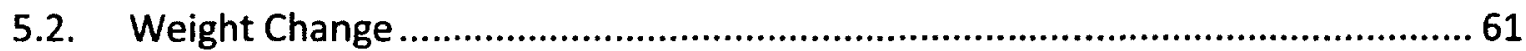

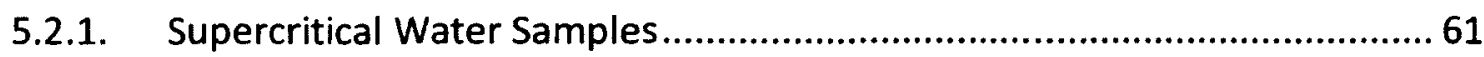

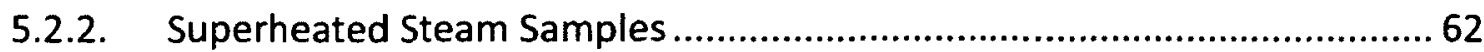

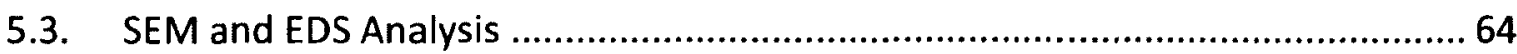




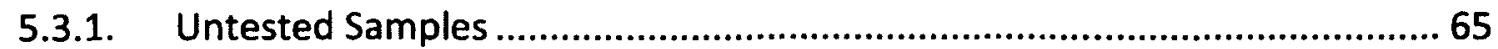

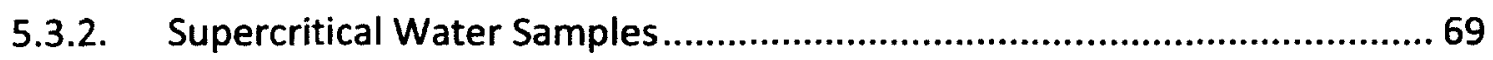

5.3.3. Superheated Steam Samples .................................................................. 83

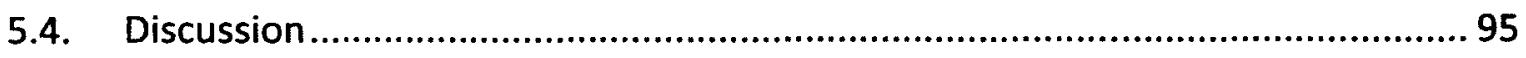

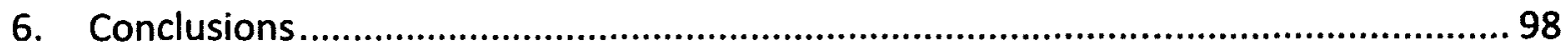

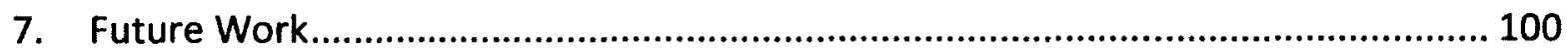

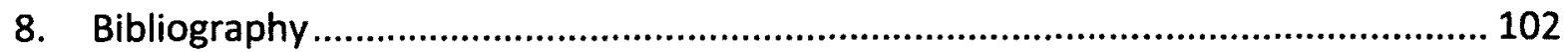




\section{List of Figures}

Figure 1 - Proposed Canadian water-cooled reactor [6]................................................ 4

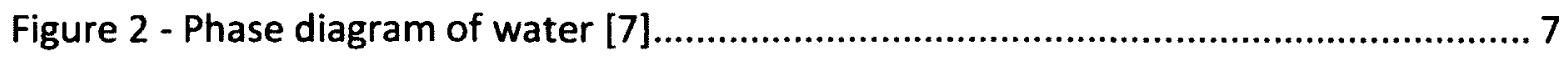

Figure 3 - Physical properties around the critical point [7] ........................................... 8

Figure 4 - Density and temperature of water at varying pressures $[8]$............................ 8

Figure 5 - Hydrogen bonding of water molecules under (a) ambient and (b) supercritical

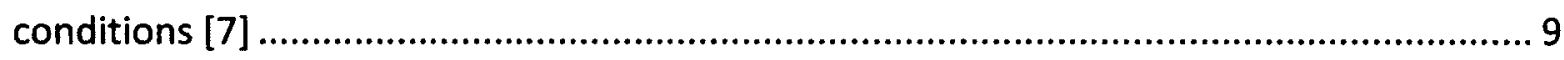

Figure 6 - Pourbaix diagram of an alloy showing "stability island" [11] ......................... 12

Figure 7 - Pourbaix diagram for chromium and nickel [9] ........................................... 14

Figure 8 - Density and corrosion rates in $\mathrm{HCl}$ solutions [11] ...................................... 16

Figure 9 - High corrosion range at varying temperatures [9] ....................................... 16

Figure 10 - Effect of physical properties on corrosion mechanisms [11] ...................... 17

Figure 11 - Steam turbine thermal efficiency vs. inlet temperature [18] ....................... 18

Figure 12 - Metal loss as a function of chromium content for a number of engineering

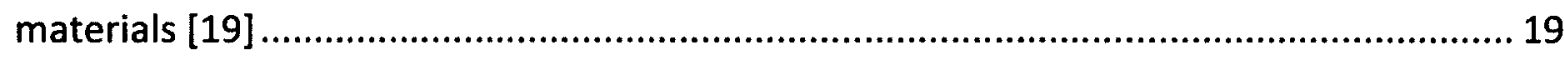

Figure 13 - Oxide layer on Alloy $800 \mathrm{H}$ stainless steel in supercritical water [22] ............ 21

Figure 14 - Weight gain of stainless steel in supercritical water [22] ............................. 22

Figure 15 - Corrosion of stainless steel in flowing steam at $650^{\circ} \mathrm{C}[27]$ at varying velocities ( $30 \mathrm{~m} / \mathrm{s}$, open circles; $60 \mathrm{~m} / \mathrm{s}$, closed circles; $90 \mathrm{~m} / \mathrm{s}$, circles with vertical line) 
Figure 16 - Schematic representation of the oxide formed on a $304 \mathrm{~L}$ sample (a) polished and exposed to $400^{\circ} \mathrm{C}$ steam for $500 \mathrm{~h}$, and (b) ground and exposed to $400^{\circ} \mathrm{C}$ steam for $500 h[28]$ 25

Figure 17 - Weight gain of IN625 in supercritical water [22]. 27

Figure 18 - Corrosion of nickel alloys in flowing steam, $650^{\circ} \mathrm{C}$ [27] 28

Figure 19 - Corrosion of AISI 304 in autoclaves: (left) water at $300^{\circ} \mathrm{C}$; (right) steam at $400^{\circ} \mathrm{C}, 6.9 \mathrm{MPa}[31]$ 30

Figure 20 - Total corrosion of AISI 304 in 1000 hr in superheated steam (autoclaves, 15-

$70 \mathrm{~kg} / \mathrm{cm}^{2}$; electropolished samples, EP, and milled samples, MT) [31]. 31

Figure 21 - Superheated steam testing rig diagram 40

Figure 22 - Superheater test chamber. 41

Figure 23 - Water reservoir and steam discharge assembly .... 43

Figure 24 - Superheated steam testing rig 44

Figure 25-(a) Autoclave and (b) sample stand 47

Figure 26 - Autoclave self-seal closure and diagram . 48

Figure 27 - Set up for visual inspection of samples . 52

Figure 28 - Digital scale and calliper used to measure weight and dimension 53

Figure 29 - Visual inspection of samples exposed to supercritical water for 100 to 300 hours $\left(600^{\circ} \mathrm{C}, 29 \mathrm{MPa}\right)$ 58

Figure 30 - Visual inspection of samples exposed to superheated steam $\left(600^{\circ} \mathrm{C}, 0.1 \mathrm{MPa}\right)$ 59

Figure 31 - Weight gain of samples exposed to supercritical water $\left(600^{\circ} \mathrm{C}, 29 \mathrm{MPa}\right) \ldots . .62$ 
Figure 32 - Weight gain of samples exposed to superheated steam $\left(600^{\circ} \mathrm{C}, 0.1 \mathrm{MPa}\right) \ldots 64$ Figure 33 - SEM images of untested A286 (magnifications 1000x top, 5000x bottom). BSE (left) and SE (right) images 65

Figure 34 - SEM images of untested AISI 310 (magnifications 1000x top, 5000x bottom). BSE (left) and SE (right) images 66

Figure 35 - SEM images of untested IN625 (magnifications 1000x top, 5000x bottom). BSE (left) and SE (right) images 67

Figure 36 - SEM images of $\mathrm{A} 286$ exposed to SCW $\left(600^{\circ} \mathrm{C}, 29 \mathrm{MPa}, 100 \mathrm{hrs}\right) \ldots \ldots \ldots \ldots \ldots . . . . . . .70$

Figure 37 - SEM images of A286 exposed to SCW $\left(600^{\circ} \mathrm{C}, 29 \mathrm{MPa}, 200 \mathrm{hrs}\right) \ldots \ldots \ldots \ldots \ldots . . . . . .71$

Figure 38 - SEM images of A286 exposed to SCW $\left(600^{\circ} \mathrm{C}, 29 \mathrm{MPa}, 300 \mathrm{hrs}\right) \ldots \ldots \ldots \ldots \ldots .72$

Figure 39 - SEM images of AISI 310 exposed to SCW $\left(600^{\circ} \mathrm{C}, 29 \mathrm{MPa}, 100 \mathrm{hrs}\right) \ldots \ldots \ldots . . . .74$

Figure 40 - SEM images of AISI 310 exposed to SCW $\left(600^{\circ} \mathrm{C}, 29 \mathrm{MPa}, 200 \mathrm{hrs}\right) \ldots \ldots \ldots \ldots .75$

Figure 41 - SEM images of AISI 310 exposed to SCW $\left(600^{\circ} \mathrm{C}, 29 \mathrm{MPa}, 300 \mathrm{hrs}\right) \ldots \ldots \ldots \ldots 76$

Figure 42 - SEM images of AISI 310 exposed to SCW $\left(600^{\circ} \mathrm{C}, 29 \mathrm{MPa}, 300 \mathrm{hrs}\right)$. Evidence of grain etching. 77

Figure 43 - SEM images of IN625 exposed to SCW $\left(600^{\circ} \mathrm{C}, 29 \mathrm{MPa}, 100 \mathrm{hrs}\right) \ldots \ldots \ldots \ldots . . . . . .79$

Figure 44 - SEM images of IN625 exposed to SCW $\left(600^{\circ} \mathrm{C}, 29 \mathrm{MPa}, 200 \mathrm{hrs}\right) \ldots \ldots \ldots \ldots \ldots . . . . .80$

Figure 45 - SEM images of IN625 exposed to SCW $\left(600^{\circ} \mathrm{C}, 29 \mathrm{MPa}, 300 \mathrm{hrs}\right) \ldots \ldots \ldots \ldots . . . . . .81$

Figure 46 - SEM images of A286 exposed to SHS $\left(600^{\circ} \mathrm{C}, 0.1 \mathrm{MPa}, 100 \mathrm{hrs}\right) \ldots \ldots \ldots \ldots . . . . . . .84$

Figure 47 - SEM images of A286 exposed to SHS $\left(600^{\circ} \mathrm{C}, 0.1 \mathrm{MPa}, 200 \mathrm{hrs}\right) \ldots \ldots \ldots \ldots \ldots . . . . . . .85$

Figure 48 - SEM images of A286 exposed to SHS $\left(600^{\circ} \mathrm{C}, 0.1 \mathrm{MPa}, 300 \mathrm{hrs}\right) \ldots \ldots \ldots \ldots \ldots . . . . . .86$

Figure 49 - SEM images of AISI 310 exposed to SHS $\left(600^{\circ} \mathrm{C}, 0.1 \mathrm{MPa}, 100 \mathrm{hrs}\right) \ldots \ldots \ldots \ldots . . . .88$ 
Figure 50 - SEM images of AISI 310 exposed to SHS $\left(600^{\circ} \mathrm{C}, 0.1 \mathrm{MPa}, 200 \mathrm{hrs}\right)$

Figure 51 - SEM images of AISI 310 exposed to SHS $\left(600^{\circ} \mathrm{C}, 0.1 \mathrm{MPa}, 300 \mathrm{hrs}\right) \ldots \ldots \ldots . . . .90$

Figure 52 - SEM images of IN625 exposed to SHS $\left(600^{\circ} \mathrm{C}, 0.1 \mathrm{MPa}, 100 \mathrm{hrs}\right) \ldots \ldots \ldots \ldots . . . . .92$

Figure 53 - SEM images of IN625 exposed to SHS $\left(600^{\circ} \mathrm{C}, 0.1 \mathrm{MPa}, 100 \mathrm{hrs}\right)$. Evidence of

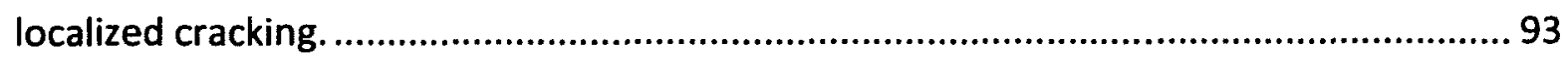

Figure 54 - SEM images of IN625 exposed to SHS $\left(600^{\circ} \mathrm{C}, 0.1 \mathrm{MPa}, 200 \mathrm{hrs}\right) \ldots \ldots \ldots \ldots . . . . .93$

Figure 55 - SEM images of IN625 exposed to SHS $\left(600^{\circ} \mathrm{C}, 0.1 \mathrm{MPa}, 300 \mathrm{hrs}\right) \ldots \ldots \ldots \ldots . . . . .94$

Figure 56 - Weight gain comparison (solid lines represent SCW and dashed lines SHS). 97 


\section{List of Tables}

Table 1 - Overview of Gen IV Systems [3] ........................................................ 2

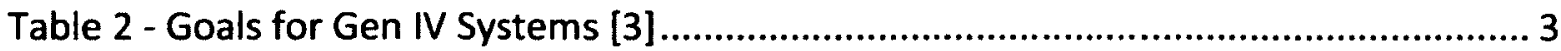

Table 3 - Composition of stainless steels (maximum wt\%) ..................................... 22

Table 4 - Chemical composition of A286 [33] .................................................. 35

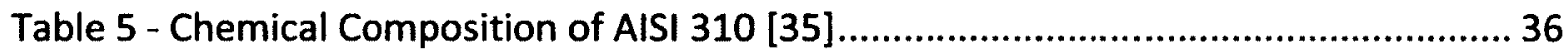

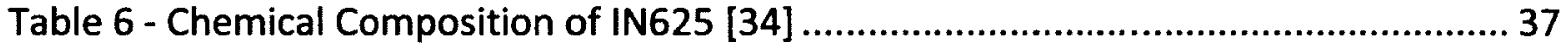

Table 7 - Components of the superheated steam testing rig .................................... 39

Table 8 - Weight gain of samples exposed to supercritical water $\left(600^{\circ} \mathrm{C}, 29 \mathrm{MPa}\right) \ldots \ldots .61$

Table 9 - Weight gain of samples exposed to superheated steam $\left(600^{\circ} \mathrm{C}, 0.1 \mathrm{MPa}\right) \ldots \ldots 63$

Table 10 - Specified and EDS determined chemical compositions for untested materials 68

Table 11 - EDS compositions of A286 exposed to SCW $\left(600^{\circ} \mathrm{C}, 29 \mathrm{MPa}\right) \ldots \ldots \ldots \ldots \ldots \ldots \ldots . . . . . . . . . . . . .73$

Table 12 - EDS compositions of AISI 310 exposed to SCW $\left(600^{\circ} \mathrm{C}, 29 \mathrm{MPa}\right) \ldots \ldots \ldots \ldots \ldots . . . . . .78$

Table 13 - EDS compositions of IN625 exposed to SCW $\left(600^{\circ} \mathrm{C}, 29 \mathrm{MPa}\right)$.................... 82

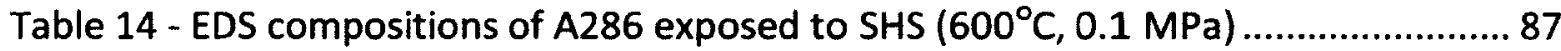

Table 15 - EDS compositions of AISI 310 exposed to SHS $\left(600^{\circ} \mathrm{C}, 0.1 \mathrm{MPa}\right)$................. 91

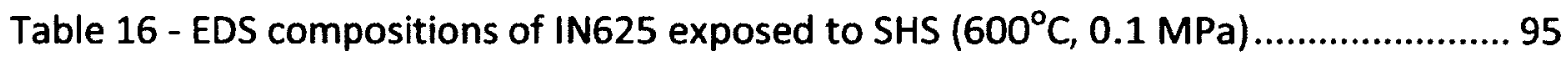

Table 17 - Etching solution compositions ....................................................... 100 


\section{Introduction}

With a rising global population, continuous industrialization, and the ever present environmental concerns, the need for sustainable, affordable, and ample power generation has never been greater. As supplies continue to drop and concerns over pollution and climate change increase, the fossil fuels that currently provide more than two-thirds of the world's electricity [1] must be replaced by more sustainable sources. Currently nuclear power generation shows the greatest promise to provide a sustainable, low-carbon generating, and stable energy source to replace fossil fuels.

For many countries around the world, electricity is generated primarily or in part by nuclear power plants. As of 2010, the International Energy Agency reported that $12.9 \%$ of the world's electricity was generated by nuclear power [1]. Industrialized countries such as the United States of America, France, Japan, and Canada produce a significant portion of their electricity from nuclear power, while emerging powers such as China and Brazil have expressed desire to build more nuclear plants to supply electricity.

In July 2001 Argentina, Brazil, Canada, France, Japan, South Korea, South Africa, the United Kingdom, and the United States established the Generation IV International Forum (GIF) by signing the GIF charter, later joined by Switzerland, Eurotom, China, and Russia [2]. This program was established to research and develop the next generation of nuclear energy systems, called Gen IV systems. The GIF has identified six advanced nuclear energy systems suitable for further development. These are shown in Table 1. 
Table 1 - Overview of Gen IV Systems [3]

\begin{tabular}{|c|c|c|c|c|c|}
\hline System & $\begin{array}{l}\text { Neutron } \\
\text { spectrum }\end{array}$ & Coolant & Temp. ${ }^{\circ} \mathrm{C}$ & $\begin{array}{l}\text { Fuel } \\
\text { cycle }\end{array}$ & Size (MWe) \\
\hline $\begin{array}{l}\text { VHTR } \\
\text { (Very high temperature } \\
\text { gas reactor) }\end{array}$ & thermal & helium & $\begin{array}{l}900 \text { to } \\
1000\end{array}$ & open & $250-300$ \\
\hline $\begin{array}{l}\text { SFR (Sodium-cooled fast } \\
\text { reactor) }\end{array}$ & fast & sodium & 550 & closed & $\begin{array}{l}30-150 \\
300-1500 \\
1000-2000\end{array}$ \\
\hline $\begin{array}{l}\text { SCIVR (Supercritical water- } \\
\text { cooled reactor) }\end{array}$ & $\begin{array}{l}\text { thermal } \\
\text { fast }\end{array}$ & water & $510-625$ & $\begin{array}{l}\text { Open' } \\
\text { closed }\end{array}$ & $\begin{array}{l}300-700 \\
1000-1500\end{array}$ \\
\hline $\begin{array}{l}\text { GFR (Gas-cooled fast } \\
\text { reactor) }\end{array}$ & fast & helium & 850 & closed & 1200 \\
\hline $\begin{array}{l}\text { LFR (Lead-cooled fast } \\
\text { reactor) }\end{array}$ & fast & lead & $480-800$ & closed & $\begin{array}{l}20-180 \\
300-1200 \\
600-1000\end{array}$ \\
\hline MSR (Molten salt reactor) & epithermal & $\begin{array}{l}\text { fluoride } \\
\text { salts }\end{array}$ & $700-800$ & closed & 1000 \\
\hline
\end{tabular}

These six systems were chosen for their ability to meet eight goals identified by the GIF, shown in Table 2. These systems, although still in early development stages, have promise as the future of nuclear energy generation and displacement of fossil fuels as a power source.

Together with European, Japanese, and Chinese researchers, Canada has begun research to support the development of supercritical water-cooled reactors (SCWRs). The SCWR was chosen as a natural evolution of Canada's existing nuclear systems, including the successful CANDU program [4].

The SCWR system is a high-temperature and pressure water-cooled reactor that operates above the critical point of water [5]. Supercritical water has a homogenous 
phase with properties of both a fluid and a gas, discussed further in the next section. A diagram of the proposed SCWR is shown in Figure 1.

\section{Table 2 - Goals for Gen IV Systems [3]}

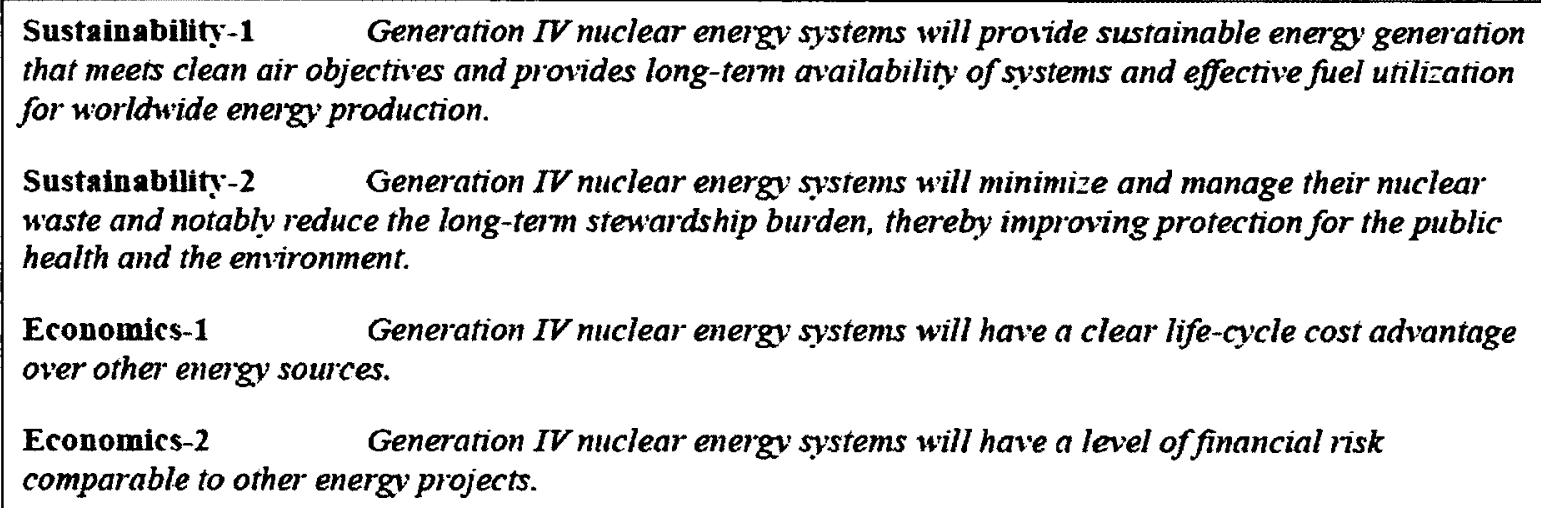

The SCWR is desirable due to its high thermal efficiency, estimated as being up to a third higher than a current light-water cooled reactor, and its relative simplicity [5]. As the coolant does not change phase within the reactor, the design of the reactor core can be made simpler and smaller, providing for efficient and simplified electricity production. The proposed Gen IV SCWR would be 1,700 MWe and operate at a pressure of $25 \mathrm{MPa}$ and a temperature of $510^{\circ} \mathrm{C}$ to $550^{\circ} \mathrm{C}[5]$. 


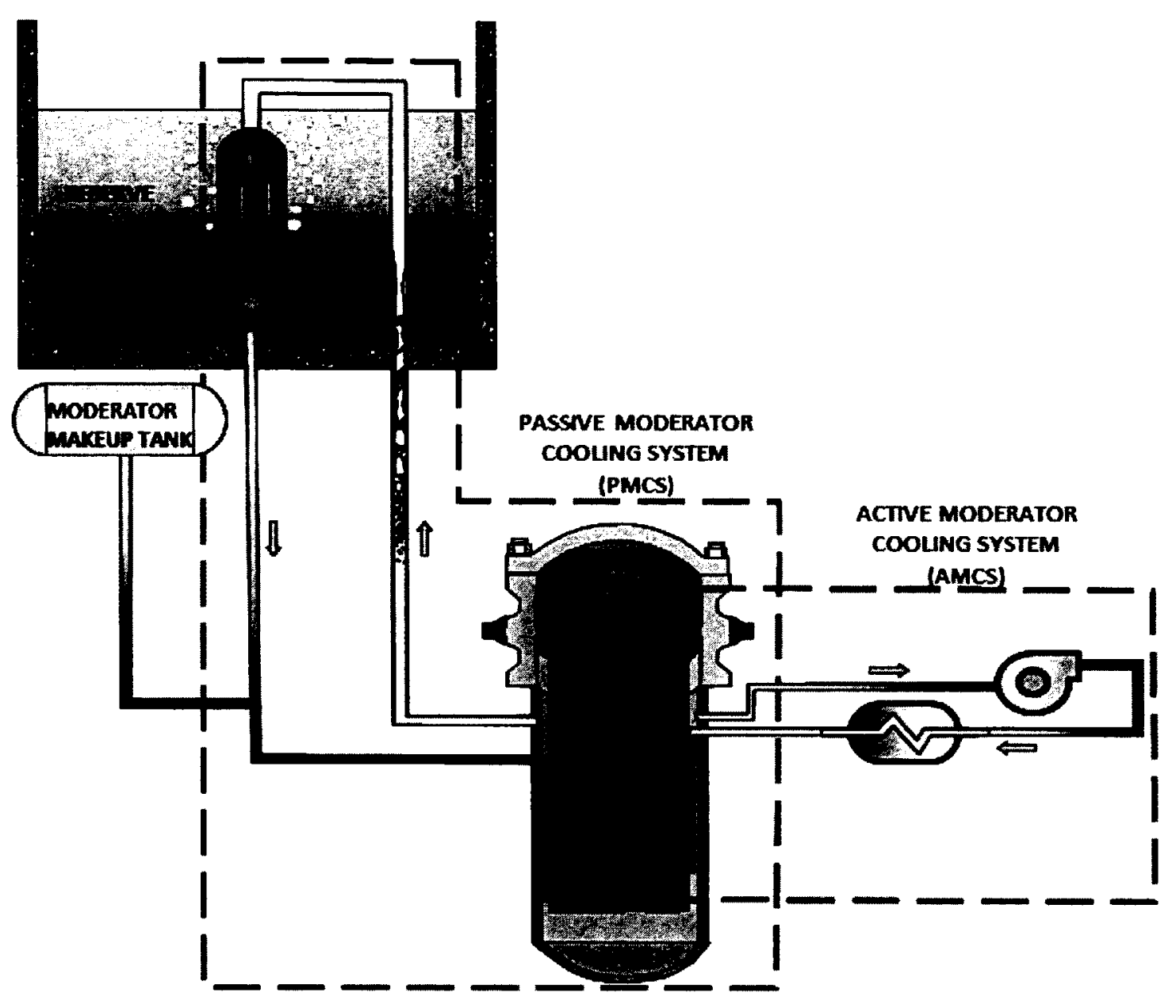

Figure 1 - Proposed Canadian water-cooled reactor [6]

The design of the Gen IV SCWR is similar in many ways to existing light-water reactors currently in use; however, Canada's National Program on Generation IV Energy Technologies has called for research in identifying appropriate candidate materials to be used inside and outside of the reactor cores [4]. Corrosion and stress-corrosion cracking during exposure to high temperature supercritical water is a concern. Stainless steels and high-nickel alloys are being considered as candidate materials, and are discussed at length in the remainder of this review. 
In addition to corrosion in supercritical water, the performance of steel and nickel alloys in high-temperature superheated steam is also discussed in the context of next generation nuclear power systems. The majority of the electrical generation capacity of the world is generated by steam turbines [7]. Thermal power plants, whether they are driven by fossil fuels, nuclear fission, or even solar energy, largely rely on steam-driven turbines to generate electricity. As the power demand of the world grows, efforts must be made to increase the efficiency and durability of power plants, including the turbines. One way to achieve this is by the use of superheated steam to drive turbines. Corrosion of alloys in steam is an important concern, and is discussed further as well. 


\section{Literature Review}

The following section will present a context of the performance of engineering materials in supercritical water and superheated steam, discuss the properties and corrosion mechanisms present under these conditions, and examine the available literature on oxidation and corrosion of stainless steels and high-nickel alloys in both supercritical water and steam.

\subsection{0xidation and Corrosion in Supercritical Water}

As supercritical water reactors are employed, the understanding of corrosion of metals and alloys becomes important. The following section will discuss the properties of supercritical water and the mechanisms and factors influencing the corrosion rates.

\subsubsection{Properties of Supercritical Water}

A supercritical fluid is a fluid that exists above a given temperature and pressure, called the critical point [8]. The critical point is where multiple coexisting fluid phases cannot be distinguished. For water, this point is at $374^{\circ} \mathrm{C}$ and $24 \mathrm{MPa}$, shown in Figure 2.

Supercritical water, a homogenous supercritical fluid, exhibits characteristics of both liquid and gas, but is considered to be neither [8]. There is no further phase transformation beyond the critical point, making it desirable for use in reactors. The properties of supercritical water do not match either those of a gas or a liquid exactly, as discussed in the following sections. 


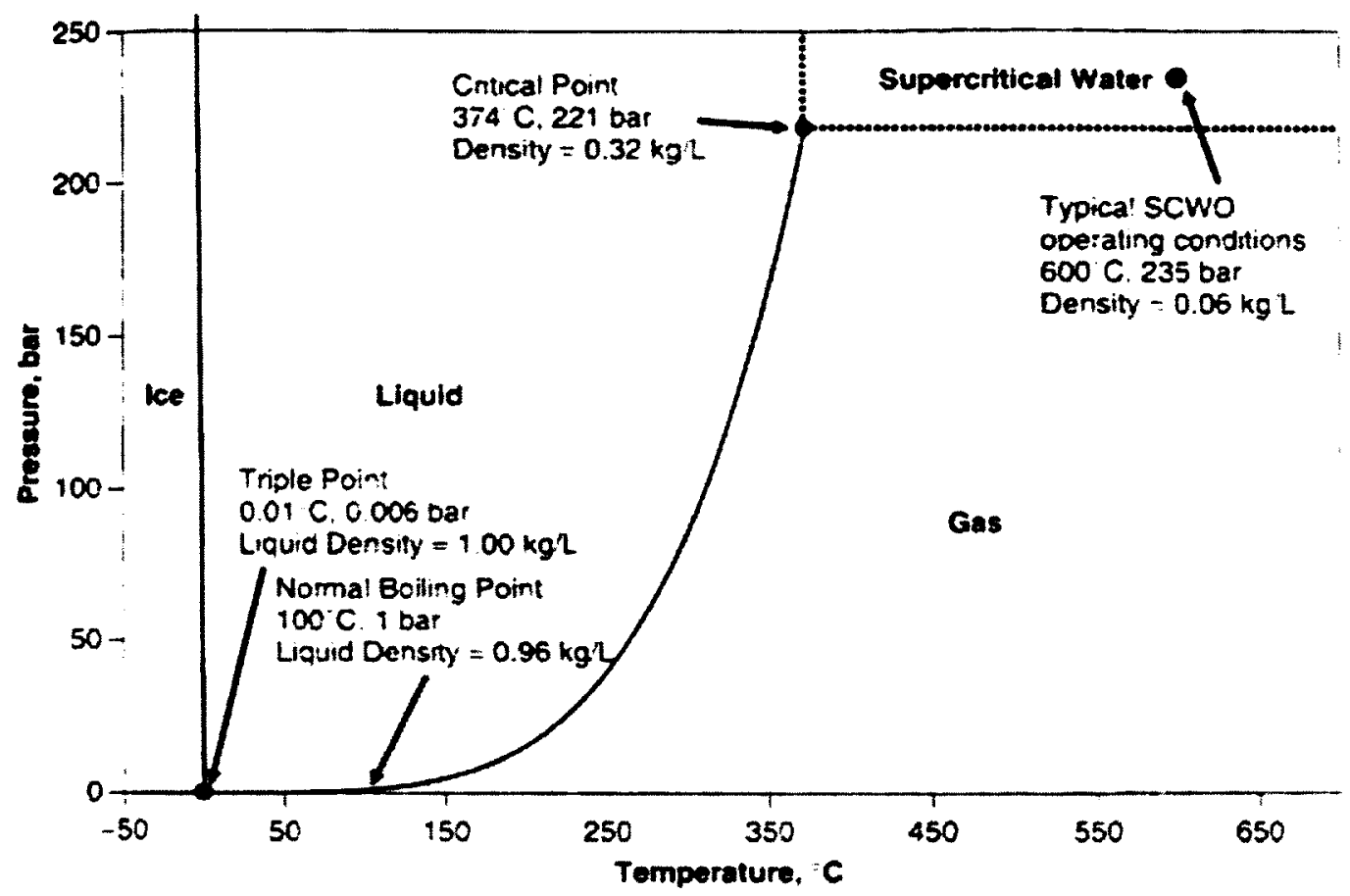

Figure 2 - Phase diagram of water [8]

\section{Density}

At ambient temperature, the density of water decreases with increasing temperature and the water is turned to steam. At the critical point, however, the density drops abruptly as the transition to supercritical water occurs [8]. This is shown in Figure 3.

Physical properties of supercritical fluids, including the density, ion product, and dielectric constant, can vary dramatically as the pressure of the fluid is changed [8]. Increasing the pressure will reduce the magnitude of the density drop at the critical point, as shown in Figure 4 below [9]. 


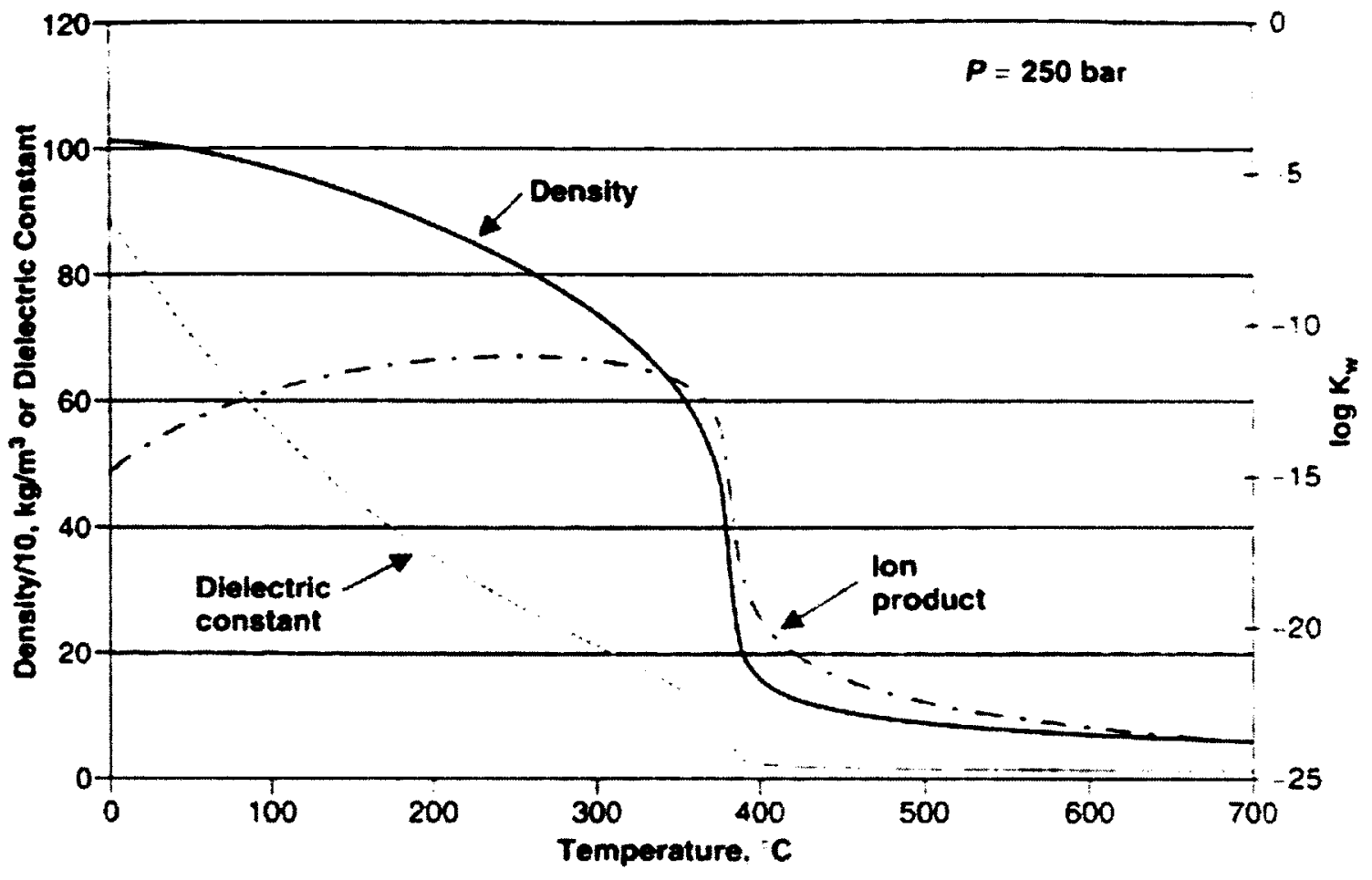

Figure 3 - Physical properties around the critical point [8]

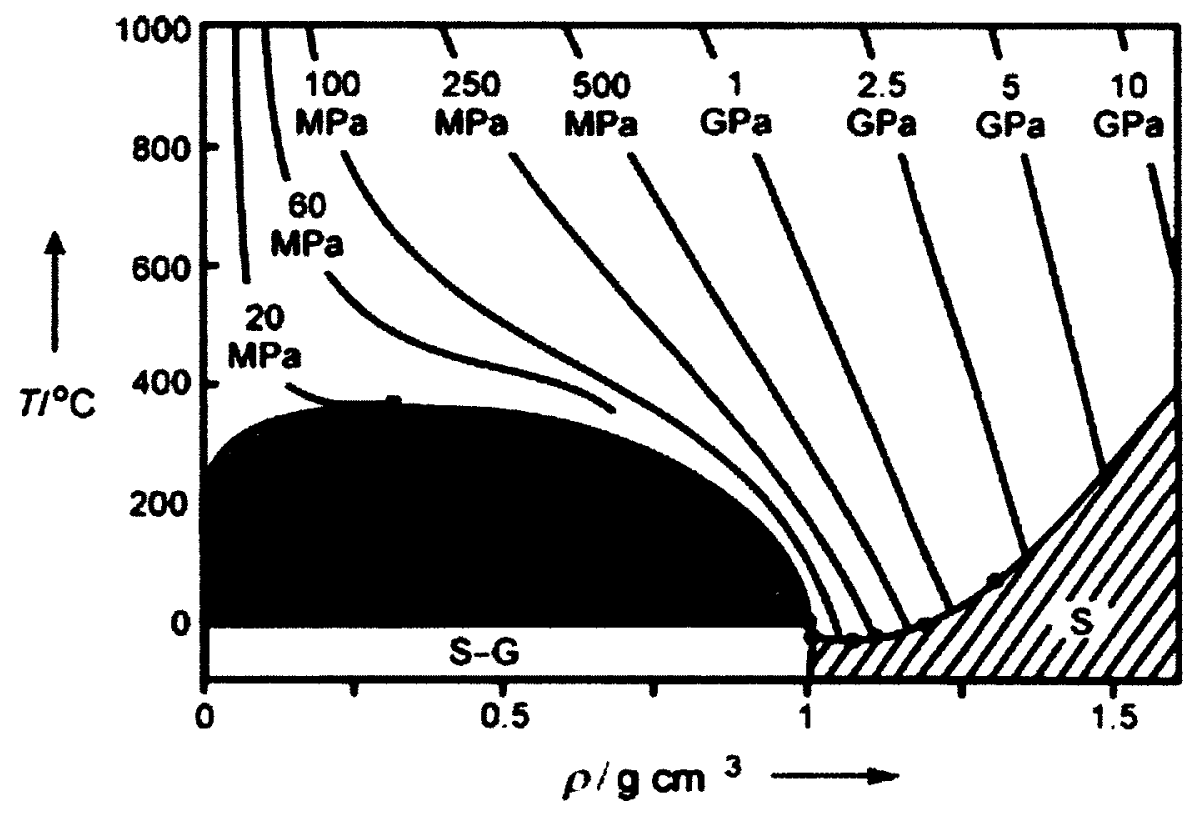

Figure 4 - Density and temperature of water at varying pressures [9] 


\section{Dielectric Constant and Hydrogen Bonding}

At ambient temperatures the difference in the electronegativity of oxygen and hydrogen atoms creates a dipole in water, giving it a strong polarity [8]. The dielectric constant, $\varepsilon$, quantifies this polarity. Water molecules form hydrogen bonds in ambient conditions as a result [10]. The water molecule's polarity allows for the solubility of salts and inorganic compounds, with its high polarity favouring solubility and dissociation of ionic species (such as salts) [11].

As water is brought above the critical point, the density decreases and hydrogen bonding cannot be sustained among the molecules [8], shown in Figure 5 below.

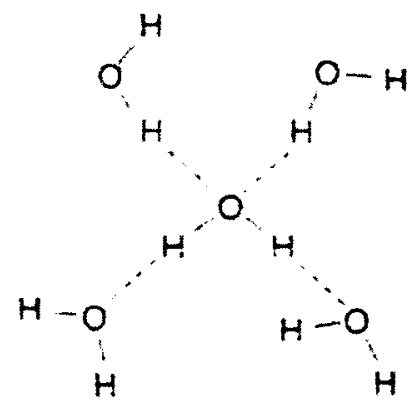

(a)

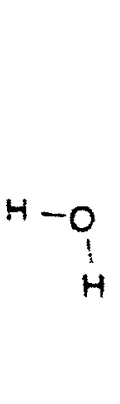<smiles>O</smiles><smiles>[18OH]</smiles>

H

Figure 5 - Hydrogen bonding of water molecules under (a) ambient and (b) supercritical conditions [8]

This decrease in hydrogen bonding and accordingly $\varepsilon$ value inhibits the solubility of salts and other inorganic compounds [8]. Like density, dielectric constant varies with pressure [8] [10]. 


\section{Ionic Product and the pH Value}

The ionic product is a measure of ions present in a solution, and decreases sharply in water at the critical point (shown in Figure 3). Under ambient conditions water selfdissociates as shown below [10]:

$$
2 \mathrm{H}_{2} \mathrm{O} \Leftrightarrow \mathrm{H}_{3} \mathrm{O}^{+}+\mathrm{OH}^{-}
$$

This reaction is endothermic, favouring the production of $\mathrm{H}_{3} \mathrm{O}^{+}$and $\mathrm{OH}^{-}$ions with increasing temperatures [12]. Since $\mathrm{H}_{3} \mathrm{O}^{+}$and $\mathrm{OH}^{-}$are produced in equal measure the $\mathrm{pH}$ value of water stays constant at 7 , considered both acidic and alkaline.

The ionic product drops significantly with increasing temperature, but is also influenced by the pressure [12]. Under low pressures water behaves like a non-polar solvent with low self-dissociation, while high pressure supercritical water has a higher ionic product [8] [10]. This can lead to the formation of acids or bases, affecting the $\mathrm{pH}$ value and the corrosion properties of water. Radiation can also increase the formation of ions within water, and could lead to an increase in oxidation or corrosion in a supercritical water reactor, however there is little and conflicting reports on the effects of radiation on water at very high temperatures and pressure [13].

\section{Oxygen Solubility}

Supercritical water generally allows for high solubility of gas, including dissolved oxygen. A high concentration of dissolved oxygen allows for a thick and stable protective oxide layer in some metals and alloys [10], however, high solubility of oxygen also increases 
the oxidizing power of supercritical water and can have detrimental effects on corrosion resistance. The impact of dissolved oxygen is discussed further below.

\subsubsection{Corrosion Mechanisms and Factors}

Many metals and alloys will form a protective oxide layer when exposed to supercritical water. A stable oxide layer provides corrosion resistance; however, the composition and phase of the oxide layer is highly dependent on the water conditions [10]. Corrosion in supercritical water proceeds through the deterioration of the oxide film, and therefore understanding the factors that determine the rate of deterioration is key to predicting and understanding the corrosion of an alloy.

\section{Temperature and Pressure}

As discussed above, the temperature and pressure of the supercritical water affects the water's physical properties, including the density, ionic product, and dielectric constant. Figure 3 above shows that at the critical point all three properties drop significantly. This yields the result that corrosion in $500^{\circ} \mathrm{C}$ supercritical water proceeds at a slower rate than in $300^{\circ} \mathrm{C}$ subcritical water, as the drop in physical properties slows the deterioration of the oxide layer formed on the alloy [10] [12].

Although deterioration of the oxide layer through corrosion is slowed as temperature increases, compounds within the oxide layer may change. This can lead to surface defects in the oxide layer and rapid dissolution as a result [12]. The increased production of $\mathrm{H}_{3} \mathrm{O}^{+}$and $\mathrm{OH}^{-}$ions with temperature can also impact the stability of the oxide layer. 
The pressure of the supercritical water will also have an effect on the corrosion rate of metals and alloys. Kritzer determined that in all cases increased pressure of a supercritical fluid led to an increase in corrosion rate and rapid dissolution of the protective oxide layer [10].

\section{pH Value and Electrochemical Potential}

Dissolution of an alloy's protective oxide layer can occur through two principle mechanisms: chemical dissolution and electrochemical dissolution. These two mechanisms are determined by the supercritical water's $\mathrm{pH}$ value and electrochemical potential, respectively [10]. A Pourbaix diagram plots the $\mathrm{pH}$ value and electrochemical potential, and shows a "stability island" at which an alloy's oxide layer is in a passive state and will remain stable. These diagrams are unique for each alloy, and vary by temperature [14] [15]. An example of a Pourbaix diagram is given in Figure 6.

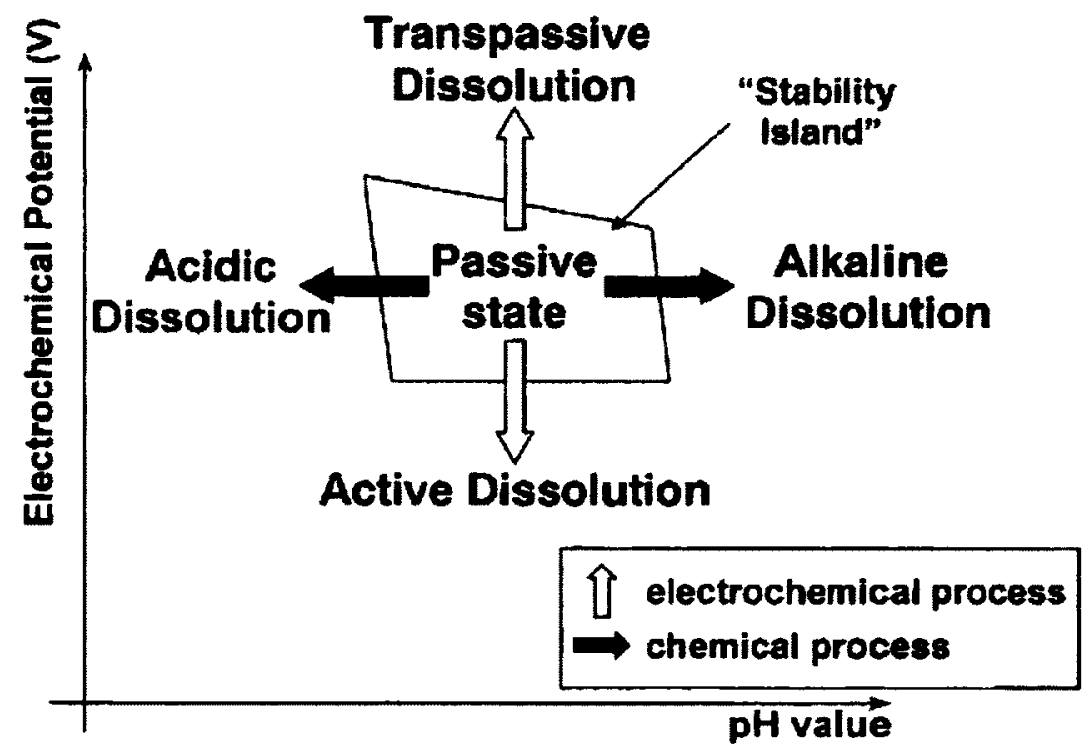

Figure 6 - Pourbaix diagram of an alloy showing "stability island" [12] 
The Pourbaix diagram shows a specific set of $\mathrm{pH}$ values and electrochemical potentials at which the alloy's oxide layer will remain stable. Increasing or decreasing these parameters out of the "stability island" will lead to dissolution of the protective oxide layer and corrosion of the alloy [12]. The passive region shown by the "stability island" can grow or shrink based on the temperature of the supercritical water [12].

Most oxides have an amphoteric character, meaning they can be dissolved in either acidic or alkaline solutions [10]. Increasing or decreasing the solution's pH value will lead to, respectively, alkaline or acidic dissolution of the protective oxide layer, referred to as chemical dissolution. Numerous studies have examined the chemical dissolution of the oxide layers of iron, chromium, and nickel alloys [16]. Chromium oxide layers are, generally, the most resistant to chemical dissolution, while those of nickel are least resistant [12]. In the case of a high-chromium alloy, an oxide layer will be composed of $\mathrm{Cr}(I I I)$. An acidic solution will promote the formation of a less stable $\mathrm{Cr}(\mathrm{II})$ layer and lead to acidic dissolution.

Electrochemical dissolution occurs as the electrochemical potential of the solution moves out of the passive region. An increase in potential will lead to transpassive dissolution, while a decrease will lead to active dissolution [10]. Many stainless steels and nickel alloys resist corrosion through the formation of a protective $\mathrm{Cr}$ (III) layer at the exposed surface. Active dissolution causes these to transform to $\mathrm{Cr}(11)$ compounds, which do not protect the surface and allow corrosion [12]. Transpassive dissolution causes the formation of chromates $(\mathrm{Cr}(\mathrm{VI}))$ or chromic acid compromising the stable 
protective oxide layer [12]. $\operatorname{Cr}(\mathrm{VI})$ is soluble in the supercritical water, and will not provide the stable protection of a $\mathrm{Cr}($ III) layer.

Oxygen is completely miscible in supercritical water, so the oxidizing power of the water is high and electrochemical corrosion processes are important [12]. This, coupled with the high temperatures, can lead to rapid dissolution of the protective chromium oxide layer of some alloys [10]. One way to prevent corrosion is to use an alloy that will form an alternative oxide layer, such as a nickel, under a different condition. The Pourbaix diagram showing the stability islands of multiple oxide layers can be used to "tune" the supercritical water to reduce corrosion. An example is shown in Figure 7 below.
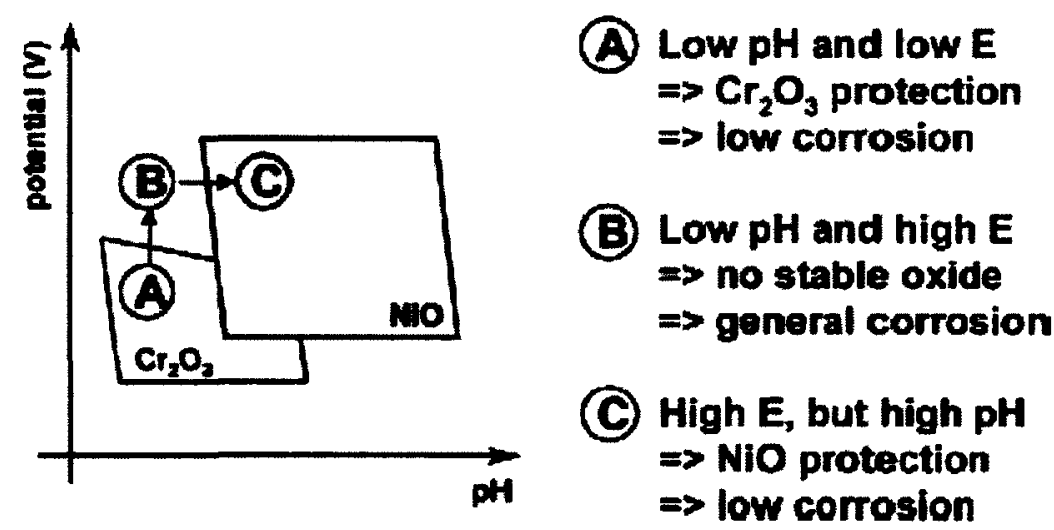

Figure 7 - Pourbaix diagram for chromium and nickel [10]

In this example, the protective chromium oxide layer, which is stable in an acidic low electrochemical potential solution (A), loses stability as the potential is increased and transpassive dissolution begins (B) [10]. Increasing the $\mathrm{pH}$, however, promotes the formation of a nickel oxide layer (C), which limits corrosion of the alloy [10]. 


\section{Dissolved Oxygen}

Dissolved oxygen in the supercritical water has a significant effect on the oxidizing power. When exposed to supercritical water, an alloy should ideally form a stable oxide layer which protects the alloy from corrosion by preventing further oxidation of the base material [17]. Temperature and length of exposure affect the formation of this oxide layer, and the concentration of dissolved oxygen in the supercritical water also influences the formation and integrity of this layer [17]. The effects of dissolved oxygen are often specific to the alloy exposed, and should be understood when choosing a material.

\section{Effect of Physical Properties on Corrosion Mechanisms}

From the above sections it is made clear that no physical property acts alone in promoting or hindering corrosion; rather there is a significant interdependence between the supercritical water's properties that must be understood. As discussed above, the density of water drops sharply at the critical point and consequently, the corrosion rate changes, as is shown in Figure 8.

Figure 8 shows that the density of the supercritical solution is controlled by the pressure. High pressure solutions were shown in the Temperature and Pressure section to have high ionic product, which controls rate of solubility and dissolution of salts (including the alloy's protective oxide layer), acids, and bases. In this manner, the density of a supercritical solution can be used as a measure of the expected corrosion rate of an alloy [10]. 


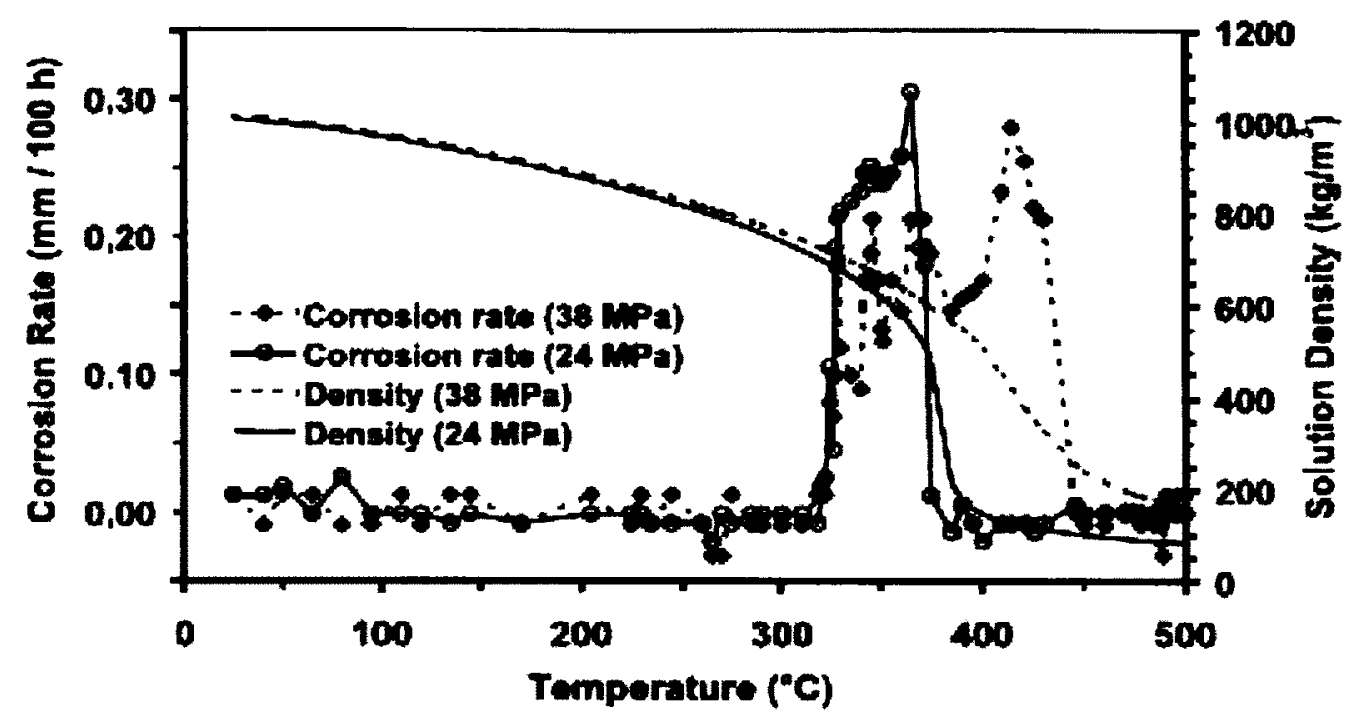

Figure 8 - Density and corrosion rates in $\mathrm{HCl}$ solutions [12]

A density threshold can be determined to differentiate low and high corrosion supercritical solutions, shown in Figure 9.

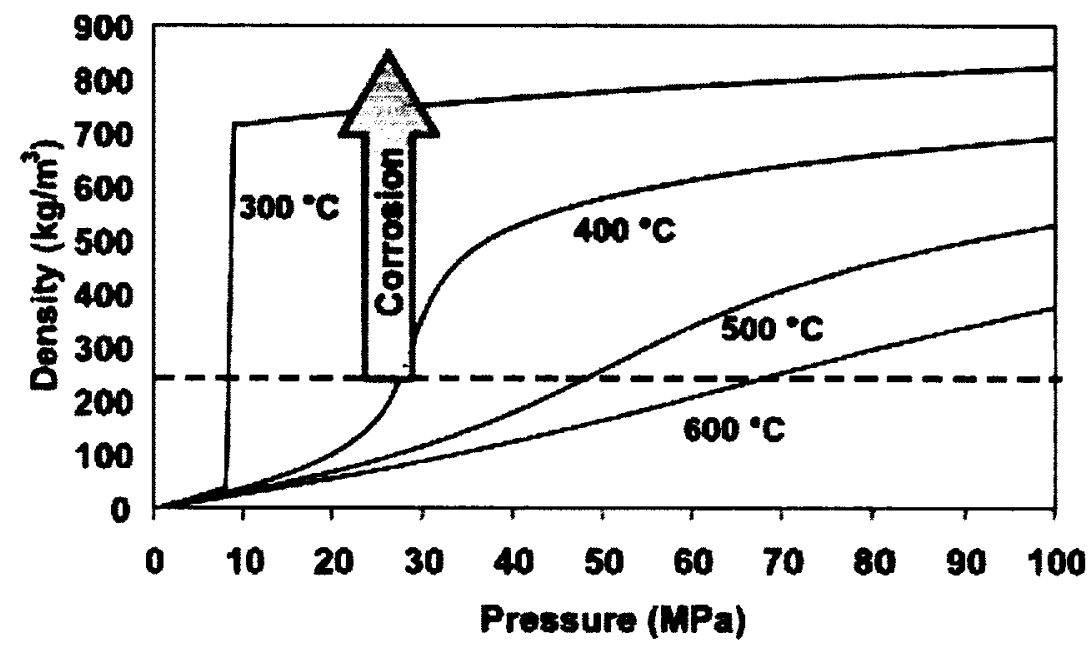

Figure 9 - High corrosion range at varying temperatures [10]

Generally, corrosion rates are found to be low in solutions with densities below 200-300 $\mathrm{kg} / \mathrm{m}^{3}$ [10]. At low temperatures, pressures of 10-20 MPa can cause solutions to fall 
above the density threshold, while increasing the solution pressure allows higher pressures to be achieved while still in the low corrosion region [10].

Figure 10 shows the interdependence of water's physical properties and corrosion mechanics in determining the rate of corrosion. The thickness of the connecting lines shows the relative influence of each factor.

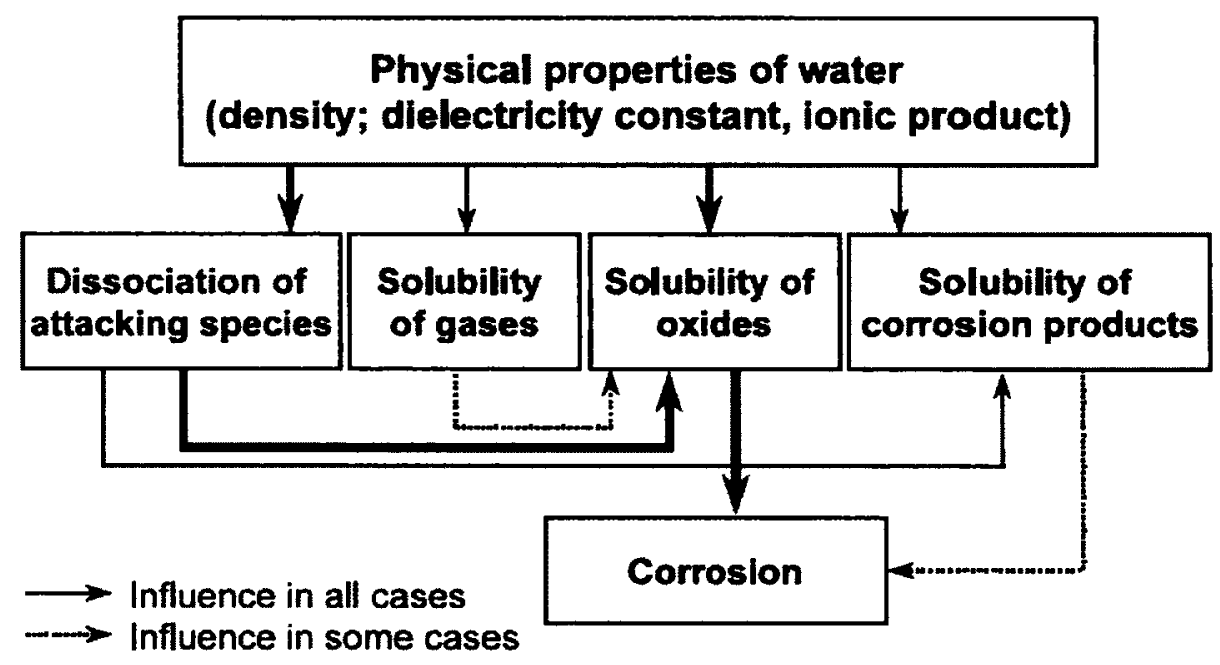

Figure 10 - Effect of physical properties on corrosion mechanisms [12]

Density and other physical properties have a strong influence on the solubility of the protective oxide layer formed on most alloys, while the dissociation of attacking species can lead to an increase in ions and further dissolution of oxides [12]. The solubility of gases and other corrosion products that may be present in the supercritical water may also play a role in determining corrosion rates.

\subsection{0xidation and Corrosion in Superheated Steam}

As saturated steam created in a boiler is further heated, superheated steam is created [18]. This can only happen in the absence of water, as further heat would just evaporate 
the liquid water, so a superheater or secondary heat exchanger must be used. The benefits of using superheated steam in a steam turbine are twofold: if the steam is sufficiently superheated, expansion in the turbine will not cause condensation, so the lifetime of the turbine blades is extended [18]; and increased steam temperature entering the steam turbine can allow for higher thermodynamic efficiency [18], as seen in Figure 11.

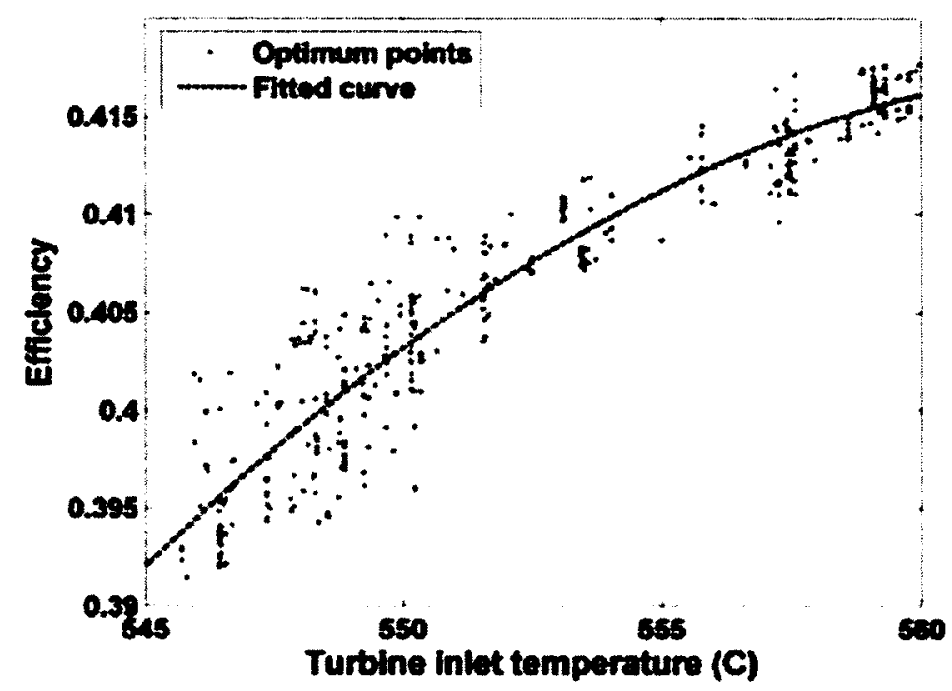

Figure 11 - Steam turbine thermal efficiency vs. inlet temperature [19]

Although condensation and excessive moisture are avoided by using superheated steam, corrosion and stress corrosion cracking can still be an issue on engineering materials used in the steam cycle.

Carbon based steels, as well as many other engineering alloy materials; undergo oxidation in steam environments, causing the formation of a scale on the surface of the material. This can be composed of one or many layers of wustite, haematite, magnetite in steel alloys, and a number of species in other alloys. These layers, depending on their 
composition, may experience dissolution or spalling, leading to destruction of the underlying material.

The introduction of chromium into an alloy allows for the creation of a protective layer of chromium-based spinels or chromia, which is resistant to corrosion and protects the base material from damage. Increasing chromium content has been shown by a number of authors to generally lead to an increase in corrosion resistance [20]. This effect is seen across a broad spectrum of ferritic, martensitic, and austenitic steels, as well as in a number of other high-temperature engineering alloys, as seen in Figure 12. The corrosion rate, expressed using weight change, was tested at atmospheric pressure with steam temperatures of $500^{\circ} \mathrm{C}$ to $650^{\circ} \mathrm{C}$.

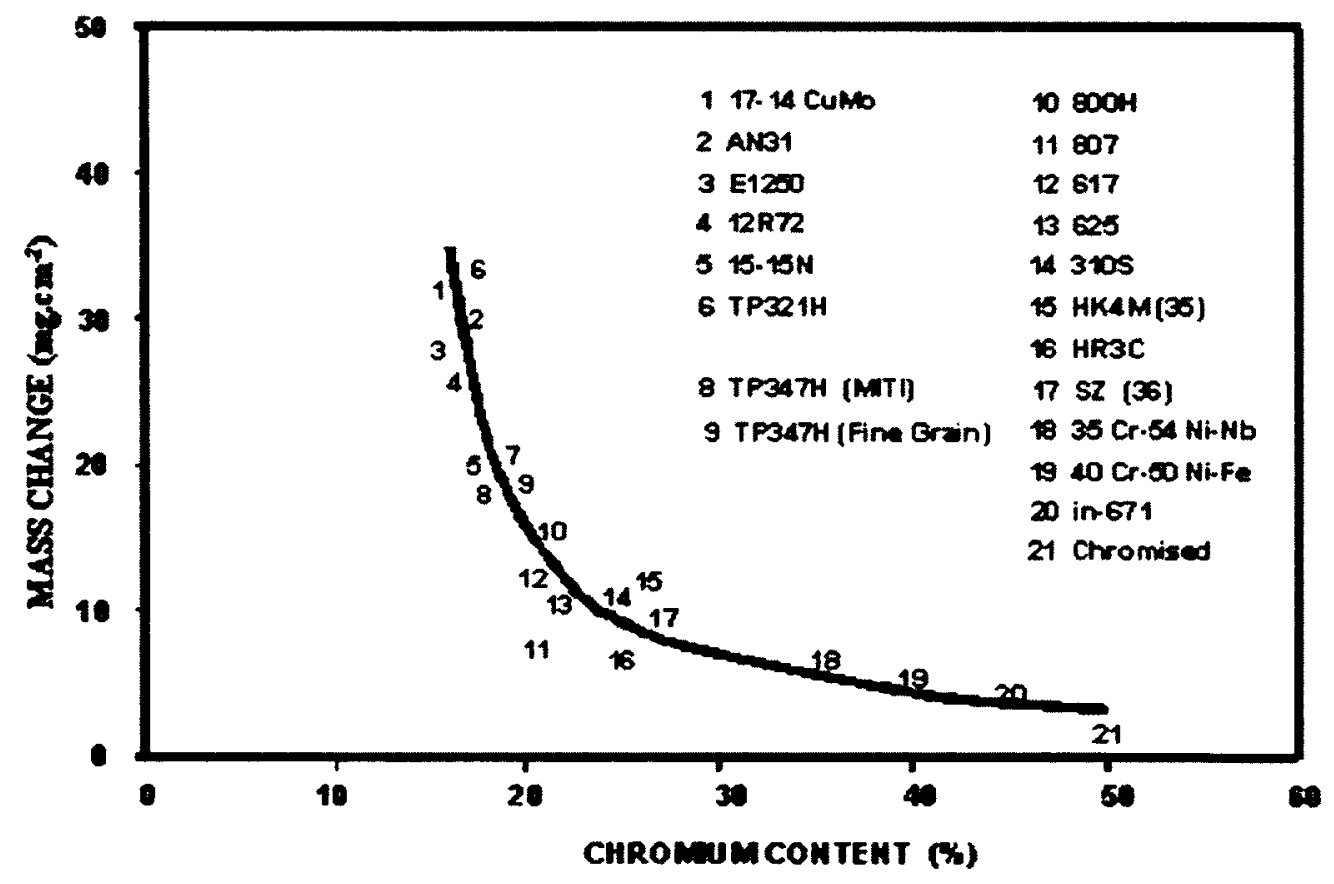

Figure 12 - Metal loss as a function of chromium content for a number of engineering materials [20] 
Figure 12 shows the beneficial effect of increased chromium content in materials exposed to high-temperature steam. It can also be seen that above $25 \%$ the impact of chromium content on the corrosion rate begins to level off. It has been speculated that at a high enough level of chromium content, a contiguous chromia layer forms between the metal and the metal oxide, slowing diffusion from the base material to the metalsteam interface [20] [21]. There may exist a limit on the chromium content that is beneficial to corrosion resistance, but generally alloys with $25 \%$ or higher chromium content will be best suited to uses in steam environments.

\subsection{Candidate Materials for Supercritical Water Reactors}

The following sections will review the corrosion of stainless steels and high-nickel alloys in superheated steam and supercritical water. The effect of surface finish on the corrosion and oxidation of materials is also discussed.

\subsubsection{Stainless Steels}

Stainless steels are used extensively in the power generation industry for their strength, engineering properties, and their corrosion resistance. Austenitic stainless steels, with a face-centred cubic crystal structure stabilized at room temperature through alloy addition (often nickel), are especially popular for their increased corrosion resistance and stability [22]. The corrosion behaviour of these steels in supercritical water and steam has been studied extensively. 


\section{Corrosion in Supercritical Water}

The corrosion behaviour of many stainless steels in supercritical water has been studied, and generally all perform similarly [23]. When exposed to supercritical water stainless steels tend to form a three-layered protective oxide layer that limits corrosion. This consists of an inner spinel layer, a middle layer of magnetite, and an outer layer of hematite [23]. The layer formed on Alloy $800 \mathrm{H}$ when exposed to $500^{\circ} \mathrm{C}$ supercritical water for 505 hours is shown in Figure 13.

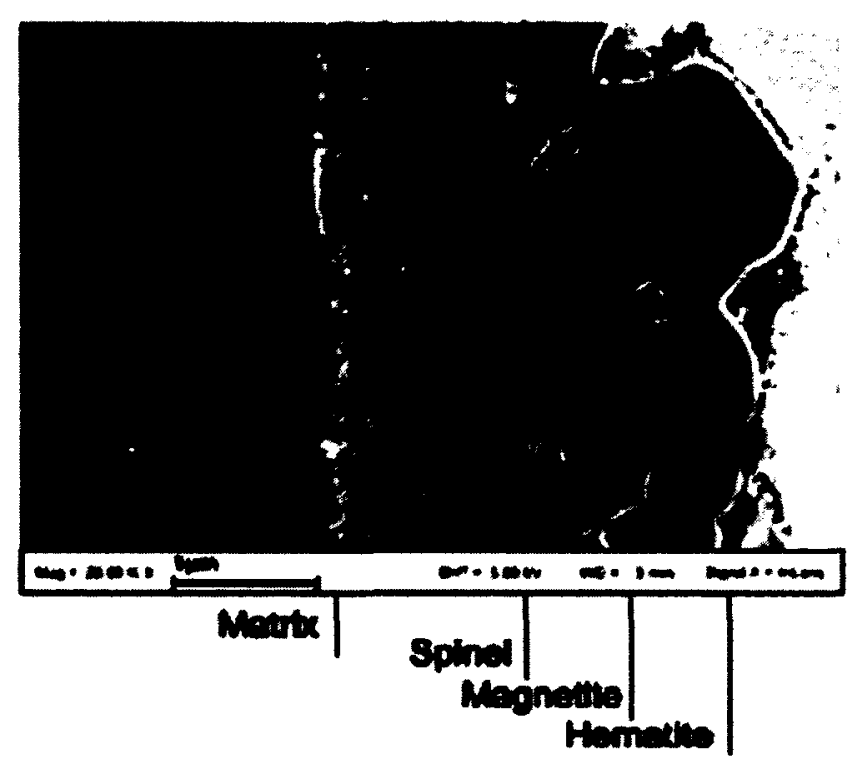

Figure 13 - Oxide layer on Alloy $800 \mathrm{H}$ stainless steel in supercritical water [23]

When exposed to supercritical water with a low dissolved oxygen concentration (20-25 $\mathrm{ppb}$ ), however, spallation of the oxide layer was observed [23]. This is a concern when choosing stainless steel as a potential engineering material for SCWR; and also stainless steel often exhibits scattered weight change during corrosion tests. The weight gain for three different stainless steels exposed to $500^{\circ} \mathrm{C}$ and $600^{\circ} \mathrm{C}$ supercritical water are shown below in Figure 14. Their compositions are given in Table 3. 

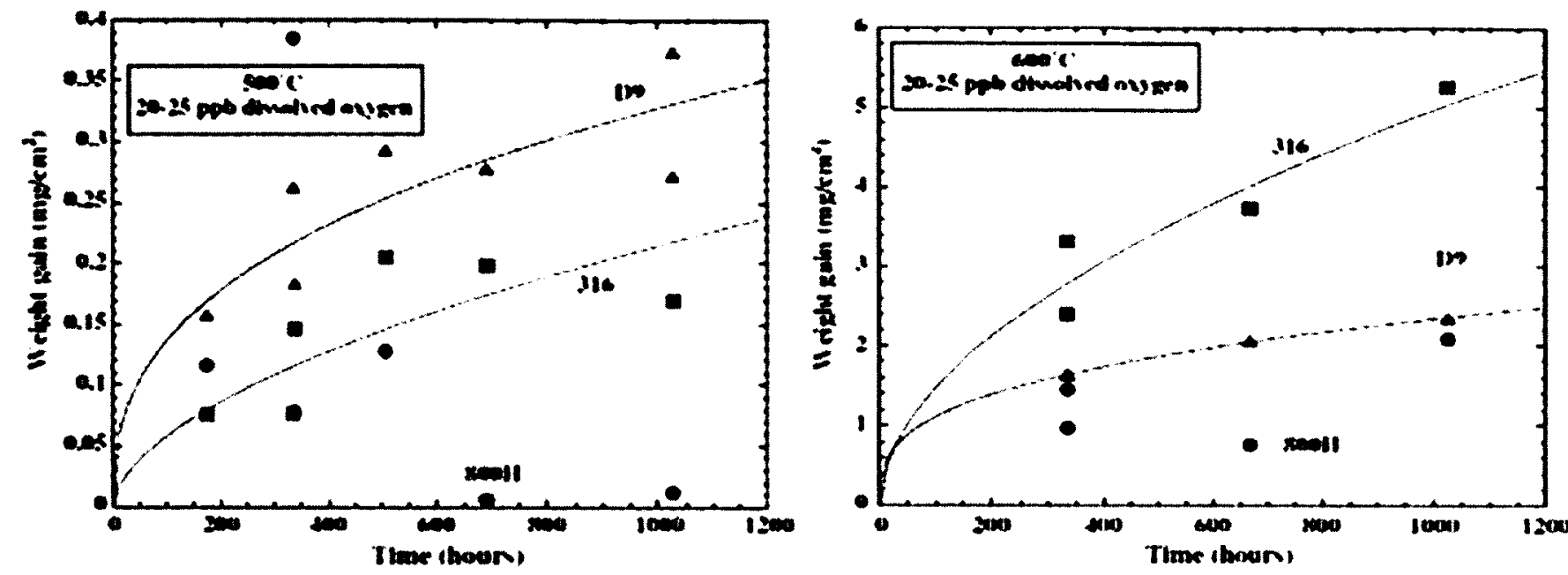

Figure 14 - Weight gain of stainless steel in supercritical water [23]

Table 3 - Composition of stainless steels (maximum wt\%)

\begin{tabular}{|c|c|c|c|}
\hline Element & D9 & $\mathbf{3 1 6}$ & $\mathbf{8 0 0 H}$ \\
\hline $\mathrm{C}$ & 0.04 & 0.04 & 0.10 \\
\hline $\mathrm{Ni}$ & 15.15 & 13.59 & 35.0 \\
\hline $\mathrm{Cr}$ & 14.04 & 17.10 & 23.0 \\
\hline $\mathrm{Mo}$ & 2.25 & 2.38 & \\
\hline $\mathrm{Ti}$ & 0.26 & & 0.60 \\
\hline $\mathrm{Si}$ & 0.61 & 0.33 & 1.00 \\
\hline $\mathrm{Mn}$ & 1.78 & 1.88 & 1.50 \\
\hline $\mathrm{S}$ & 0.002 & 0.009 & 0.015 \\
\hline $\mathrm{P}$ & 0.007 & 0.009 & 0.045 \\
\hline $\mathrm{Al}$ & 0.006 & 0.005 & 0.60 \\
\hline $\mathrm{B}$ & 0.0015 & & \\
\hline $\mathrm{N}$ & 0.0037 & 0.044 & Balance \\
\hline $\mathrm{Fe}$ & Balance & Balance & \\
\hline
\end{tabular}

Stainless steels exposed to lower temperature supercritical water gained less weight, indicating an increase in spallation [23]. Similar results were found for a number of 
other stainless steels, including 304NG and AL-6XN [24]. Addition of chromium, nickel, or molybdenum to stainless steel is shown to improve corrosion resistance [24] [25].

\section{Corrosion in Superheated Steam}

As previously discussed, stainless steels show a trend of lower corrosion rates with increased levels of chromium. Croll and Wallwork [25] determined that the addition of nickel to stainless steels can also provide an oxidation resistance benefit, likely due to the formation of a nickel enriched layer. It was suggested that the growth of the protective chromium oxide layer could be promoted through a finer grain size [26]. More details on effect of grain size are included in a later section on surface treatment.

Maekawa et al [27] studied the corrosion of AISI 304 stainless steel in high-temperature water and steam, and determined the corrosion rate increased substantially with elevated temperature. Similarly, Ruther and Greenberg [28] found the corrosion rate of AISI 304 increased rapidly with temperature from $540^{\circ} \mathrm{C}$ to $650^{\circ} \mathrm{C}$, but decreased with time during long term testing ( 80 days).

Ruther and Greenberg also tested the effect of steam velocity on corrosion rate of AISI 304 , varying from 30 to 90 meters per second. They determined that velocity had little effect on corrosion rates, as shown in Figure 15, where open circles represent a velocity of $30 \mathrm{~m} / \mathrm{s}$, closed circles represent $60 \mathrm{~m} / \mathrm{s}$, and circles with a vertical line represent 90 $\mathrm{m} / \mathrm{s}$. 


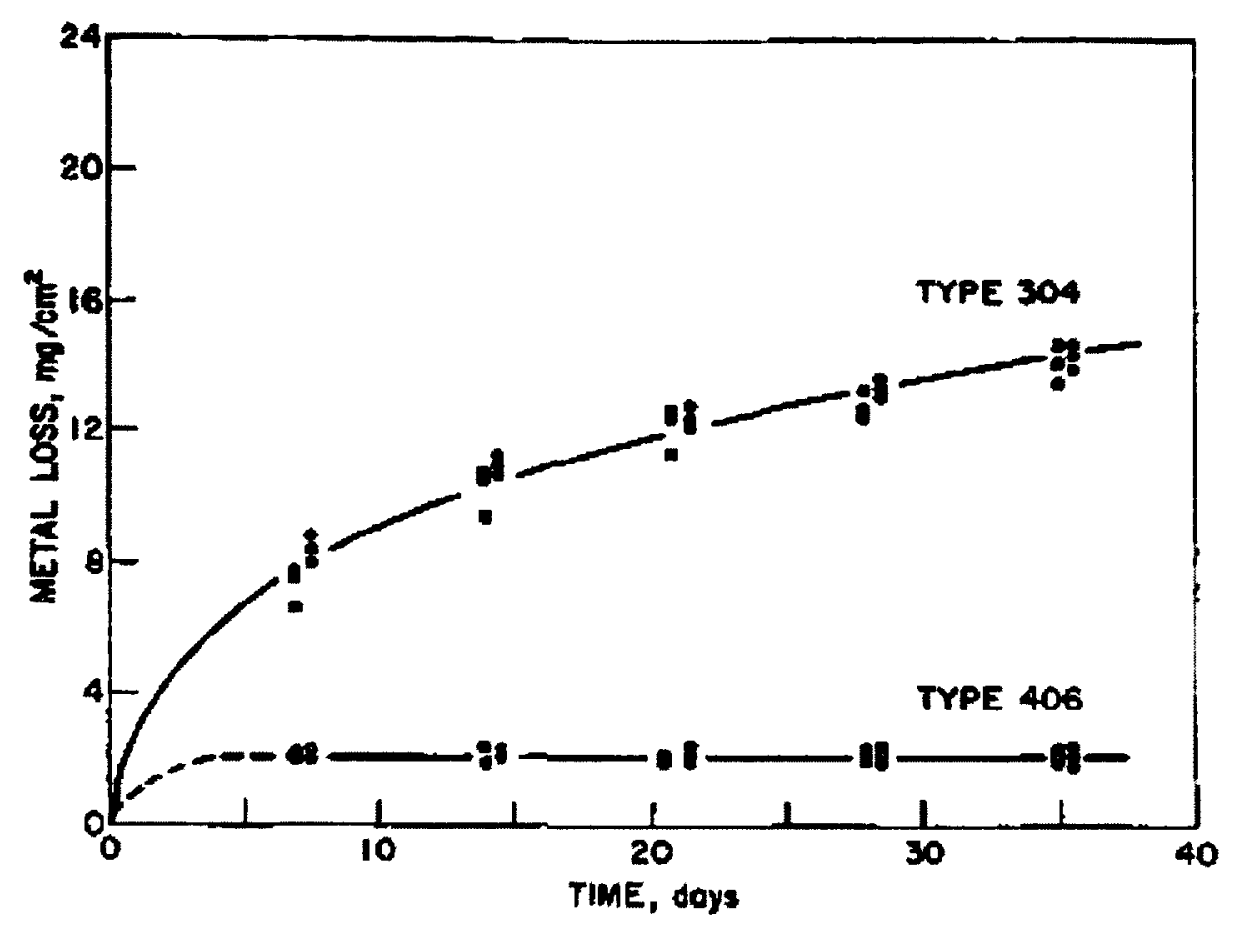

Figure 15 - Corrosion of stainless steel in flowing steam at $650^{\circ} \mathrm{C}[28]$ at varying velocities ( $30 \mathrm{~m} / \mathrm{s}$, open circles; $60 \mathrm{~m} / \mathrm{s}$, closed circles; $90 \mathrm{~m} / \mathrm{s}$, circles with vertical line) From Figure 15 it is clear that varying the velocity does not change the corrosion rate to a noticeable degree. In comparing these dynamic tests with static tests performed in autoclaves, however, Ruther and Greenberg did determine that the corrosion rates were about 1.5 times higher in dynamic tests that more closely resemble operating conditions in a power plant [28].

To understand the corrosion mechanisms of stainless steel in high-temperature steam, Cisse et al studied AISI $304 \mathrm{~L}$ specimens exposed to $400^{\circ} \mathrm{C}$ steam for 500 hours [29]. They found a duplex oxide layer was formed on the steel, composed of an inner layer rich in chromium and an outer layer of large magnetite crystals with smaller spinels enriched in 
iron and chromium, as had been suggested in past work [30]. A schematic representation of these layers is presented in Figure 16.

(a)

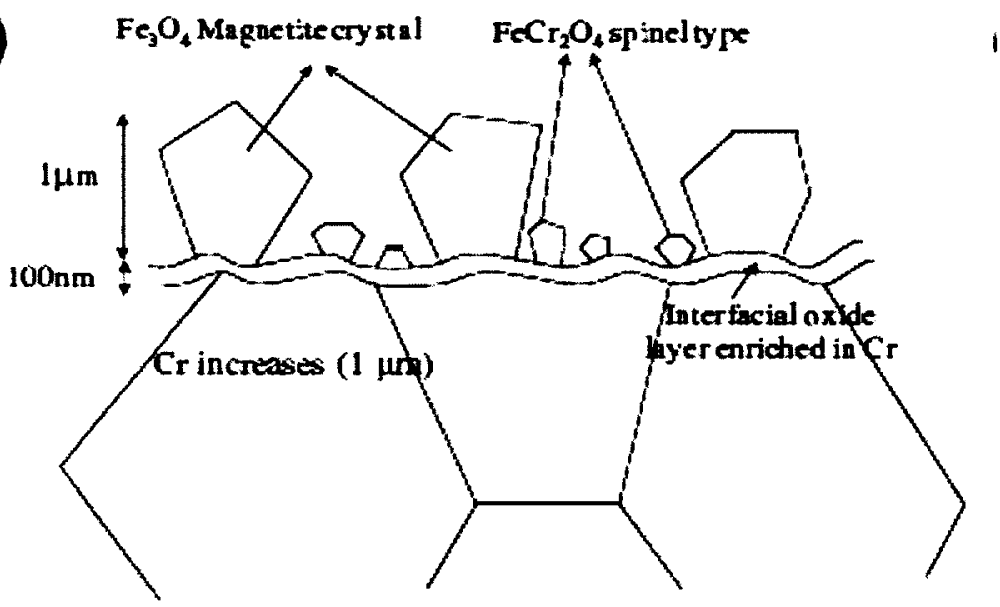

(b)

b) $\mathrm{Fe}_{3} \mathrm{O}_{4}$ Magnetitecrystal $\mathrm{FeCr}_{3} \mathrm{O}_{4}$ spineleype

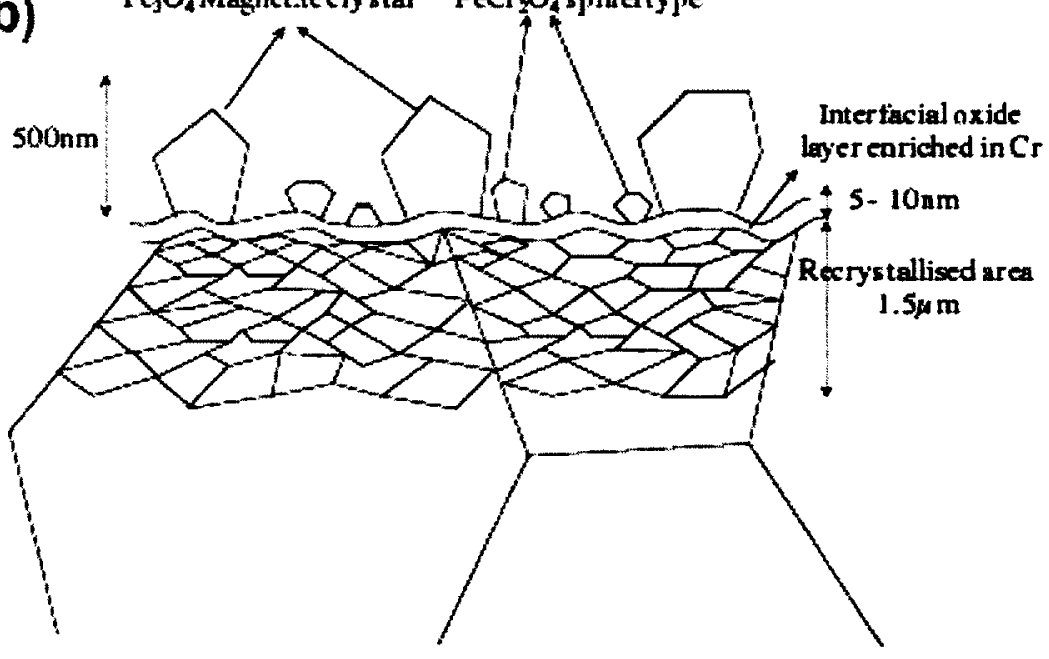

Figure 16 - Schematic representation of the oxide formed on a $304 \mathrm{~L}$ sample (a) polished and exposed to $400^{\circ} \mathrm{C}$ steam for $500 \mathrm{~h}$, and (b) ground and exposed to $400^{\circ} \mathrm{C}$ steam for $500 \mathrm{~h}[29]$

By retaining protective elements such as chromium in the inner layer, the oxide layer acts to protect the steel from corrosion. The oxide layer grows by diffusion of active elements through the solid oxide and grain boundaries. Fe diffuses to the outer layer 
and $\mathrm{O}$ diffuses through the oxide layer, while $\mathrm{Cr}$ and $\mathrm{Ni}$ enrichment at the metal oxide interface help protect the base material [29]. Cisse et al also reported similar results for 316L stainless steel [29].

The base material under the oxide layer was also found to be recrystallized, with fine elongated nanograins [29]. A thick recrystallized area corresponds with a thin oxide layer, and vice versa. The thickness of this layer is related to the surface finish, discussed later in this report.

\subsubsection{Nickel Alloys}

Nickel alloys are much stronger at elevated temperatures and are resistant to heat and corrosion. A number of high-nickel alloys have been considered for use in a potential supercritical water reactor, despite a higher cost compared to stainless steels.

\section{Corrosion in Supercritical Water}

Nickel alloys tend to have better corrosion resistance at high temperatures; however, in supercritical water the oxide layer formed on nickel alloys is thinner than that of stainless steels [23]. The weight gain due to the formation of an oxide layer of one highnickel alloy, IN625, in supercritical water is shown in Figure 17.

The oxide layer formed on this alloy is too thin to provide sufficient resistance to corrosion, and evidence of pitting and general corrosion was found [23]. Was et al determined that chromium rich oxides formed at the surface, depleting chromium at the grain boundaries and decreasing corrosion resistance [23]. Additional research into 
the corrosion resistance of nickel-alloys in supercritical water is required before using these materials in a SCWR.

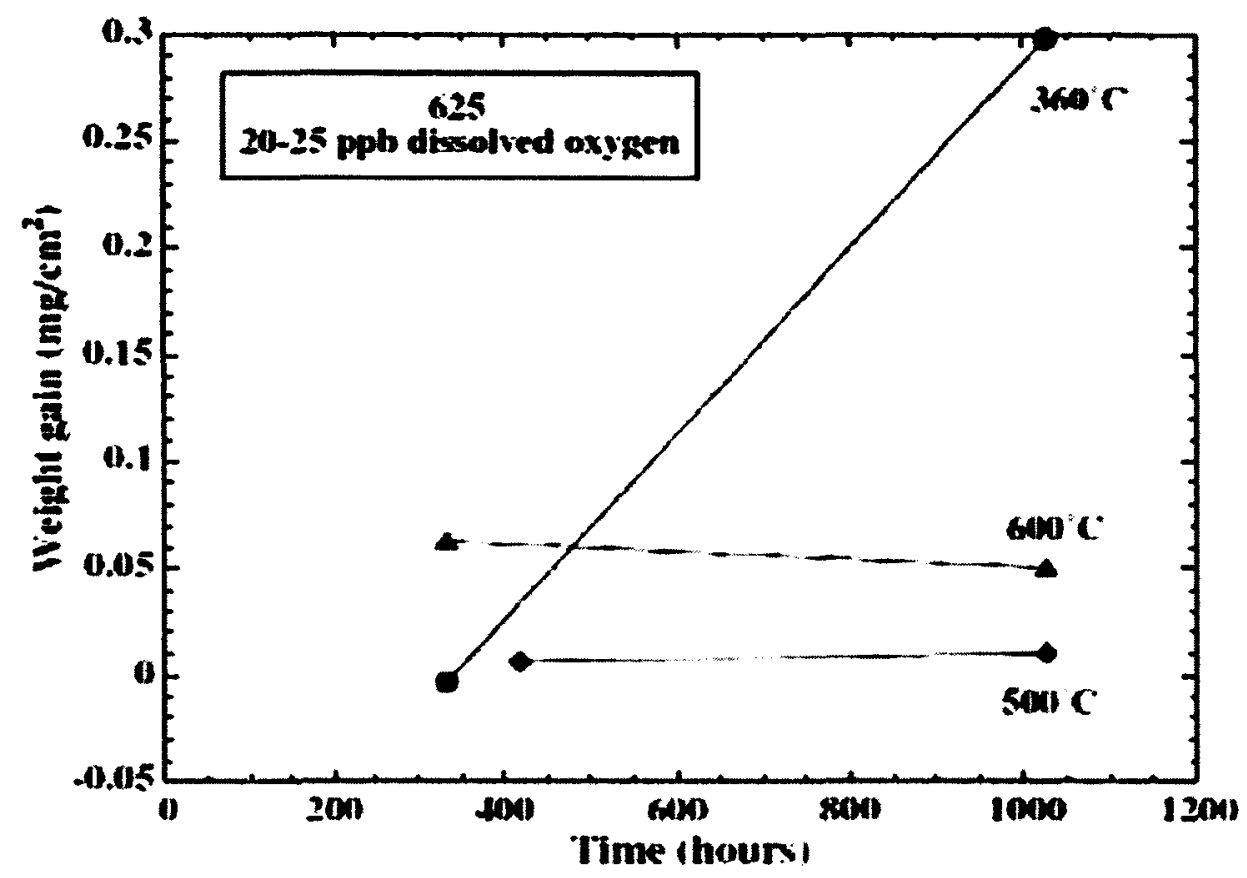

Figure 17 - Weight gain of IN625 in supercritical water [23].

\section{Corrosion in Superheated Steam}

Unlike stainless steels, little literature exists on the corrosion of nickel based alloys in superheated and high-temperature steam. Nonetheless, nickel alloys are a promising material class for use in power plants due to their high strength, heat resistance, and oxidation resistance.

Ruther and Greenberg tested some high nickel alloys in $650^{\circ} \mathrm{C}$ steam. They found Inconel 625 and Incoloy 800 to be more corrosion resistant than AISI 406 stainless steel, while Inconel 600 and Inconel $X-750$ did not perform as well. Their results are shown in Figure 
18. Note that these samples were chemically etched after testing to remove oxides, so a weight loss is shown.

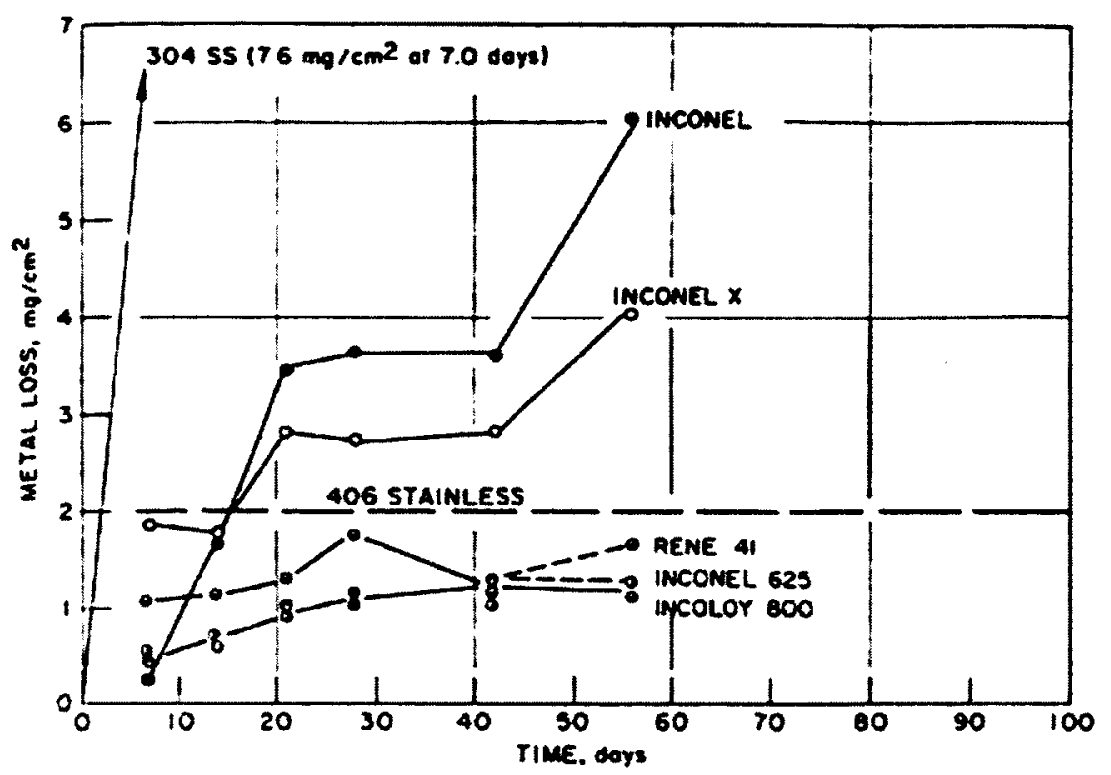

Figure 18 - Corrosion of nickel alloys in flowing steam, $650^{\circ} \mathrm{C}$ [28]

Inconel 625 and Incoloy 800 likely demonstrated high corrosion resistance due to their high chromium content, $22 \%$ and $20 \%$ respectively. Conversely, Inconel 600 and Inconel $x-750$ both have chromium contents of less than $20 \%$, accounting for their relatively poor performance.

Similarly, Griess and Maxwell [31] found Alloy 617 demonstrated excellent corrosion resistance in steam at temperatures of $482^{\circ} \mathrm{C}$ and $538^{\circ} \mathrm{C}$. This alloy also has high chromium content, at $20.3 \%$.

\subsubsection{Effect of Surface Finish}

The surface finish of a steel or nickel alloy can affect the surface structure, and influences the corrosion behaviour in superheated steam. The effect of various surface 
finish techniques have been studied, primarily for stainless steels, by a number of authors.

Warzee et al [32] studied the effect of surface treatment on stainless steel corrosion in high-temperature water and steam. AISI 304 and 410 stainless steels, as well as a high chromium and nickel steel alloy $(23.5 \mathrm{Cr}, 21.5 \mathrm{Ni})$, were exposed to steam at temperatures of $400^{\circ} \mathrm{C}$ to $600^{\circ} \mathrm{C}$ for durations of up to 2000 hours. The materials were differentiated by their primary surface treatments: electrolytic polishing in a perchloricacetic acid bath, mechanical polishing with 600 grit paper, machine grinding with carborundum (grain size 80 ), and milling.

Warzee et al concluded that the effect of the surface treatment in high-temperature steam was markedly different than in high-temperature water [32]. In high-temperature water electrolytic polishing greatly reduces the corrosion of the stainless steel, whereas in high-temperature water a mechanical surface treatment is preferred. A comparison of the corrosion of AISI 304 stainless steel in water and steam is given in Figure 19 below.

Figure 19 shows that in steam at $400^{\circ} \mathrm{C}$ the samples that were mechanically treated exhibited increased corrosion resistance than in water at $300^{\circ} \mathrm{C}$, and performed better than the electrolytically polished sample. To study the effect of the steam temperature on the corrosion behaviour of the polished and mechanically treated specimens, further testing by Warzee et al compared milled (taken to be representative of the mechanical 
treatments) and electrolytically polished samples in a range of steam temperatures [32].

The results of this are shown in Figure 20.
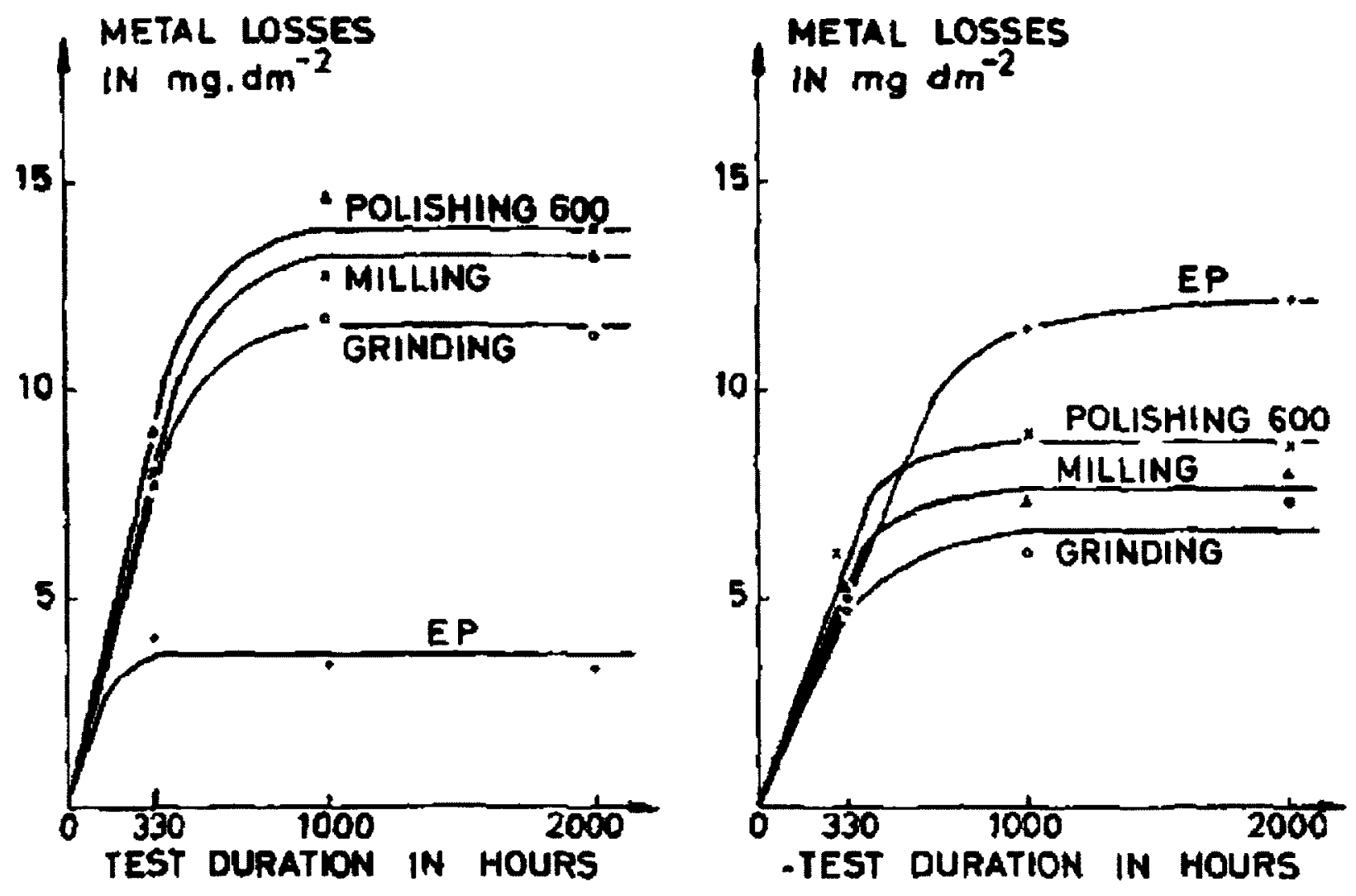

Figure 19 - Corrosion of AISI 304 in autoclaves: (left) water at $300^{\circ} \mathrm{C}$; (right) steam at $400^{\circ} \mathrm{C}, 6.9 \mathrm{MPa}[32]$

As can be seen in Figure 20 , below $350^{\circ} \mathrm{C}$ the choice of surface treatment had no effect on the corrosion. As temperature was raised above $350^{\circ} \mathrm{C}$, however, the corrosion of the electrolytically polished samples increased at a much higher rate than that of the milled samples. The corrosion of the milled samples increased slowly to a maximum at $500^{\circ} \mathrm{C}$, above which total corrosion dropped off. The favourable effect of a mechanical 
surface treatment on corrosion behaviour was retained in tests up to 2000 hours in length [32].

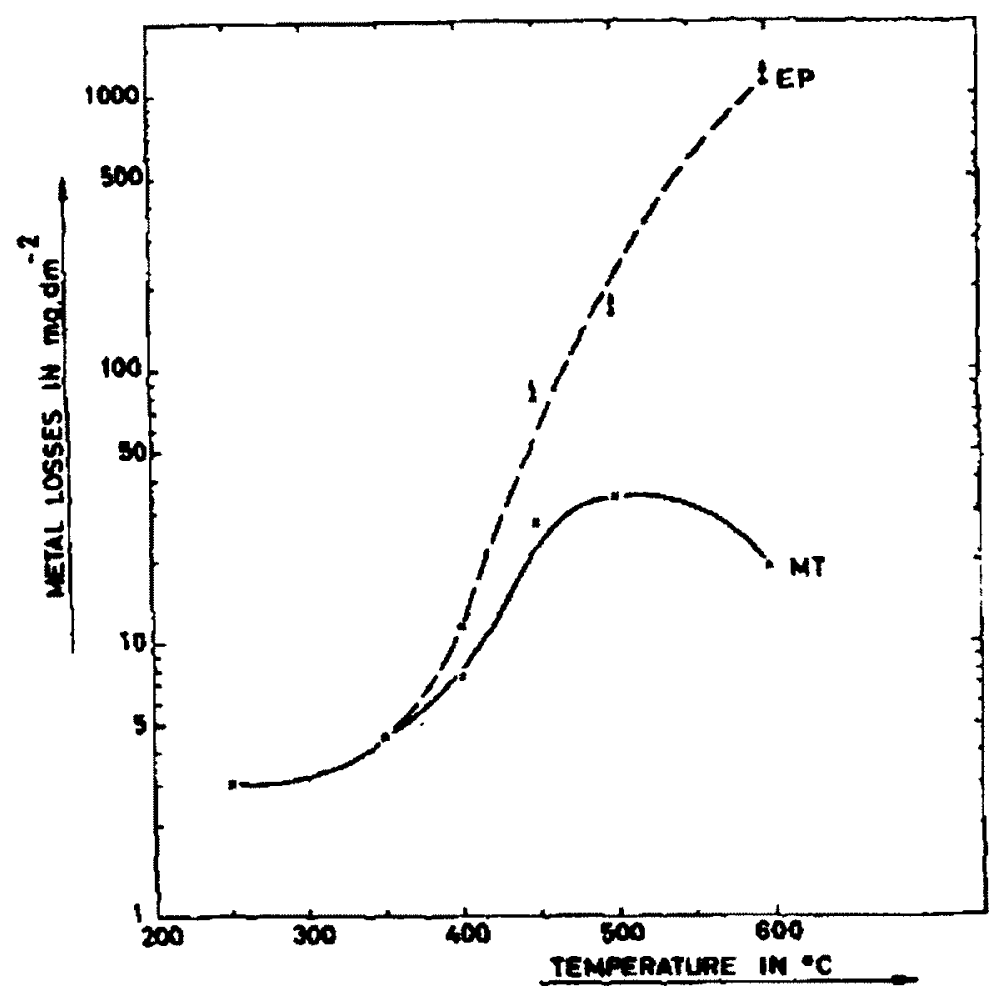

Figure 20 - Total corrosion of AISI 304 in 1000 hr in superheated steam (autoclaves, 15$70 \mathrm{~kg} / \mathrm{cm}^{2}$; electropolished samples, EP, and milled samples, MT) [32]

The corrosion behaviours of high chromium stainless steel (AISI 410) and $23.5 \mathrm{Cr}-21.5$ Ni steel were also examined by Warzee et al [32]. They determined that the increase in corrosion resistance in high-temperature steam as a result of mechanical surface treatment was also present for these two steels.

In their work, Warzee et al concluded that the surface roughness of the stainless steel samples did not alter the corrosion behaviour to an appreciable extent [32]. Instead, the reduced corrosion was determined to be caused by a cold-worked layer present in the 
mechanically treated samples. Warzee et al suggested the improvement is due to diffusion of chromium from the base metal to the oxide layer, made possible by the increased number of dislocations in the cold-worked crystal lattice [32]. An oxide layer high in chromium content would protect the base material against corrosion.

The beneficial impact of cold-working on the corrosion behaviour of stainless steels has been confirmed by a number of other authors [28] [27] [29]. Maekawa et al also concluded that the surface finish played a larger role at higher temperatures [27].

\subsection{Summary}

From the review conducted, it is clear that there is a lack of information in the literature concerning material's performance at higher temperatures $\left(>650^{\circ} \mathrm{C}\right)$. With the current SCWR design calling for a peak temperature of $850^{\circ} \mathrm{C}$ [33], it is important that the existing materials be evaluated under similar conditions. However, current equipment standards for pressurized vessels cannot exceed $650^{\circ} \mathrm{C}$ while a superheated steam rig (under ambient pressure) can reach as high as $1100^{\circ} \mathrm{C}$. As such, this study was initiated to study the effect of pressure on corrosion behaviour of three types of alloys, $\mathrm{Fe}-, \mathrm{Ni}-$ and Fe-Ni- based alloys. The results from this study will establish a basis to determine the suitability of material testing in superheated steam. 


\section{Objectives}

As development of a supercritical water cooled nuclear reactor continues, research into engineering materials behaviour in a corrosive high temperature fluid environment is needed. The objective of this thesis is to document and analyze testing performed on engineering materials in two corrosive environments.

Traditionally stainless steels and nickel super alloys have been thought to have the optimal balance of structural strength and corrosion resistance needed for high temperature power plant applications. To best assess these materials, an iron based stainless steel, a high nickel alloy, and a blended iron-nickel alloy were chosen for testing.

Samples of each material were exposed to supercritical water and to superheated steam to study effects of the environment on the material's corrosion behaviour. By testing in both supercritical water and superheated steam, a comparison of the influence of pressure on corrosion behaviour of iron based, nickel based, and iron-nickel based alloys can also be made.

As no known test facility exists to test materials in supercritical water at temperatures above $650^{\circ} \mathrm{C}$ and $30 \mathrm{MPa}$, the use of superheated steam as an equivalent fluid for corrosion testing has been proposed. The work documented in this thesis will determine whether these environments can be used interchangeably in testing the corrosion behaviour of iron based, nickel based, and iron-nickel based alloys. 


\section{Materials and Procedures}

Three alloys were chosen in this study to be tested in superheated steam and supercritical water, an alloy with high composition of both iron and nickel (A286), an iron-based alloy (AISI 310), and a nickel alloy (IN625). Descriptions of the alloys chosen, and their material compositions are given in the following section.

\subsection{Material Compositions}

A286 is an iron-based, high nickel content alloy purchased from Super Alloys International Limited [34]. The alloy is age-hardenable with high oxidation resistance. Aqueous corrosion resistance is comparable to that of $316 \mathrm{LC}$ stainless steel [34]. A286 is typically used in jet engine components or other applications where a high-strength at high-temperature is required. The chemical composition of A286 is given in Table 4 .

Grade 310 stainless steel (AISI 310) is an austenitic iron alloy designed for high temperature service, with good strength, ductility, and weldability [35]. This alloy is specially cast by Sophisticated Alloys. It has shown strong corrosion resistance in high temperature aqueous environments and has been used widely in furnaces, boilers, and reactors. The chemical composition of AISI 310 is given in Table 5.

Inconel 625 (IN625) is a nickel alloy purchased from Dynamic Metals [36]. IN625 has high heat and corrosion resistance and strong fabricability. This alloy has been widely used in aerospace, nuclear, and chemical applications. The chemical composition of IN625 is given in Table 6 below. 
Table 4 - Chemical composition of A286 [34]

\begin{tabular}{|l|c|c|}
\hline Element & Minimum Percentage & Maximum Percentage \\
\hline Chromium (Cr) & 13.50 & 16.00 \\
\hline Nickel (Ni) & 24.00 & 27.00 \\
\hline Molybdenum (Mo) & 1.00 & 1.50 \\
\hline Cobalt (CO) & - & 1.00 \\
\hline Vanadium (V) & 0.10 & 0.50 \\
\hline Aluminum (Al) & - & 0.35 \\
\hline Titanium (Ti) & 1.90 & 2.35 \\
\hline Boron (B) & 0.003 & 0.01 \\
\hline Carbon (C) & - & 0.08 \\
\hline Iron (Fe) & - & Remainder \\
\hline Manganese (Mn) & - & 2.00 \\
\hline Silicon (Si) & - & 1.00 \\
\hline Phosphorus (P) & - & 0.025 \\
\hline Sulfur (S) & - & \\
\hline & & \\
\hline
\end{tabular}


Table 5 - Chemical Composition of AISI 310 [36]

\begin{tabular}{|l|c|c|}
\hline Element & Minimum Percentage & Maximum Percentage \\
\hline Carbon (C) & - & 0.25 \\
\hline Manganese (Mn) & - & 2.00 \\
\hline Silicon (Si) & - & 1.50 \\
\hline Phosphorus (P) & - & 0.045 \\
\hline Sulfur (S) & 24.00 & 0.030 \\
\hline Chromium (Cr) & 19.00 & 26.00 \\
\hline Nickel (Ni) & & 22.00 \\
\hline Iron (Fe) & & Remainder \\
\hline
\end{tabular}


Table 6 - Chemical Composition of IN625 [35]

\begin{tabular}{|l|c|c|}
\hline Element & Minimum Percentage & Maximum Percentage \\
\hline Nickel (Ni) & - & Remainder \\
\hline Chromium (Cr) & 20.00 & 23.00 \\
\hline Iron (Fe) & - & 5.00 \\
\hline Molybdenum (Mo) & 8.00 & 10.00 \\
\hline Niobium (Nb) and Tantalum & 3.15 & 4.15 \\
\hline (Ta) & & 0.10 \\
\hline Carbon (C) & - & 0.50 \\
\hline Manganese (Mn) & - & 0.50 \\
\hline Silicon (Si) & - & 0.015 \\
\hline Phosphorus (P) & - & 0.015 \\
\hline Sulfur (S) & - & 0.40 \\
\hline Aluminum (Al) & & 0.40 \\
\hline Titanium (Ti) & & \\
\hline Cobalt (Co) & & \\
\hline
\end{tabular}

\subsection{Material Preparation}

The A286 and IN625 were provided in sheets $1.5 \mathrm{~mm}$ thick, while the AISI 310 was provided in a $12.5 \mathrm{~mm}$ diameter bar. Eight test samples of each material were prepared using the following procedure: 
1) Cutting - A286 and IN625: $2 \mathrm{~cm}$ squares were sheared from the sheet metal. AISI 310: $5 \mathrm{~mm}$ thick coupons were cut from the bar using a diamond cutter.

2) Drilling - Holes were drilled in the supercritical water test samples to allow for hanging within the autoclave using $2.5 \mathrm{~mm}$ diameter carbide drill bits in a drill press.

3) Grinding - Samples were ground on all sides by hand to 600 grit. Four sandpapers of progressive fineness were used: $240,320,400$, and 600 grit.

4) Cleaning - Samples were placed in an ultrasonic cleaner in water with a few drops of liquid detergent and cleaned for $\mathbf{4 0}$ minutes followed by solvent cleaning. After cleaning, samples were handled using only tweezers to avoid contamination.

5) Baking - Samples were placed in an oven at $200^{\circ} \mathrm{C}$ for 2 hours to remove moisture.

6) Weighing - Samples were weighed three times using a Mettler Toledo AG285 digital scale to an accuracy of $0.1 \mathrm{mg}$.

7) Resting - Samples were placed in covered containers and rested for a minimum of 1 day. This step had resulted in improved corrosion resistance in previous tests, likely due to the formation of a very thin layer of oxygen on the sample surface.

8) Weighing - Samples were weighed three times immediately before testing. 


\subsection{Superheated Steam Testing Rig}

Superheated steam testing was performed in a test rig custom built for this project. This test rig used a steam generator and superheater from Micropyretics Heaters International $(\mathrm{MHI})$ to generate steam and superheat it to the desired temperatures. Set-up of the equipment and design of a custom steam cooling system is described in this section.

\subsubsection{Rig Set-Up}

A combination of manufactured equipment and custom designed components was used to build the superheated steam testing rig. Table 7 details the major components of the test rig.

Table 7 - Components of the superheated steam testing rig

\begin{tabular}{|l|l|l|}
\hline Component & Manufacturer/Supplier & Purpose \\
\hline HGA-S-01 Steamer & MHI & Steam generator \\
\hline CXamber & MHI & Superheater \\
\hline $\begin{array}{l}\text { BPAN-O-Plus-2010 } \\
\text { Control panel }\end{array}$ & MHI & Superheater controller \\
\hline $\begin{array}{l}\text { BPAN-O-Plus-2010 } \\
\text { Control panel }\end{array}$ & MHI & Steam generator controller \\
\hline Peristaltic pump & MHI & Water pump \\
\hline M-6D Aqua still & Pure Water Society Inc. & Water distiller \\
\hline Steam cooling & Swagelok (built from custom & Steam discharge \\
& design) & and \\
\hline Water reservoir & Custom assembly & Steam cooling \\
\hline
\end{tabular}


The superheated steam testing rig was designed according to the diagram shown in Figure 21.

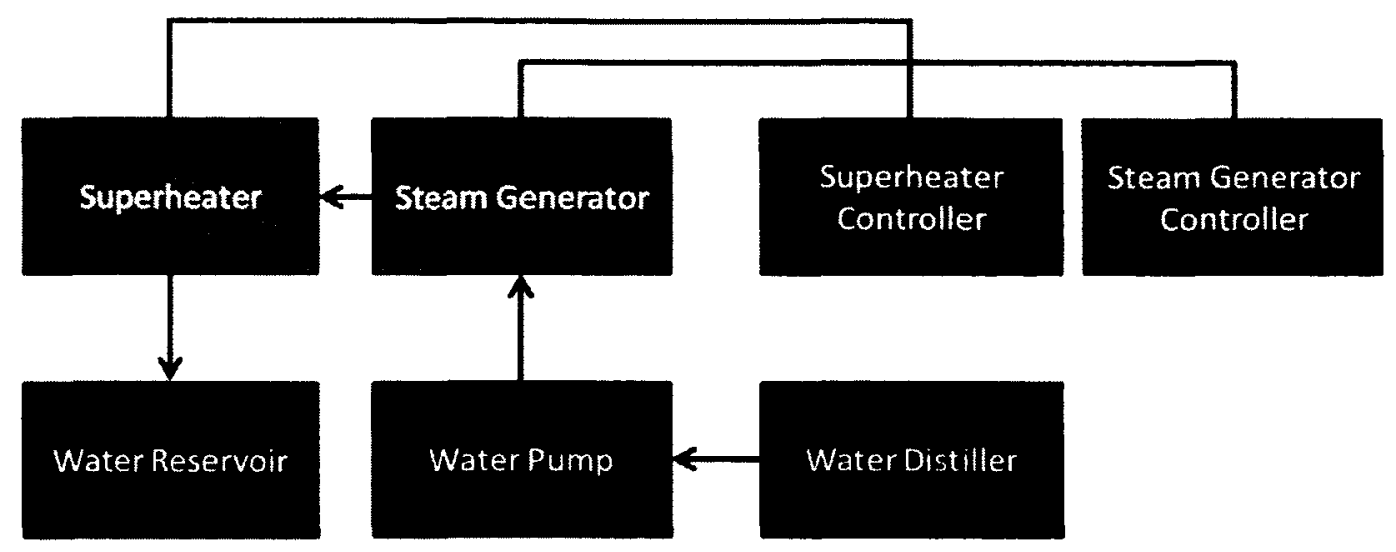

Figure 21 - Superheated steam testing rig diagram

The system from $\mathrm{MHI}$ would pump water into the steam generator, where steam would be produced at temperatures of up to $550^{\circ} \mathrm{C}$. Steam would then pass into a test chamber in the superheater, where samples would be located and steam further heated as high as $1300^{\circ} \mathrm{C}$. The superheater test chamber as provided by $\mathrm{MHI}$ was an alumina tube $1.5^{\prime \prime}$ in diameter and $18^{\prime \prime}$ long. This was replaced with a tube of 316 grade stainless steel with the same dimensions after the alumina tube was cracked due to thermal shock. This stainless steel test chamber did not seal as tightly to the stainless steel end caps as the alumina had, so rubber gaskets were made to fit between the chamber and the end caps. The superheater with the stainless steel test chamber and gasket material can be seen in Figure 22 below. 


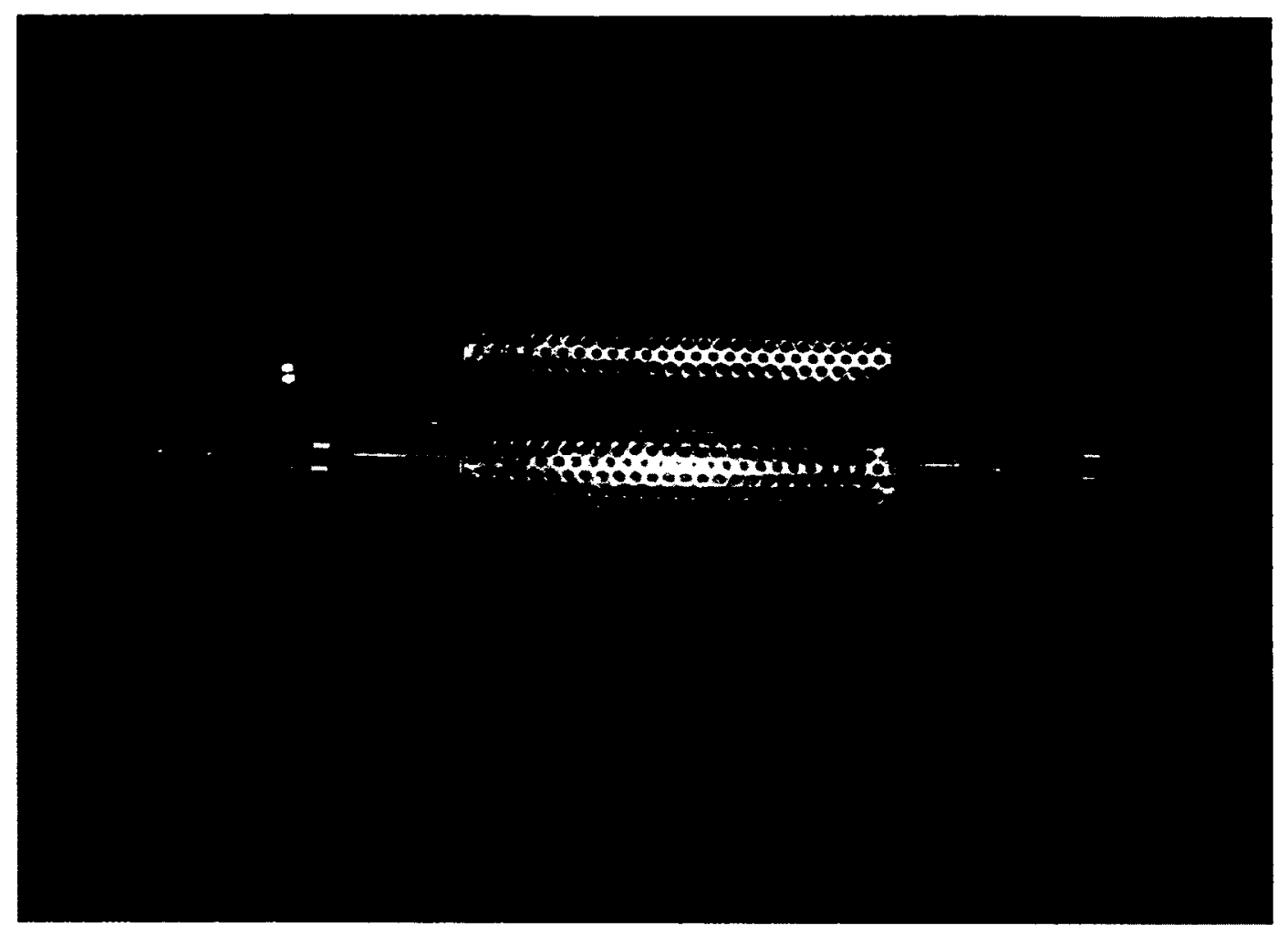

Figure 22 - Superheater test chamber

The gasket material was not rated to $600^{\circ} \mathrm{C}$, the desired operating temperature, so a fan was used to provide forced convection over the gaskets. The MHI equipment was otherwise installed according to their instructions.

To protect the steam generator, a supply of distilled water was needed. To provide this, an M-6D Aqua Still manufactured by Pure Water Society Inc. was purchased. This water distiller operated autonomously, starting and stopping production of distilled water as the level in its integrated reservoir fluctuated. Rate of water distillation was slightly higher than the rate of supply needed for the steam generator (approximately $1 \mathrm{~kg}$ per hour), so a steady supply of distilled water was ensured for the duration of the testing. 
The discharge and cooling of the superheated steam posed a major problem. A system from $\mathrm{MHI}$ to cool and recirculate the steam was considered, but could not be acquired in time to complete the test. Instead, an open cooling loop was designed and built.

A 2" diameter 310 grade stainless steel discharge pipe was fitted with an inlet to fasten to the superheater's steam outlet. This pipe was bent to carry steam from the superheater to an open water reservoir, a large plastic tub. Copper tubing $1 \mathbf{4}^{\prime \prime}$ in diameter was wrapped around the stainless steel pipe, with a fitting to allow connection to a water supply. Cool water would flow through the copper tubing to the reservoir, cooling the stainless steel pipe to avoid damage and providing a steady flow of cool water to the water reservoir. The steam discharge assembly was designed by the author, and was assembled by Swagelok Central Ontario. Figure 23 below shows the water reservoir (bottom left) and the steam discharge and cooling assembly with its connections to the laboratory's water supply and the superheater outlet (top right).

As steam was discharged through the stainless steel pipe to the water reservoir, it was cooled and condensed into water. A steady supply of cool water was provided to the reservoir, and a garden fountain pump and float valve were installed. As water rose above a set level, the float valve activated the pump and water was pumped from the reservoir out of the lab, to be drained outside the building. Once the water level in the reservoir fell below a certain set point, the float valve cut power to the pump and allowed the water level to again rise. This kept the water reservoir from overflowing or running dry for the duration of the testing. 


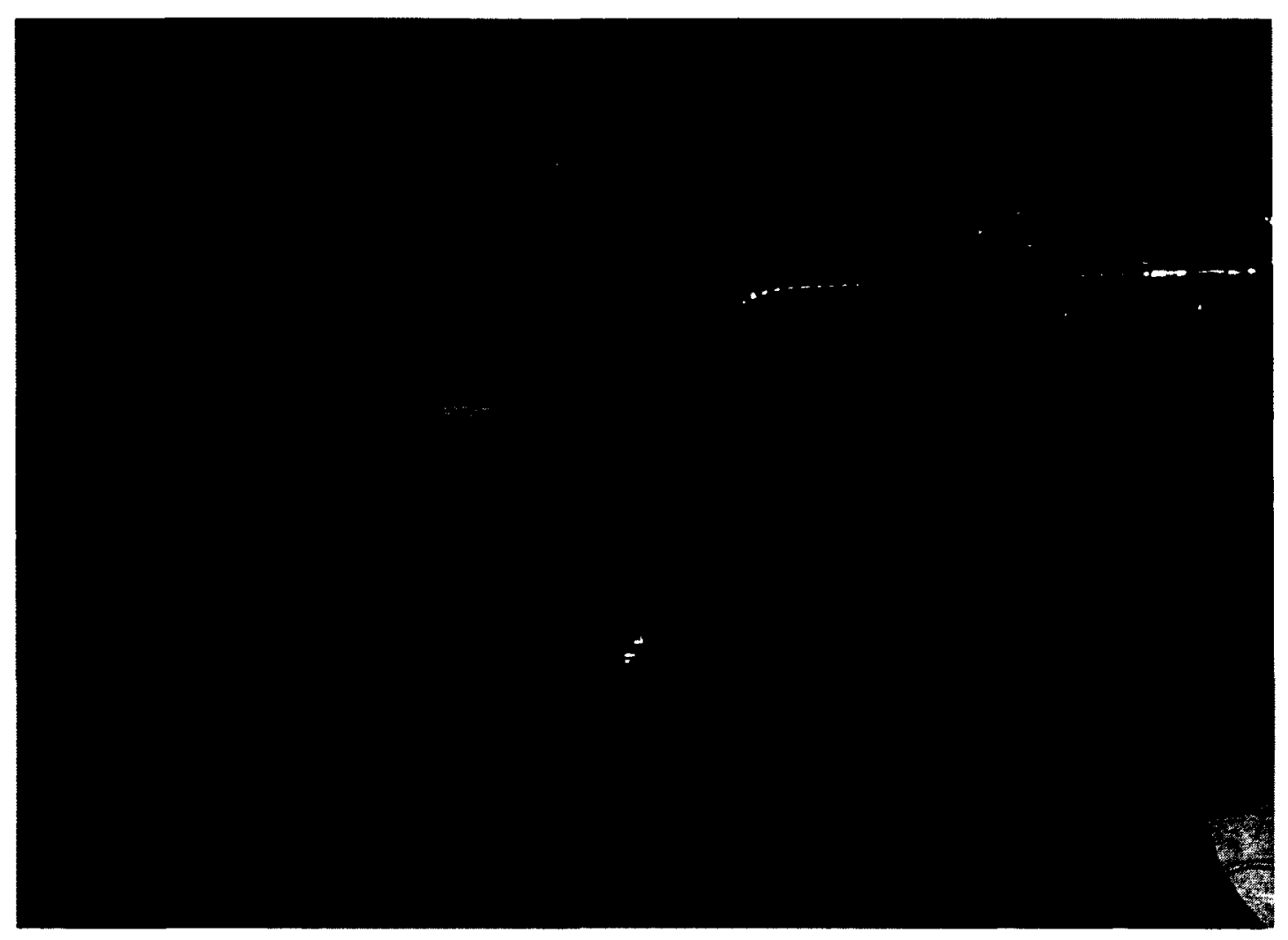

Figure 23 - Water reservoir and steam discharge assembly

The finished superheated steam testing rig is shown in Figure 24. The test rig operated reasonably well for the 300 hours required for these tests, but a number of issues were identified. The peristaltic pump was prone to damage, with a leak in the tubing found early in the test rig operation. Once the tubing was replaced, flow rates were found to be highly variable, leading to difficulty in meeting the precise rate needed for the steam generator. Too high a flow rate caused leaks in the steam generator and difficulty in reaching the desired steam temperature, while too low a flow rate caused the steam generator to overheat. A more reliable pump is recommended for longer term testing. 


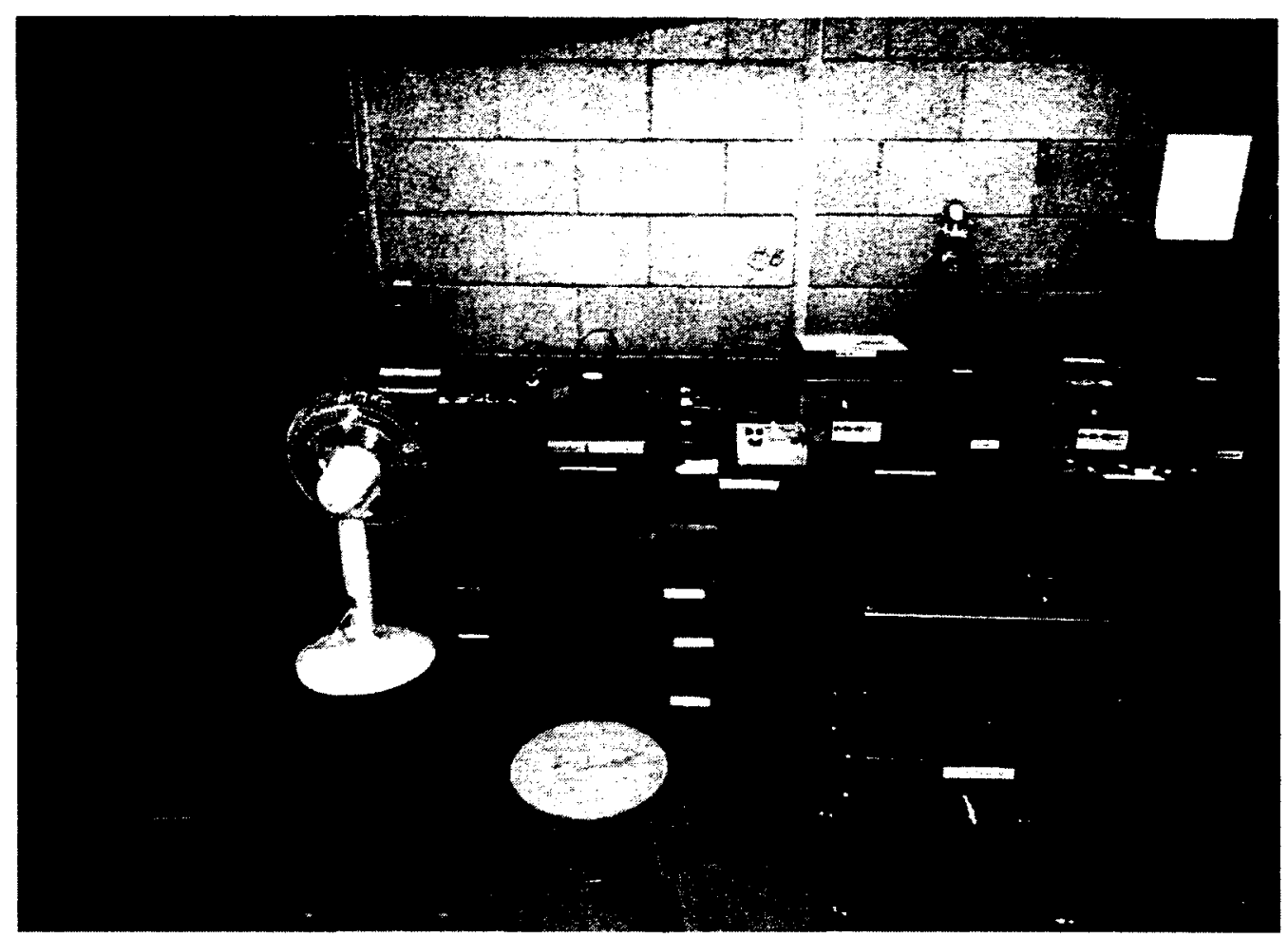

Figure 24 - Superheated steam testing rig

\subsubsection{Operating Procedure}

To operate the superheated steam testing rig, the following operating procedure was used:

1) Check power and water supply to all equipment.

2) Start water distiller by placing timer dial to "Off", main switch to "Auto", and fan switch to "On". Start loading samples after an ample supply of distilled water in the water distiller reservoir is available.

3) Place prepared test samples on porous alumina insulation to allow the bottom of the samples to be exposed to steam.

4) Load test samples and alumina insulation into the stainless steel superheater test chamber. 
5) Close test chamber by fastening rubber gasket and steam generator outlet face plate to the stainless steel superheater tubing.

6) Prime peristaltic water pump by placing the inlet tube in water distiller reservoir and setting switches to "Forward" and "Prime" until water flows from the outlet tubing. Flow rate can be adjusted as desired using the dial and speed switch. Outlet tubing should be connected to steam generator. Use a flow rate of approximately $1 \mathrm{~kg}$ per hour.

7) The steam generator and superheater controllers are powered on by turning breakers to "On". Desired temperatures can be set using the Temperature and Over Temperature Controllers on both units. The steam generator temperature is set to $400^{\circ} \mathrm{C}$ while the superheater temperature to $600^{\circ} \mathrm{C}$.

8) Start the water supply to the superheater outlet tubing assembly using the flow valve on the cooling water coil.

9) Start the steam generation by pressing "Heater On" on the steam generator controller and switching water pump to "Forward" simultaneously.

10) Once steam generation is started, turn on the superheater by pressing "Heater On" on the superheater controller.

During this experiment once superheated steam was flowing through the testing rig, it was able to operate automatically for the duration of the testing period. Distilled water supply was maintained by the water distiller, which was activated as its water reservoir level was lowered. The level in the cooling water reservoir was maintained using the float switch and water pump, with water being drained from the reservoir as needed. 
Upon completion of the test, the following procedure was used to shut-down the equipment safely.

1) Turn off the steam generator by pressing "Heater Off" on the steam generator controller and the water pump switch to "Off" simultaneously.

2) Reduce the superheater temperature slowly using the Temperature Controller on the superheater controller to avoid thermal shock. Temperature should be lowered to near ambient, 100 degrees at a time (over several hours).

3) Turn off superheater by pressing "Heater Off" on the superheater controller.

4) Power off the steam generator and superheater controllers using the main breakers on each.

5) Stop the water flow through the cooling coil using the flow valve.

6) Remove samples by disconnecting the steam generator from the superheater test chamber.

\subsection{Supercritical Water Testing Autoclave}

The supercritical water testing was performed in an autoclave manufactured by Parker Autoclave Engineers. The autoclave is rated to $650^{\circ} \mathrm{C}$ and $38 \mathrm{MPa}$ and features a selfsealing closure.

\subsubsection{Autoclave Set-Up}

The autoclave was assembled according to the manufacturer's instructions. A custom steel guard was installed around the heating vessel. The blow-off valve was fitted with a tube extending straight above the autoclave to avoid user injury in the case of over- 
pressure. The autoclave, with shielding and extended blow-off tubing, is shown in Figure 25 (a). To test samples in the autoclave, a sample stand was constructed from Inconel 625, shown in Figure 5(b).

Alumina rods were inserted through the holes of the stand, and the test samples were hung from the rods. The test stand could then be lowered into the heater vessel.

To ensure no loss of pressure over an extended testing period the autoclave was fitted with a self-sealing metal closure assembly, shown in Figure 26.

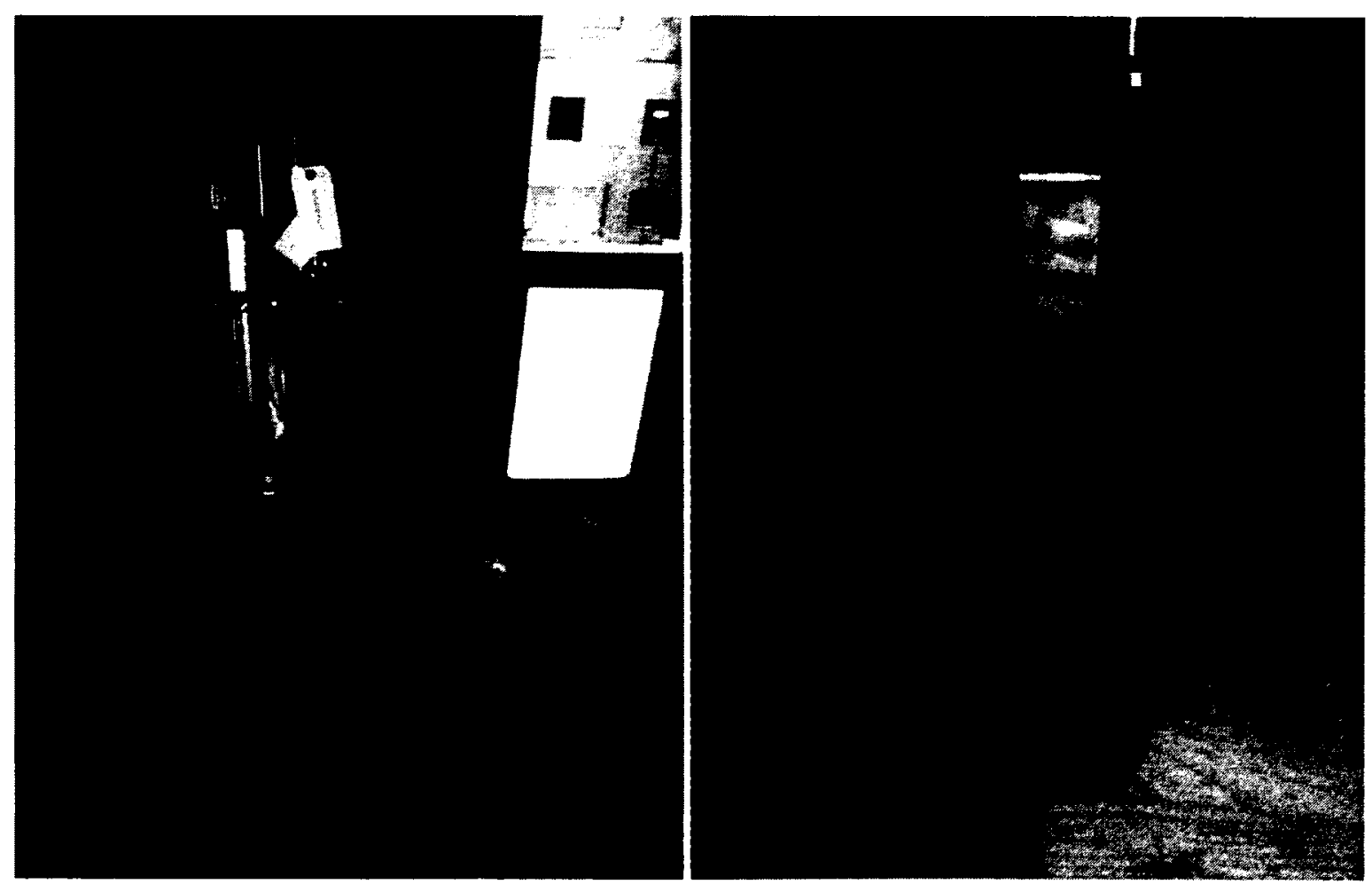

Figure 25 - (a) Autoclave and (b) sample stand 


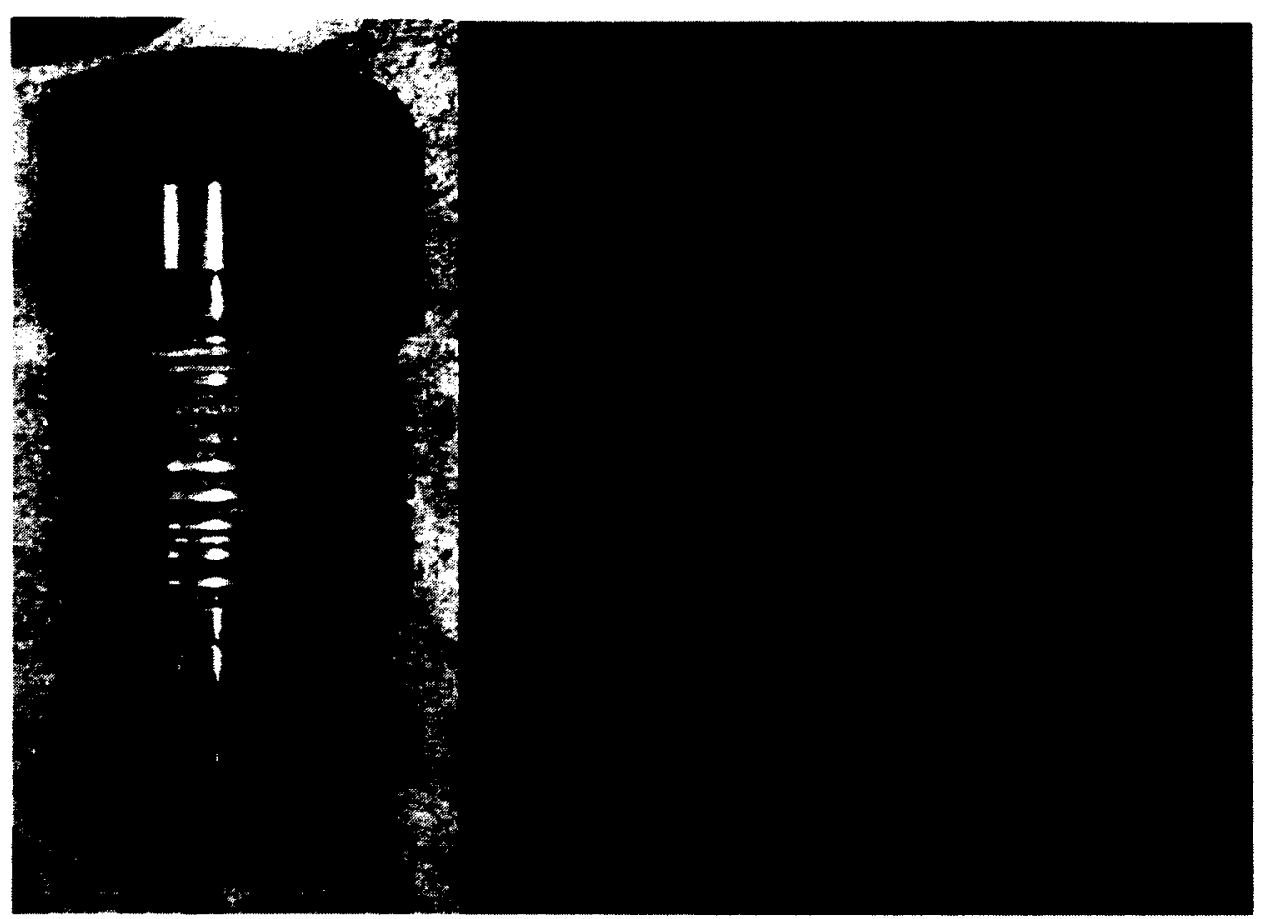

Figure 26 - Autoclave self-seal closure and diagram

\subsubsection{Operating Procedure}

To perform the supercritical water testing in the autoclave, the following procedure was used:

1) Wipe the heating vessel with a clean rag to remove any water or contamination.

2) Lower the samples hung from the test stand alumina rods into the autoclave vessel.

3) Add distilled water to the vessel using a syringe. To reach $29 \mathrm{MPa}$ at $600^{\circ} \mathrm{C}, 106$ $\mathrm{mL}$ of water was added.

4) Clean all components of the self-sealing closure using clean rags, and apply copper lubricant to the main nut external threads, the bottom bearing surface of the main nut, the body internal threads, the top of the seal ring, the lock nut 
internal threads, the set screw threads, the bottom of the set screws, and the sealing surfaces of the seal ring.

5) Assemble the seal ring, bearing washer, main nut, thrust washer, and lock nut onto the cover, with the set screws flush with the bottom surface of the lock nut. The lock nut is threaded onto the cover until the total gap between parts reaches approximately $1 / 16^{\prime \prime}$.

6) Lower the cover into the vessel while threading the main nut in place. The cover should not move during the installation process to avoid interference with the sample stand.

7) Once the main nut is engaged, a tommy bar is inserted into it and tightened a quarter turn using a mallet to create a seal between the seal ring and the vessel body.

8) Tighten the set screws by hand using an alternating cross pattern to evenly torque the screws. Using a torque wrench and the same pattern, the screws are tightened to $10 \mathrm{ft}$-lbs, then $20 \mathrm{ft}-\mathrm{lbs}$, then $30 \mathrm{ft}$-lbs gradually. The screws are further tightened to $30 \mathrm{ft}$-lbs a second time.

9) Slide the thermocouple into the cavity on the top of the cover.

10) Fasten the piping to the pressure gauge and blow-off valve to the cover.

11) Power on the autoclave controller using the breaker on the back of the unit. The "Heater" breaker must be off for this step.

12) The "Process Temperature" controller is set to 0.0 to ensure the heater does not blow the controller fuse when the autoclave is powered on. 
13) Power on the heater using the "Heater" breaker.

14) Raise the "Process Temperature" gradually (100 degrees at a time) to the desired test temperature. To reach $600^{\circ} \mathrm{C}$, several hours are required. The "Process Pressure" should be monitored to ensure pressure does not spike above 5546 psi, the blow-off valve burst pressure rating.

Once the temperature and pressure of the autoclave are stabilized at the desired levels, the autoclave could be left for the test duration (with daily check). No loss of pressure was observed over the 300 hours of testing.

To remove the samples and shut off the autoclave, the following procedure was used:

1) Turn off the heater using the "Heater" breaker on the autoclave controller. The autoclave takes up to 24 hours to cool, so the rest of the steps are generally performed a day later.

2) Once the autoclave pressure and temperature reach ambient levels, open the pressure valve to relieve excess pressure.

3) Remove the piping to the pressure gauge and blow-off valve and the thermocouple from the cover.

4) Loosen the set screws from the lock nut.

5) Using a tommy bar and a mallet, loosen the main nut one quarter turn. The cover must not be allowed to rotate during the removal process.

6) Two opposing set screws are tightened slightly to pull the seal ring free from the body. 
7) Lift the cover and unthread the main nut in order to remove the closure.

8) Lift the sample stand out of the autoclave.

9) The heating vessel and closure should be thoroughly dried and cleaned for next operation.

\subsection{Material Analysis}

Once test samples were removed from the superheated steam testing rig and the supercritical water autoclave, they were handled with tweezers at all times to avoid contamination and were cleaned using the following procedure:

1) Cleaning - Samples were placed in an ultrasonic cleaner in water with a few drops of liquid detergent and cleaned for 40 minutes followed by solvent cleaning.

2) Baking - Samples were placed in an oven at $200^{\circ} \mathrm{C}$ for 2 hours.

Once the samples had been cleaned, a series of inspections and tests were performed, detailed below.

\subsubsection{Visual Inspection}

The first, and most basic, analysis performed on the samples was a simple visual inspection. To ensure conformity, samples were placed in a box for inspection, shown in Figure 27. 


\section{Figure 27 - Set up for visual inspection of samples}

Samples placed in this box were photographed using a digital camera, maintaining the same lighting levels and camera settings. Samples were inspected and the colouring and lustre were recorded. Any imperfections or inconsistencies were recorded.

When testing of all the samples had been completed (for 100, 200 and 300 hours), they were placed in the visual inspection box and comparative analysis was performed. The results of the visual analysis are discussed in the Results section.

\subsubsection{Weight Change}

An important measure of corrosion behaviour is the weight change of the samples after exposure to superheated steam and supercritical water. The weight and dimensions of each sample had been recorded prior to testing using a Mettler Toledo digital scale and a calliper, shown in Figure 28. The tested samples were weighed three times 
immediately after cleaning, and three more times after a minimum of one day. The absolute weight change and weight change by surface area for each sample was computed and graphed, discussed further in the Results section.

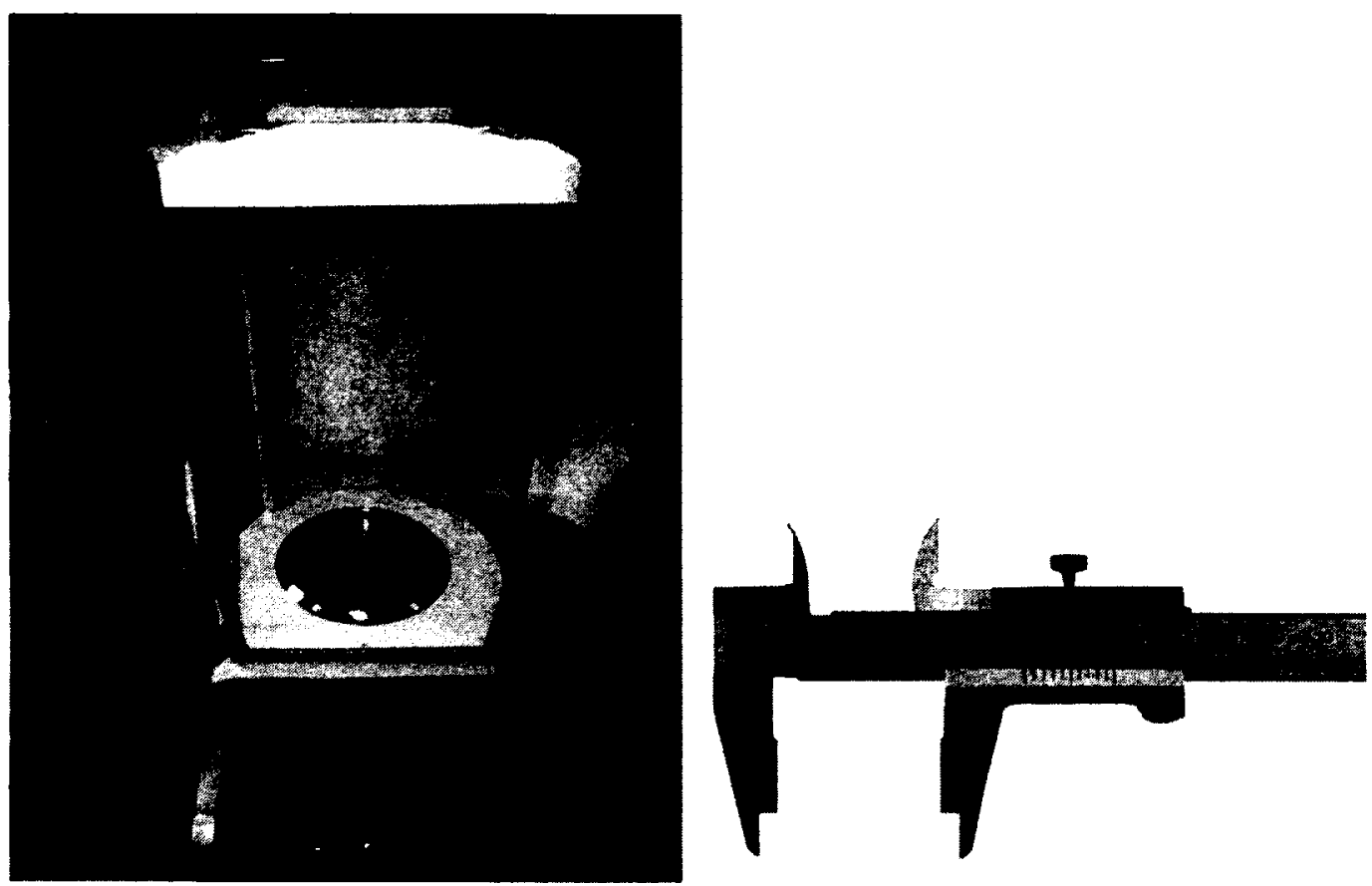

Figure 28 - Digital scale and calliper used to measure weight and dimension

\subsubsection{SEM and EDS}

To examine the effects of corrosion on the material's microstructures and compositions, scanning electron microscope (SEM) and energy dispersive $x$-ray spectrometry (EDS) analysis was performed. Both were performed using a Tescan Vega-II XMU SEM equipped with Oxford X-Ray detection systems (INCA EDS) at Carleton University's Nano Imagining Facility. SEM and EDS analysis was performed with assistance from Dr. Jianqun Wang (Technical Director of the Nano Imaging Facility). 
A SEM allows images of a material to be taken at a very high degree of magnification. A beam of electrons is emitted from a filament and is focussed by condenser lenses onto the surface of the material. Some of the electrons from this beam are reflected (backscattered) off of the surface due to scattering interactions with the material's atoms. A back-scattered electron detector, consisting of a ring around the electron beam above the material surface, collects these electrons and is used to create a back-scattered electron (BSE) image, which is used to show contrast between areas of different chemical composition on the material's surface.

A secondary electron (SE) image is created using low energy electrons that are ejected from the orbitals of the material's atoms after scattering interactions with the electron beam. These are detected by a secondary electron detector and produce well-defined, clear images of the material's surface morphology.

Energy dispersive spectrometry (EDS) uses secondary electrons to determine the chemical composition of a region on a material's surface. In EDS analysis, the electron beam scatters orbital electrons from the material's atoms as in SE imaging. If an electron from an inner, low energy shell is ejected, an electron from an outer, high energy shell will move to fill the hole, and the difference in energy will be released as $\mathrm{x}$-rays. Since each element has a unique atomic structure, detecting and measuring the $x$-rays released allows the elemental composition of the area being analysed to be determined.

SEM images were generated for a number of regions on each sample. A minimum of three magnifications were used - 1000x, 5000x, and 10,000x. In some cases different 
magnifications were used to highlight points of interest. EDS was performed on multiple sites on each sample in order to provide chemical compositions of the background, uniform material as well as of oxides and any heterogeneous areas. SEM and EDS results are presented and discussed in the Results section. 


\section{Results and Discussion}

The results of the visual inspection, weight change, and SEM and EDS analysis, as discussed in the Methods section, are presented in the following subsections for samples before and after being exposed to supercritical water and superheated steam. Dissolved oxygen content for both the supercritical water and superheated steam was 6 $\mathrm{ppm}$ and $\mathrm{pH}$ value was 5 . The slightly acidic nature of the distilled water was due to the presence of carbonic acid from dissolved $\mathrm{CO}_{2}$.

\subsection{Visual Inspection}

Samples were removed from the testing apparatus at 100 hour intervals, cleaned, and photographed. The observation is summarized below.

\subsubsection{Supercritical Water Exposed Samples}

Figure 29 shows samples of all three materials before and after exposure to supercritical water $\left(600^{\circ} \mathrm{C}, 29 \mathrm{MPa}\right)$ for varying durations.

Significant changes in the colouring and lustre of the samples were observed. The A286 samples showed dramatic changes as exposure time was increased. Unexposed A286 was silver and reflective, but after exposure to supercritical water the material darkened and became matte. The sample exposed for 300 hours was seen to be uniformly dull and matte, with a blue-gray colouring, indicating progressive surface oxidation with time.

The unexposed AISI 310 sample is similar to that of A286. After 100 hours of exposure samples became a dull gray. The difference in appearance between samples exposed for 
100,200 , and 300 hours was not significant, with little change in colouring or lustre as exposure time was increased. This suggests that the oxide film was formed in the early stage of the test and remained stable and protective during extended exposure.

Similarly, IN625 samples were silvery when unexposed. As with the AISI 310, samples exposed for 100,200 , or 300 hours were nearly uniform in colouring and lustre. Samples retained a small amount of reflectiveness, but become a darker blue-gray colour. Among all exposed samples, IN625 exhibited the least surface color change, i.e., the least surface oxide formation.

The visual inspection of the materials exposed to supercritical water suggests that A286 experiences the most dramatic change as exposure time increases, likely forming more oxides. Conversely, the AISI 310 and IN625 samples did not appear to change significantly after the initial 100 hour exposure. 


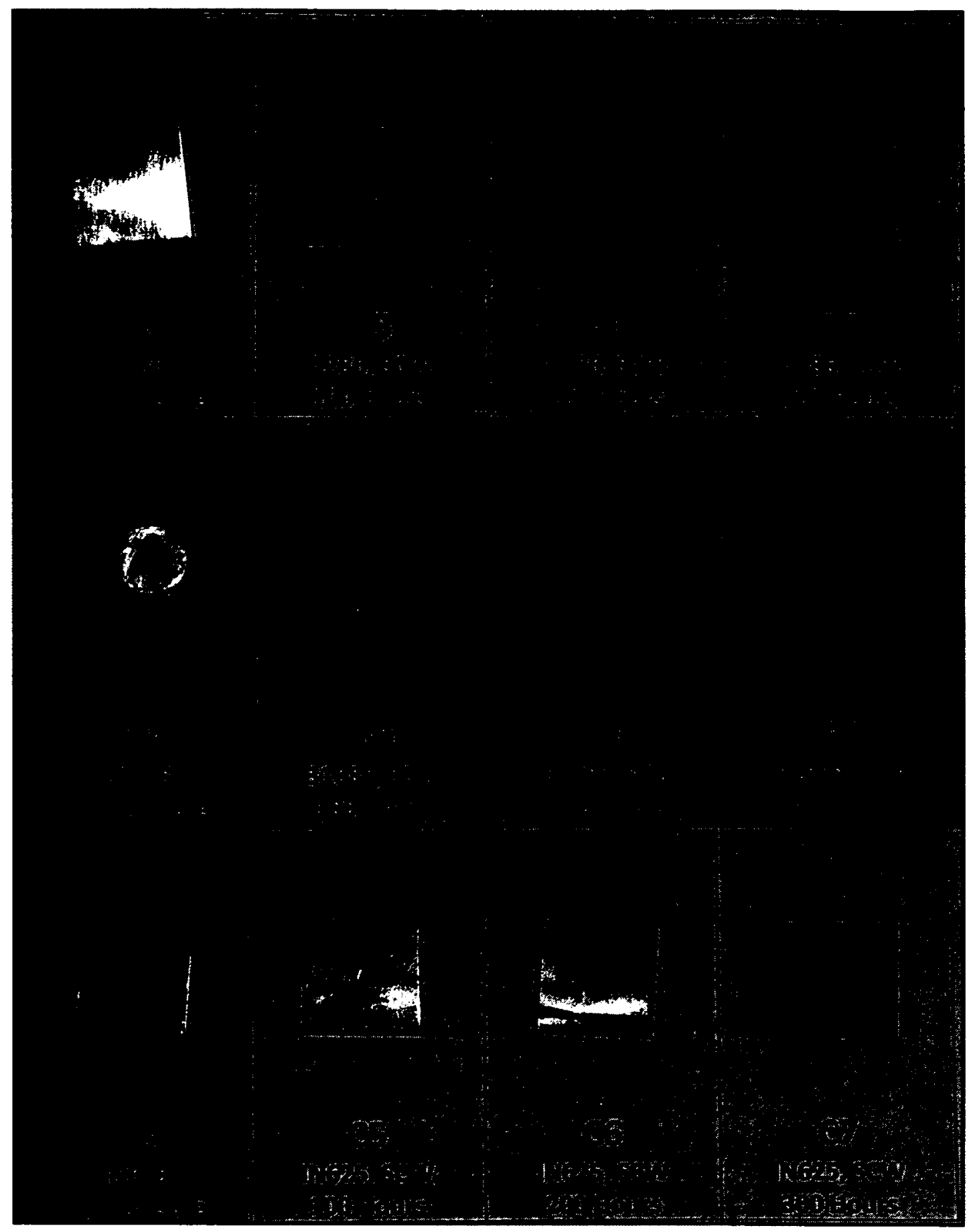

Figure 29 - Visual inspection of samples exposed to supercritical water for 100 to 300 hours $\left(600^{\circ} \mathrm{C}, 29 \mathrm{MPa}\right)$ 


\subsubsection{Superheated Steam Samples}

Figure 30 shows samples of all three materials exposed to superheated steam $\left(600^{\circ} \mathrm{C}\right.$,

$0.1 \mathrm{MPa}$ ) for varying durations.

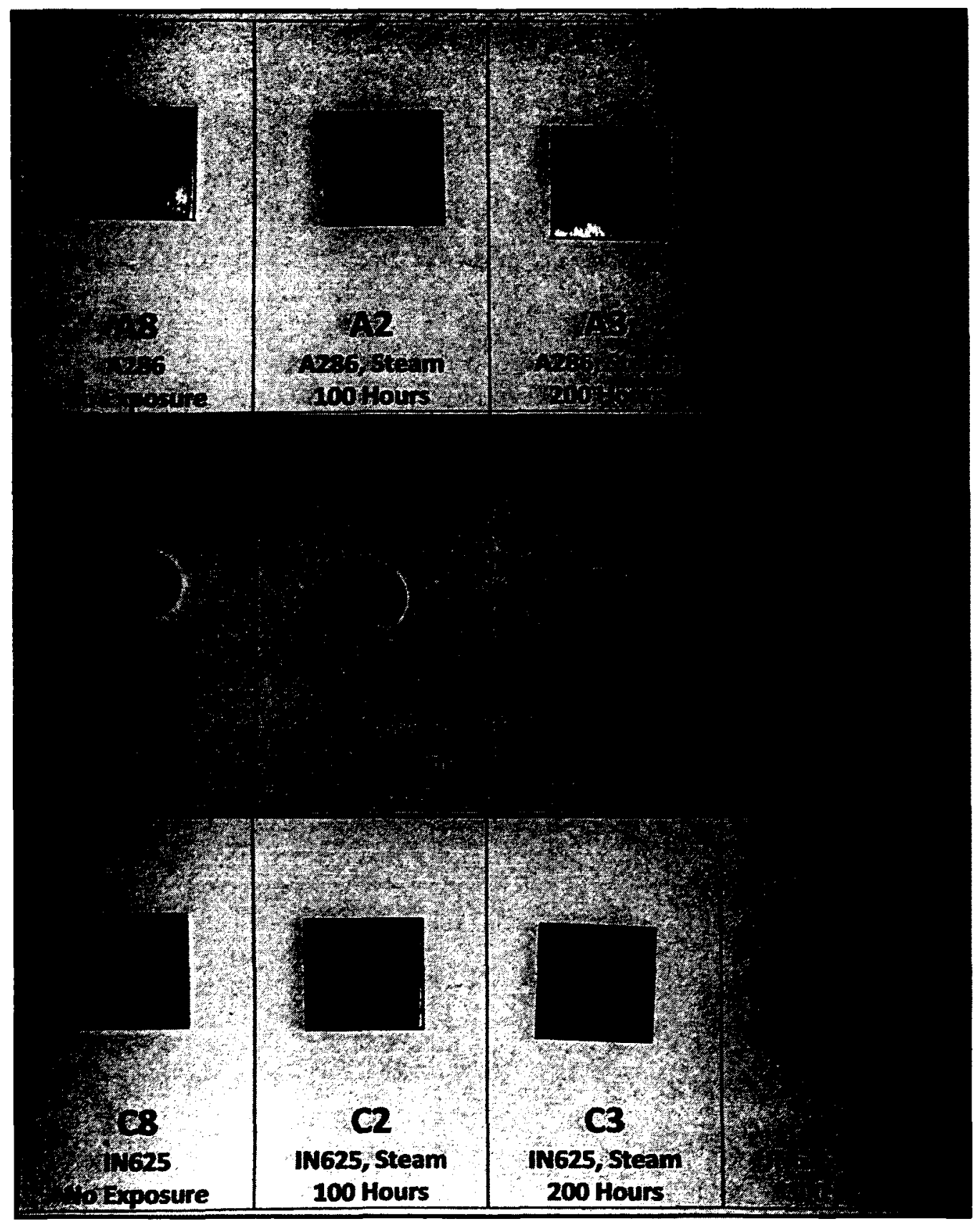

Figure 30 - Visual inspection of samples exposed to superheated steam $\left(600^{\circ} \mathrm{C}, 0.1\right.$ $\mathrm{MPa})$ 
As with the samples exposed to supercritical water, the samples exposed to superheated steam showed significant change as the exposure time was increased. The A286 sample exposed for 100 hours turned from reflective silver to a dark, matte bluish gray. As exposure time further increased, however, the samples turned matte gray.

The AISI 310 did not show as significant a change in appearance. After 100 hours exposure the sample became a slightly darker gray, while retaining some reflectance. The 200 hours exposure sample was brown and more matte. Finally, the 300 hour sample was slightly matte and a lighter gray than either of the other exposed AISI 310 samples.

A similar effect was observed in the IN625 samples. The sample exposed to steam for 100 hours turned a gold/brown colour while remaining somewhat reflective, while the 200 hour exposure sample was dark and somewhat spotty. The sample exposed for 300 hours was darker, but more reflective and more uniform in scale than the 200 hour sample.

These results suggest a very different effect in superheated steam than in supercritical water. The A286 appeared to change significantly upon initial exposure, then lose its colouring and lustre as exposure time increased. This suggests oxides may have formed immediately, and then been lost due to dissolution/spallation as exposure time increased. Both the AISI 310 and IN625 showed more significant surface color changes after 200 hours, with samples regressing closer to the unexposed appearance after 300 
hours. It appears the most oxides form around 200 hours, but are lost (due to dissolution or spallation) as time increases beyond that.

\subsection{Weight Change}

The samples were weighed before and after testing, showing a weight gain after exposure to supercritical water and superheated steam due to the formation of oxides on the exposed surfaces. The following results were observed.

\subsubsection{Supercritical Water Samples}

Table 8 and Figure 31 show the weight gain per surface area of samples exposed to supercritical water $\left(600^{\circ} \mathrm{C}, 29 \mathrm{MPa}\right)$ for increasing durations.

Table 8 - Weight gain of samples exposed to supercritical water $\left(600^{\circ} \mathrm{C}, 29 \mathrm{MPa}\right)$

\begin{tabular}{|c|c|c|c|c|c|}
\hline \multirow[b]{2}{*}{ Material } & \multirow{2}{*}{$\begin{array}{c}\text { Average } \\
\text { Initial } \\
\text { Weight } \\
\text { (g) }\end{array}$} & \multirow{2}{*}{$\begin{array}{c}\text { Average } \\
\text { Surface Area } \\
\qquad\left(\mathrm{cm}^{2}\right)\end{array}$} & \multicolumn{3}{|c|}{ Weight Gain (mg) } \\
\hline & & & 100 hours & 200 hours & 300 hours \\
\hline A286 & 5.431 & 9.2 & 1.293 & 2.022 & 2.489 \\
\hline AISI 310 & 4.331 & 4.5 & 0.088 & 0.066 & 0.088 \\
\hline IN625 & 5.918 & 9.2 & 0.054 & 0.087 & 0.098 \\
\hline
\end{tabular}




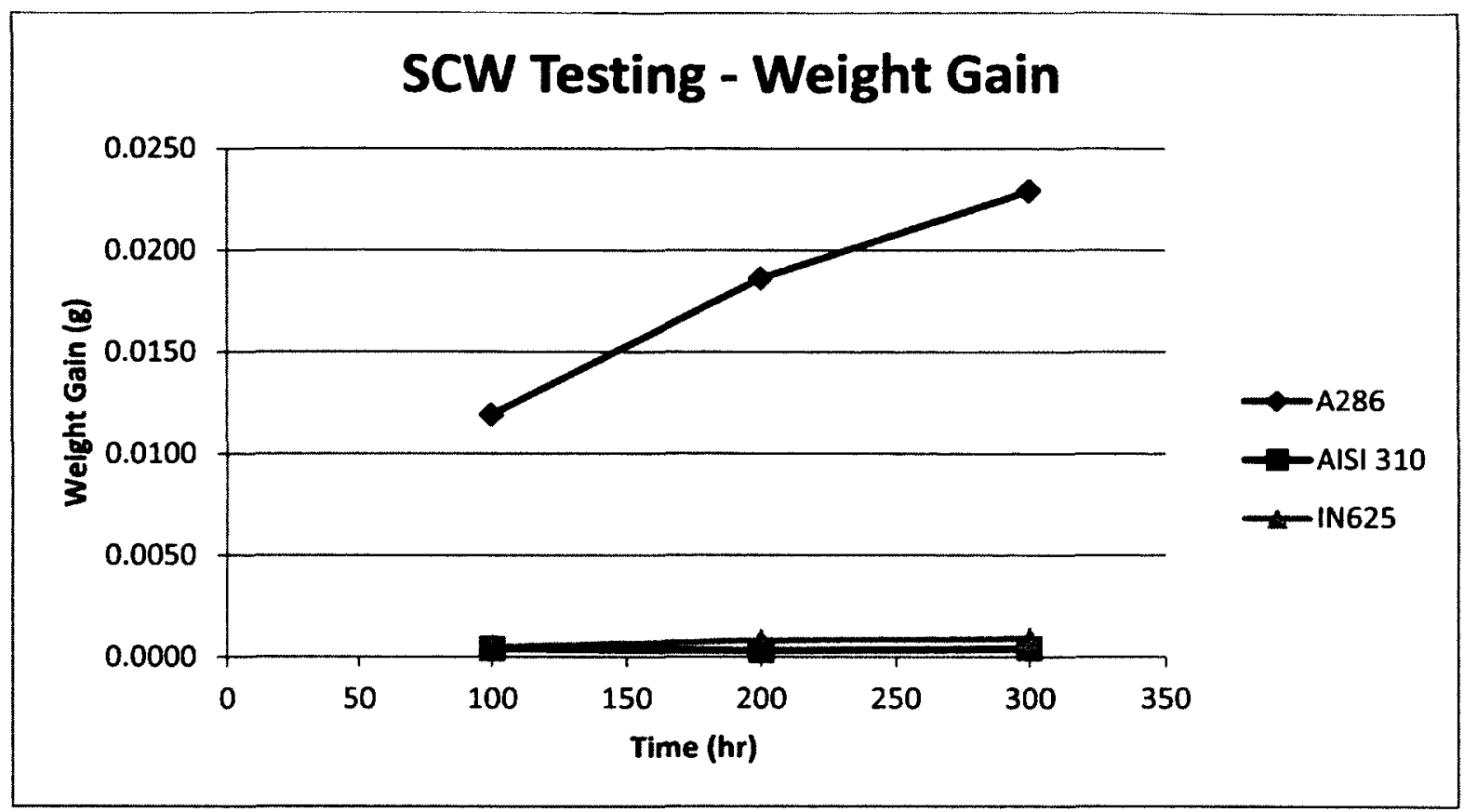

Figure 31 - Weight gain of samples exposed to supercritical water $\left(600^{\circ} \mathrm{C}, 29 \mathrm{MPa}\right)$ The results agree with what was observed by the visual inspection. As exposure time increases, the A286 samples continue to increase in weight, suggesting increasing formation of oxides at the exposed surfaces. The AISI 310 and IN625, however, show a small initial weight gain that remains fairly constant as exposure time increases. This suggests these two samples form an oxide surface layer after 100 hours that remains stable throughout the testing. By examining the compositions of all three alloys, one noticeable difference is the $\mathrm{Cr}$ content. A286 contains 16 wt\% $\mathrm{Cr}$, lower than AISI 310 and IN625, and suffered the most oxidation as represented by the weight gain. This suggests that higher $\mathrm{Cr}$ content in both $\mathrm{Fe}$ and $\mathrm{Ni}$ based alloys helps to delay oxidation.

\subsubsection{Superheated Steam Samples}

Table 9 and Figure 32 show the weight gain per surface area of samples exposed to supercritical water $\left(600^{\circ} \mathrm{C}, 0.1 \mathrm{MPa}\right)$ for increasing durations. 
Table 9 - Weight gain of samples exposed to superheated steam $\left(600^{\circ} \mathrm{C}, 0.1 \mathrm{MPa}\right)$

\begin{tabular}{|c|c|c|c|c|c|}
\hline \multirow[b]{2}{*}{ Material } & \multirow{2}{*}{$\begin{array}{c}\text { Average } \\
\text { Initial } \\
\text { Weight } \\
\text { (g) }\end{array}$} & \multirow{2}{*}{$\begin{array}{c}\text { Average } \\
\text { Surface Area } \\
\left(\mathrm{cm}^{2}\right)\end{array}$} & \multicolumn{3}{|c|}{ Weight Gain $\left(\mathrm{mg} / \mathrm{cm}^{2}\right)$} \\
\hline & & & 100 hours & 200 hours & 300 hours \\
\hline A286 & 5.460 & 9.2 & 0.413 & 0.196 & 0.043 \\
\hline AISI 310 & 4.532 & 4.5 & 0.132 & 0.220 & 0.044 \\
\hline IN625 & 5.955 & 9.2 & 0.359 & 0.609 & 0.043 \\
\hline
\end{tabular}

The degree of the weight gains for the superheated steam samples is smaller than that of the supercritical water samples, and also agrees with the visual inspection. The A286 samples show a high initial weight gain that decreases as exposure time is increased, suggesting the initial formation of an oxide layer being lost as exposure time increases. Both the AISI 310 and IN625 show the increase in weight after 200 hours, and then experience weight loss after 300 hours. This suggests an oxide layer is formed and grows until 200 hours exposure, after which point it is being removed by oxide dissolution or spallation. Comparing Figure 31 and Figure 32, it is noted that the initial weight gain of all samples in superheated steam is much less than that in supercritical water. This is an important observation since the increased pressure of SCW leads to more oxidation on sample surfaces. On the other hand, the flow of steam in the superheated steam (1 $\mathrm{kg} /$ hour) creates a dynamic condition (vs. static condition in autoclave) which contributes to surface scale removal. Again this is an important finding from this 
research and suggests the need to test samples under flowing supercritical water in order to truly simulate the operating condition of the reactor core.

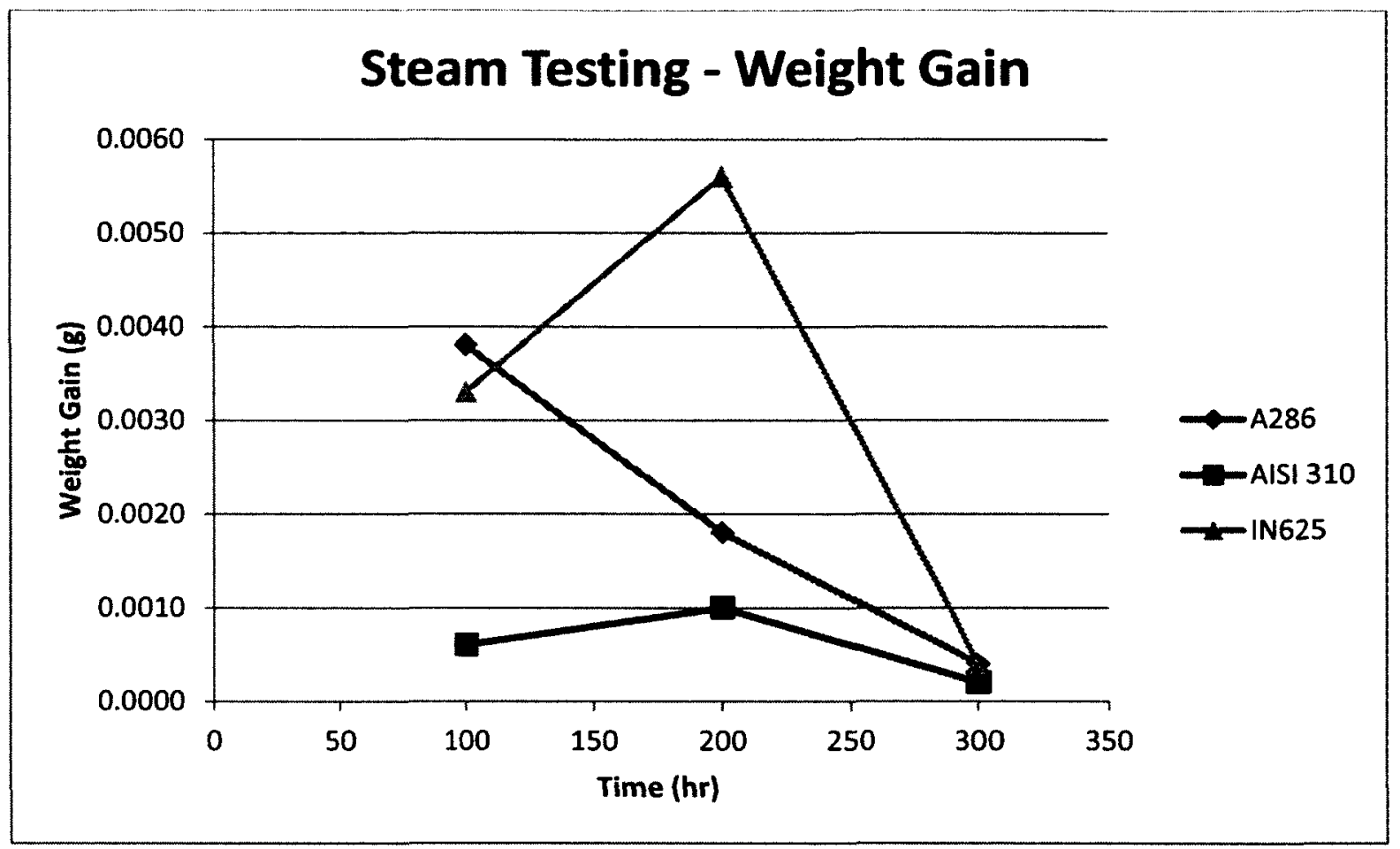

Figure 32 - Weight gain of samples exposed to superheated steam $\left(600^{\circ} \mathrm{C}, 0.1 \mathrm{MPa}\right)$

\subsection{SEM and EDS Analysis}

Following the visual inspection and weight change analysis, scanning electron microscope and energy-dispersive $x$-ray spectroscopy analysis was performed as described in the Methods section. Untested samples were first examined to determine a baseline, followed by the samples exposed to supercritical water and superheated steam. The following results were observed. 


\subsubsection{Untested Samples}

Samples prepared as described in the Methods section, but not exposed to supercritical water or superheated steam were examined using SEM and EDS analysis. Figure 33, Figure 34, and Figure 35 below show the SEM images taken of the untested A286, AISI 310, and iN625 samples, respectively.

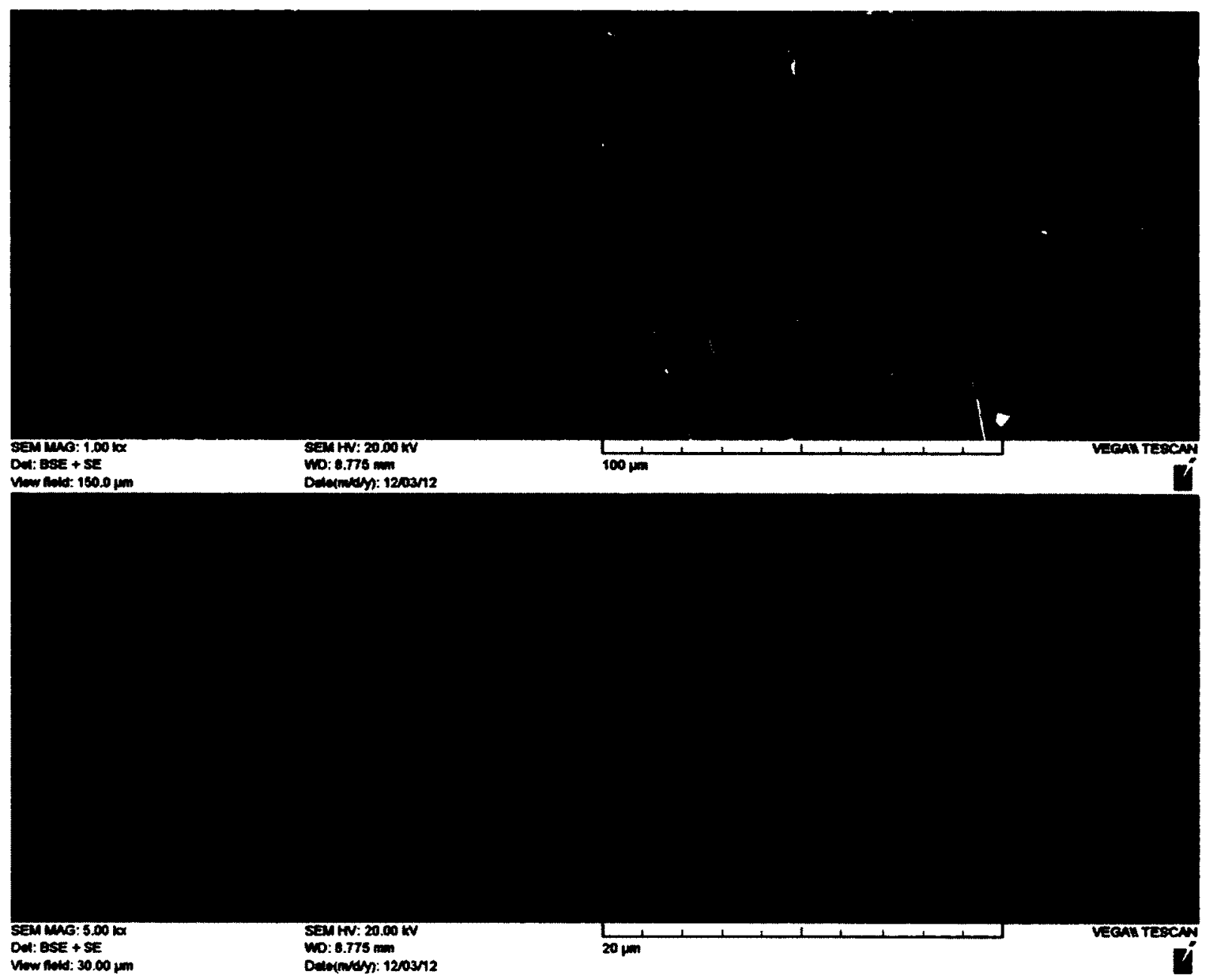

Figure 33 - SEM images of untested A286 (magnifications 1000x top, 5000x bottom). BSE (left) and SE (right) images 


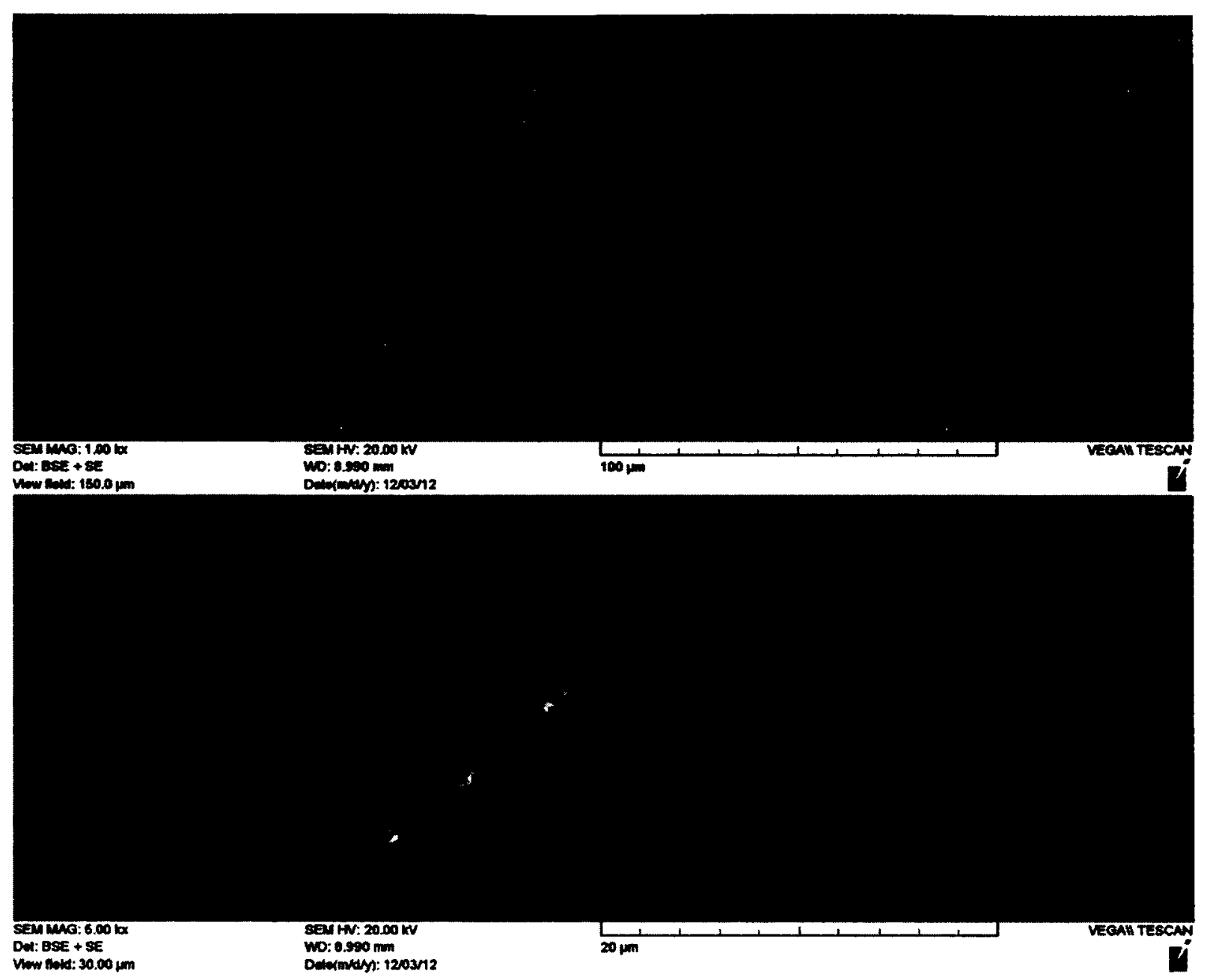

Figure 34 - SEM images of untested AISI 310 (magnifications 1000x top, 5000x bottom). BSE (left) and SE (right) images 


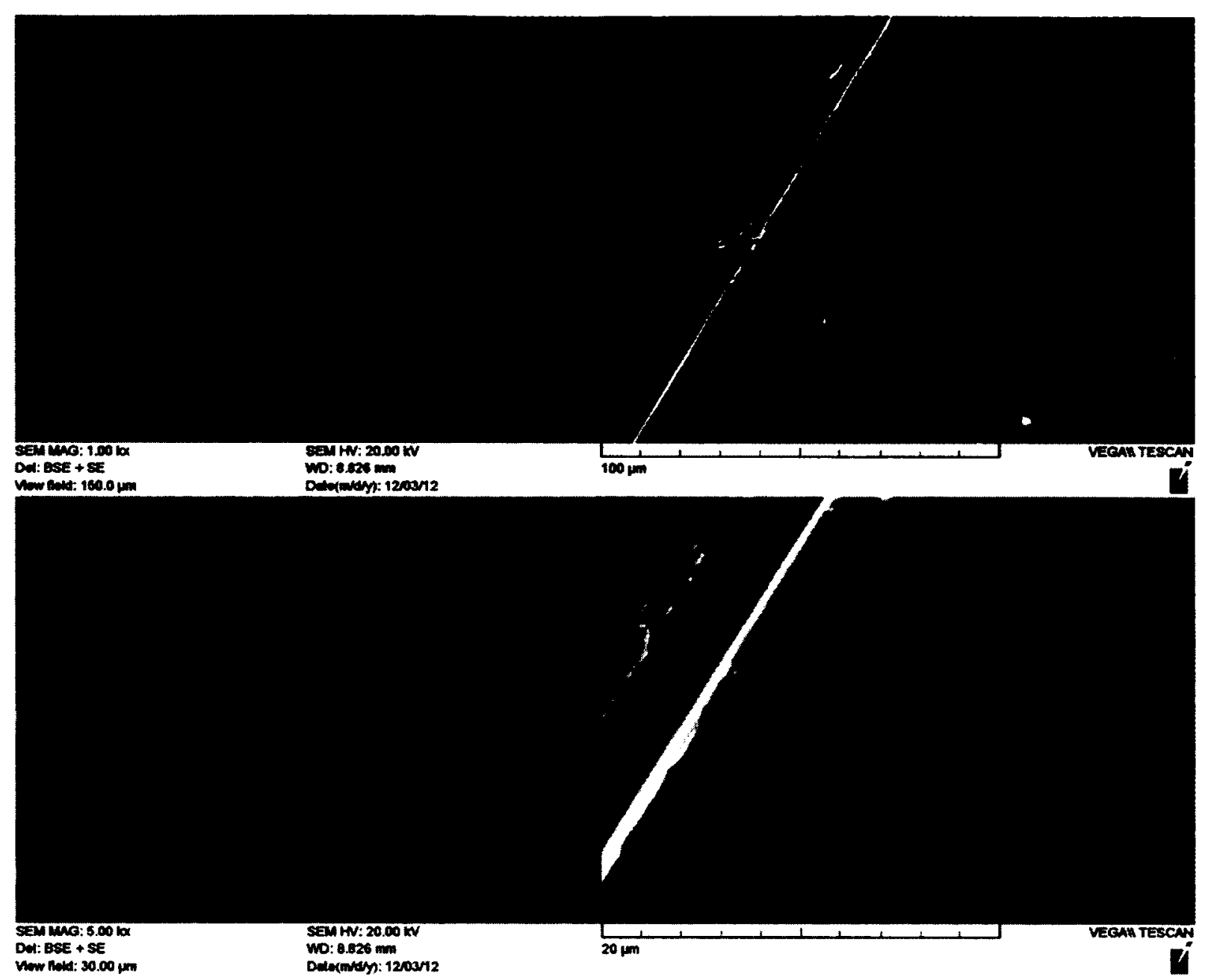

Figure 35 - SEM images of untested IN625 (magnifications 1000x top, 5000x bottom). BSE (left) and SE (right) images

These SEM images provide a baseline of the samples as-polished samples, showing the surface morphology before exposure to a corrosive environment. These images show no noticeable defects in the base material other than some occasional voids in the base metals, and will be used for comparison with the exposed samples.

EDS analysis was also performed on the as-polished materials, to compare the material composition to the supplier's specification. Table 10 below shows the chemical composition of all three materials as specified and as determined by EDS analysis. 
Table 10 - Specified and EDS determined chemical compositions for untested materials

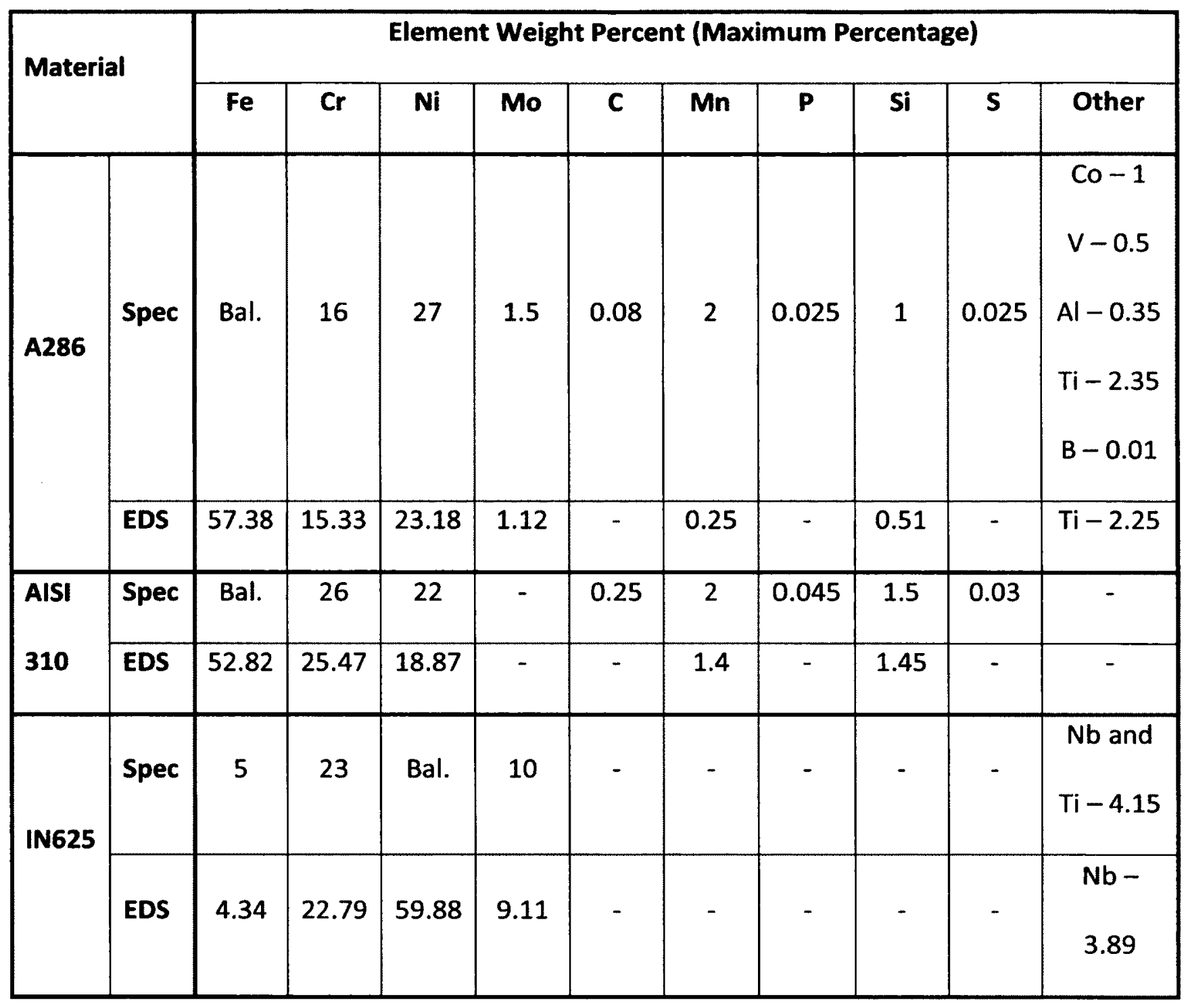

EDS analysis confirmed that the chemical composition of the materials tested matched the manufacturer's specifications (note that the EDS analysis yields semi-quantitative results with accuracy within $+/-2 \%)$. Some minor elements, specified in small quantities, may have been present in the samples, but not detectable by EDS. These results were used as a baseline to compare samples exposed to supercritical water and superheated steam. 


\subsubsection{Supercritical Water Samples}

SEM and EDS analysis was performed on samples exposed to supercritical water $\left(600^{\circ} \mathrm{C}\right.$, $29 \mathrm{MPa}$ ) for varying durations. The results are shown below.

\section{A286}

A286 samples were exposed to supercritical water $\left(600^{\circ} \mathrm{C}, 29 \mathrm{MPa}\right)$ for durations of 100 , 200 , and 300 hours. Samples were cleaned according to the procedure described in the Methods section, and SEM and EDS analysis was performed. Figure 36 shows the SEM images of A286 exposed for 100 hours. 


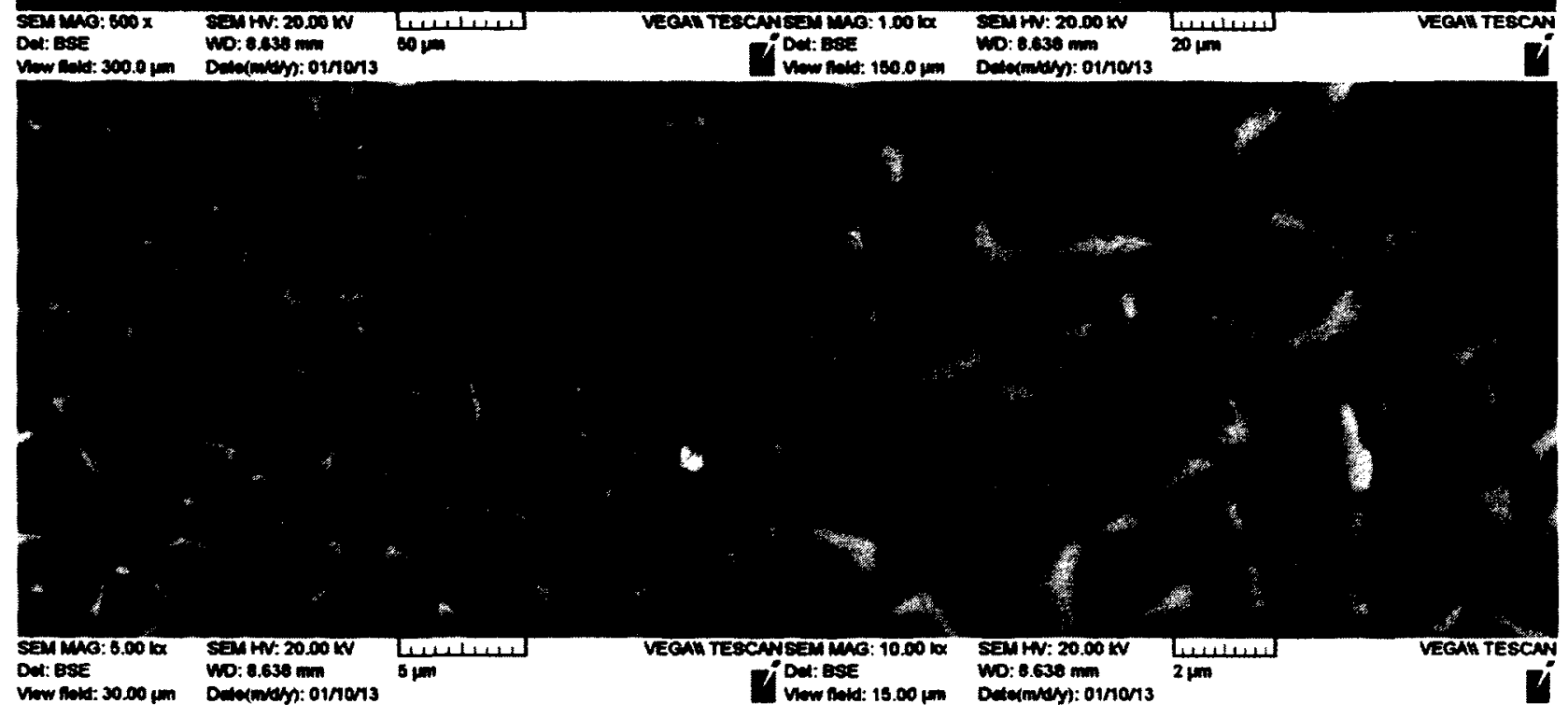

Figure 36 - SEM images of A286 exposed to SCW $\left(600^{\circ} \mathrm{C}, 29 \mathrm{MPa}, 100 \mathrm{hrs}\right)$ 


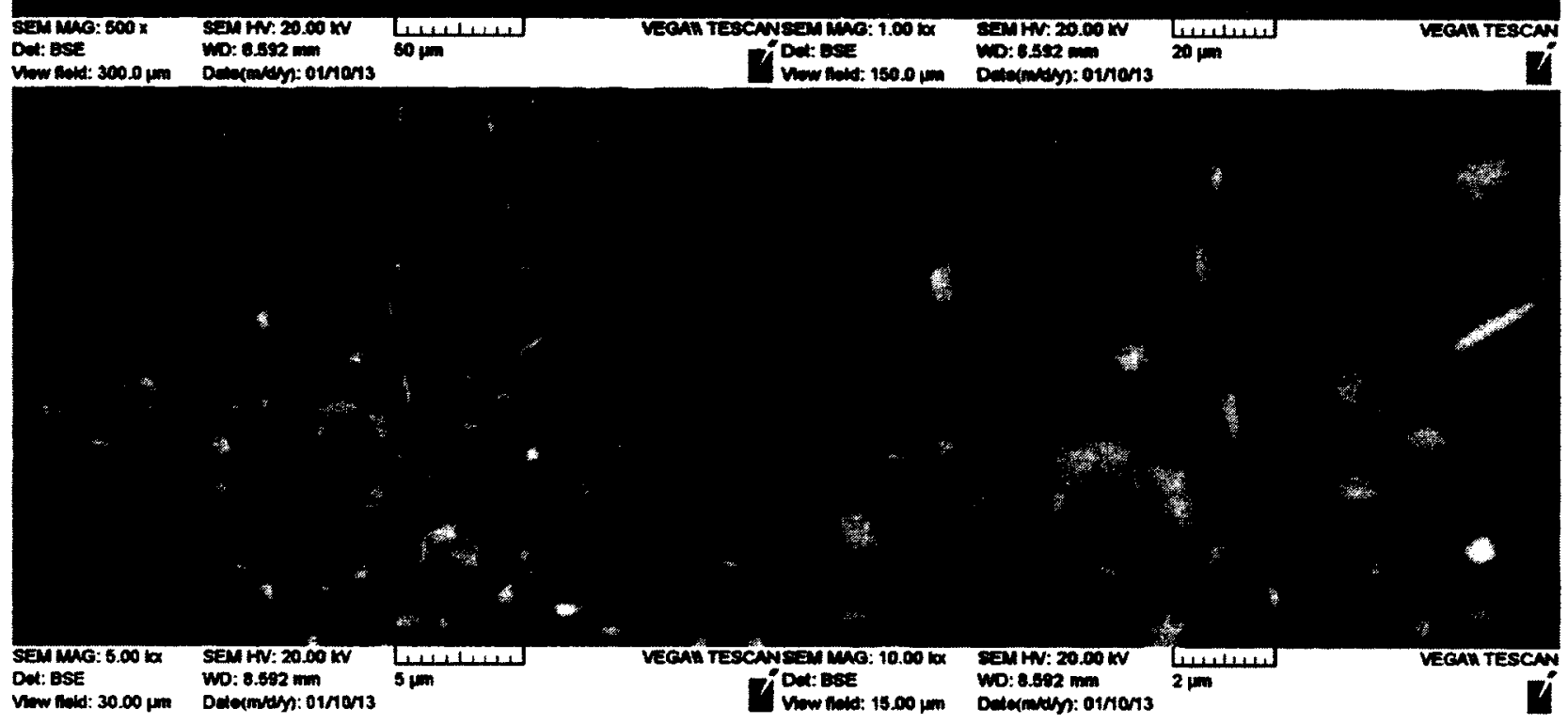

Figure 37 - SEM images of A286 exposed to SCW $\left(600^{\circ} \mathrm{C}, 29 \mathrm{MPa}, 200 \mathrm{hrs}\right)$

After 200 hours of exposure, the nodular oxide scales still remain and have become finer in grain size. Small needles are also seen on the surface. This suggests the protective oxide layer still adhere to the sample surface and finer oxide has formed as exposure duration increases. This is consistent with the weight gain results, where the A286 samples show increased weight gain with increased exposure duration. Figure 38 shows SEM images of the sample exposed for 300 hours. 


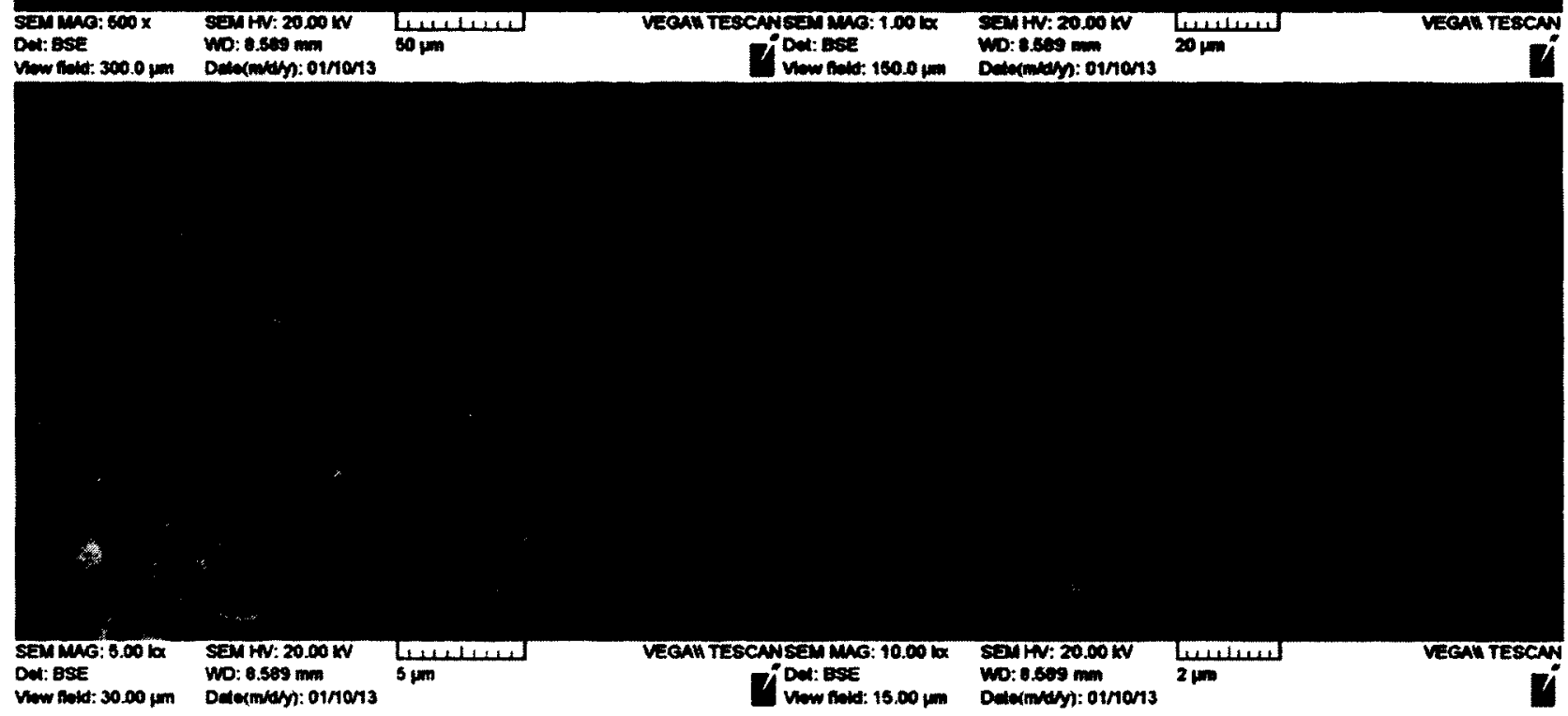

Figure 38 - SEM images of A286 exposed to SCW $\left(600^{\circ} \mathrm{C}, 29 \mathrm{MPa}, 300 \mathrm{hrs}\right)$

A layer of oxide scales is still visible across the sample surface after 300 hours of exposure to supercritical water. The oxide layer appears to continue growing into more irregular shaped grains as exposure time increases, suggesting A286 is capable of withstanding corrosion in supercritical water by forming protective, dense oxide layer. This is consistent with the weight gain results, which show increases in weight gain after every increase in exposure time. 
The compositions of the A286 samples after exposure to supercritical water, as determined through EDS analysis, are given in Table 11.

Table 11 - EDS compositions of A286 exposed to SCW $\left(600^{\circ} \mathrm{C}, 29 \mathrm{MPa}\right)$

\begin{tabular}{|c|c|c|c|c|c|}
\hline \multirow{2}{*}{$\begin{array}{c}\text { Exposure } \\
\text { (Hours) }\end{array}$} & \multicolumn{5}{|c|}{ Composition by Element (Weight Percent) } \\
\cline { 2 - 6 } & $\mathbf{O}$ & $\mathrm{Al}$ & $\mathrm{Cr}$ & $\mathrm{Fe}$ & $\mathrm{Ni}$ \\
\hline 100 & 32.05 & 0.49 & 1.10 & 66.37 & 0.00 \\
\hline 200 & 32.97 & 0.00 & 2.84 & 64.19 & 0.00 \\
\hline 300 & 30.62 & 0.00 & 0.90 & 68.48 & 0.00 \\
\hline
\end{tabular}

The EDS analysis showed high levels of Oxygen at the surface of all three samples, indicating the formation of an oxide layer. The iron levels are also high, with little to no chromium or nickel detectable, indicating the oxide layer formed is likely composed completely of an iron oxide, most likely magnetite $\left(\mathrm{Fe}_{3} \mathrm{O}_{4}\right)$ [30]. Levels of oxygen and iron at the samples' surfaces remained constant, suggesting that the surface of the oxide was stable throughout the testing, and the additional oxide formation indicated by the increase in weight must be occurring through inward diffusion of $O$ and outward diffusion of Fe in the oxide layer. This could lead to integrity issues in the A286 with long-term exposure since the iron oxide form was not able to impede diffusion of these elements. 


\section{AISI 310}

AISI 310 samples were exposed to supercritical water $\left(600^{\circ} \mathrm{C}, 29 \mathrm{MPa}\right)$ for durations of 100,200 , and 300 hours. Samples were cleaned according to the procedure described in the Methods section, and SEM and EDS analysis was performed. Figure 39 shows the SEM images of AISI 310 exposed for 100 hours.

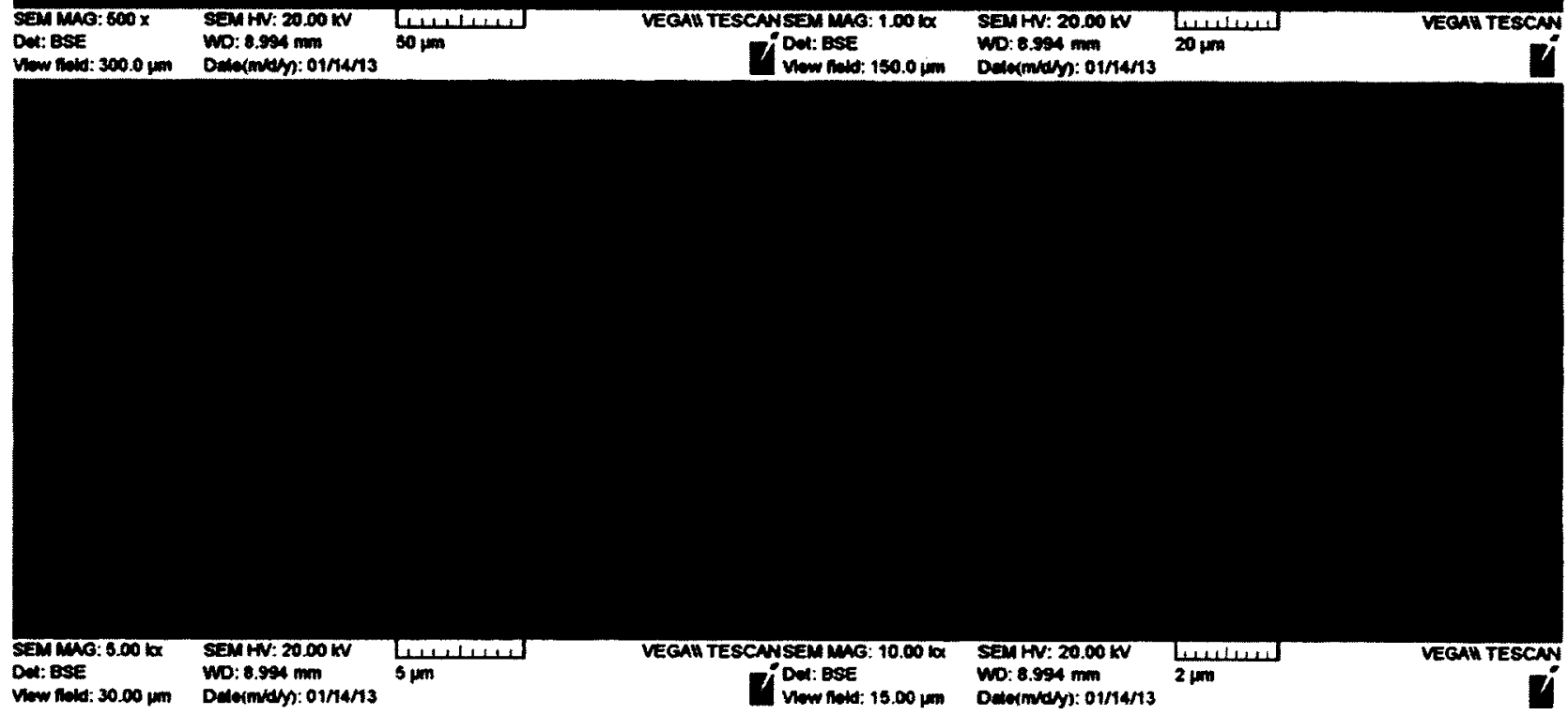

Figure 39 - SEM images of AISI 310 exposed to SCW $\left(600^{\circ} \mathrm{C}, 29 \mathrm{MPa}, 100 \mathrm{hrs}\right)$

Figure 39 shows the formation of small spherical particles on the surface of the samples after 100 hours of exposure to the supercritical water. This was consistent across the 
surface of the sample. These particles are varying in sizes and loosely distributed on the surface. Figure 40 shows the SEM images of the sample exposed for 200 hours.

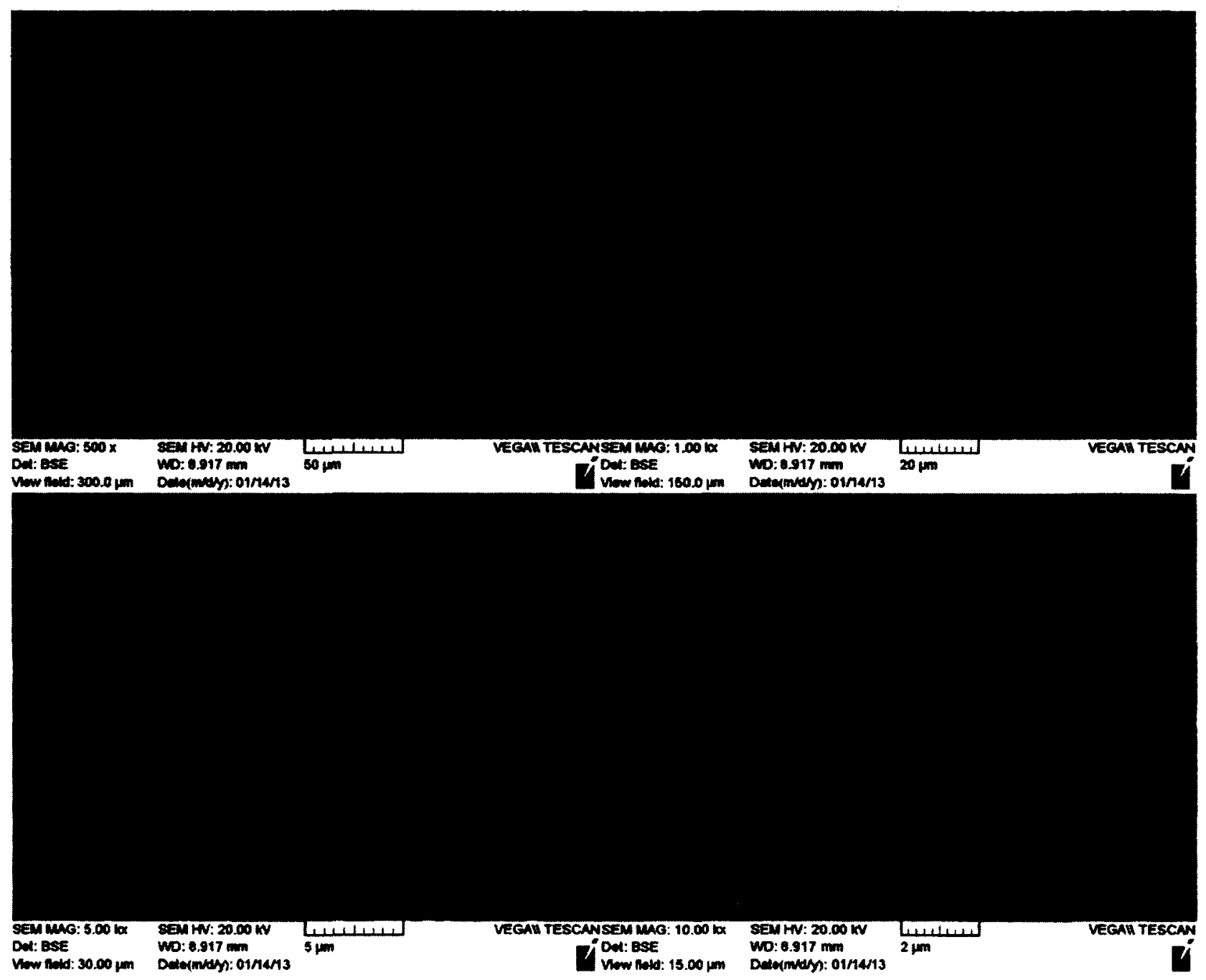

Figure 40 - SEM images of AISI 310 exposed to SCW $\left(600^{\circ} \mathrm{C}, 29 \mathrm{MPa}, 200 \mathrm{hrs}\right)$

The samples exposed for 200 hours showed similar features as that exposed for 100 hours. This is consistent with the visual inspection and weight gain analysis, which suggested that the AISI 310 samples formed a stable oxide layer soon after being exposed, and did not exhibit significant change in oxide formation as exposure duration 
increased. Figure 41 shows the SEM images of the sample exposed to supercritical water for 300 hours.

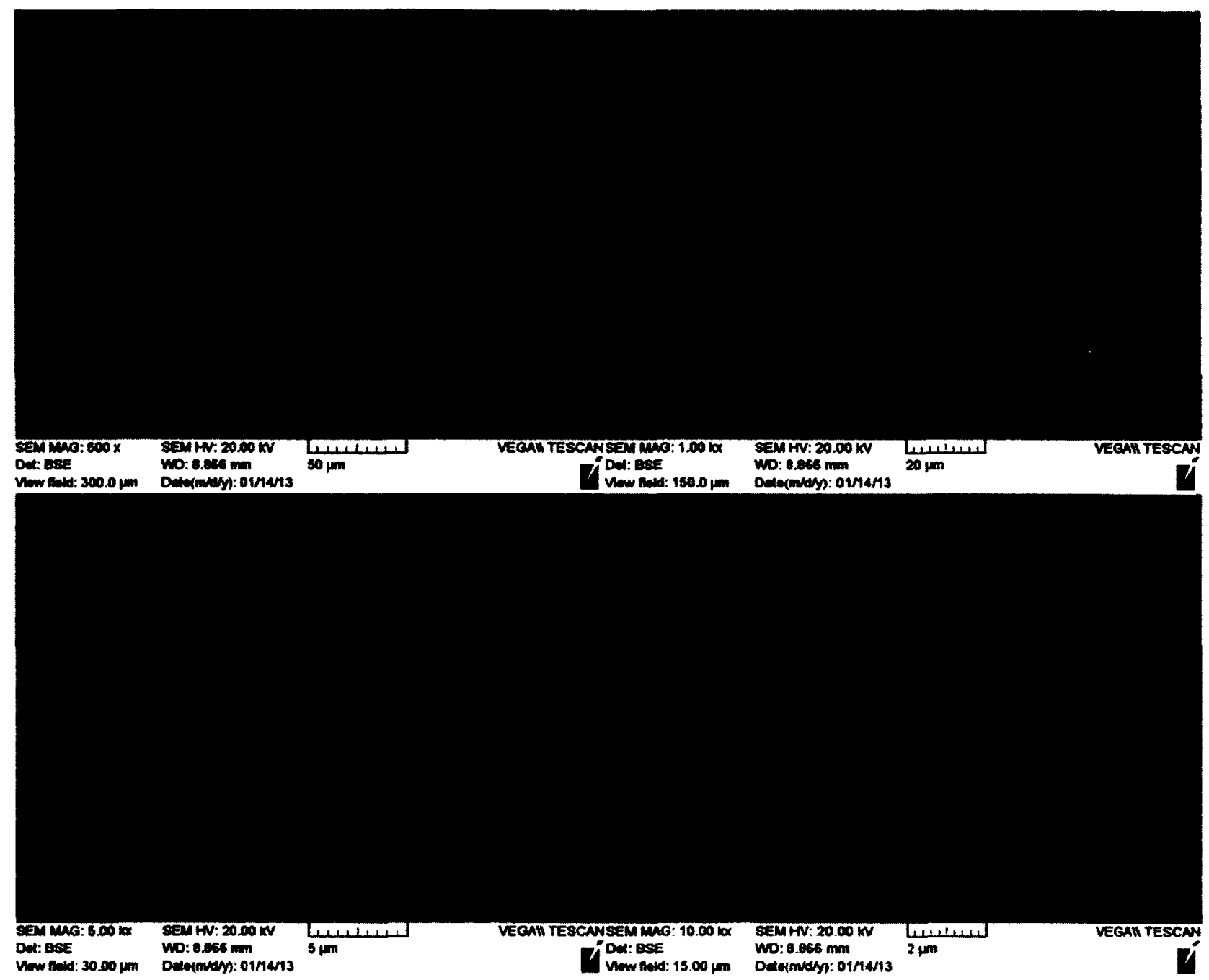

Figure 41 - SEM images of AISI 310 exposed to SCW $\left(600^{\circ} \mathrm{C}, 29 \mathrm{MPa}, 300 \mathrm{hrs}\right)$

The oxide particles become more densely spaced and cover the majority of the sample surface, suggesting the oxide particles formed early in the test has grown and merged together as time increases. In some locations on the sample's surface, however, signs of grain etching were observed. One such location is shown in Figure 42 . The lighter patch seen here shows that after 300 hours exposure to supercritical water etching begins to 
occur at the grain boundaries, and within the etched grain the surface morphology is different from other locations. It more or less resembles a dimpled structure and no discrete oxide particles can be found.

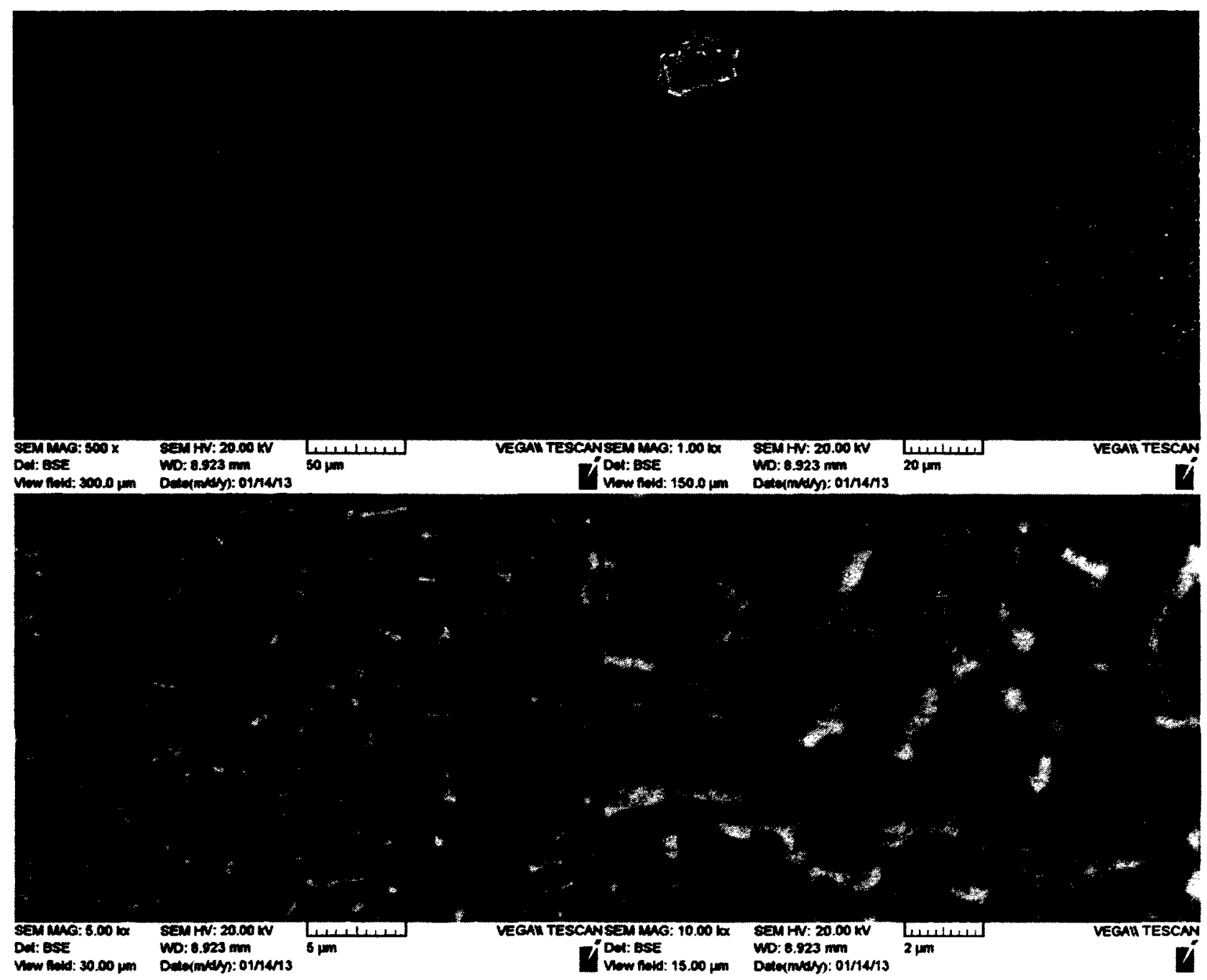

Figure 42 - SEM images of AISI 310 exposed to SCW $\left(600^{\circ} \mathrm{C}, 29 \mathrm{MPa}, 300 \mathrm{hrs}\right)$. Evidence of grain etching.

The compositions of the AISI 310 samples after exposure to supercritical water, as determined through EDS analysis, are given in Table 12. 
Table 12 - EDS compositions of AISI 310 exposed to SCW $\left(600^{\circ} \mathrm{C}, 29 \mathrm{MPa}\right)$

\begin{tabular}{|c|c|c|c|c|c|c|c|}
\hline \multirow{2}{*}{ (hours) } & \multicolumn{6}{|c|}{ Composition by Element (Weight Percent) } \\
\cline { 2 - 8 } & $\mathbf{0}$ & $\mathrm{Al}$ & $\mathrm{Si}$ & $\mathrm{Cr}$ & $\mathrm{Mn}$ & $\mathrm{Fe}$ & $\mathrm{Ni}$ \\
\hline 100 & 30.20 & 1.21 & 1.73 & 33.77 & 3.51 & 23.01 & 6.57 \\
\hline 200 & 34.32 & 0.97 & 0.00 & 37.10 & 4.22 & 19.71 & 3.69 \\
\hline 300 & 30.28 & 0.72 & 0.50 & 30.57 & 3.81 & 28.53 & 5.59 \\
\hline
\end{tabular}

As expected from the SEM analysis, oxygen levels on the surface of the exposed samples are elevated. Elevated chromium levels at the surface suggest that the scales formed are primarily composed of chromium oxide $\left(\mathrm{Cr}_{2} \mathrm{O}_{3}\right)$. The oxygen and chromium levels remain relatively consistent as exposure time increases, which suggest a stable oxide layer has been formed and is capable of protecting the AISI 310 from further oxidation. This is consistent with the literature on corrosion of stainless steels [23].

\section{IN625}

IN625 samples were exposed to supercritical water $\left(600^{\circ} \mathrm{C}, 29 \mathrm{MPa}\right)$ for durations of 100,200 , and 300 hours. Samples were cleaned according to the procedure described in the Methods section, and SEM and EDS analysis was performed. Figure 43 shows the SEM images of IN625 exposed for 100 hours. 


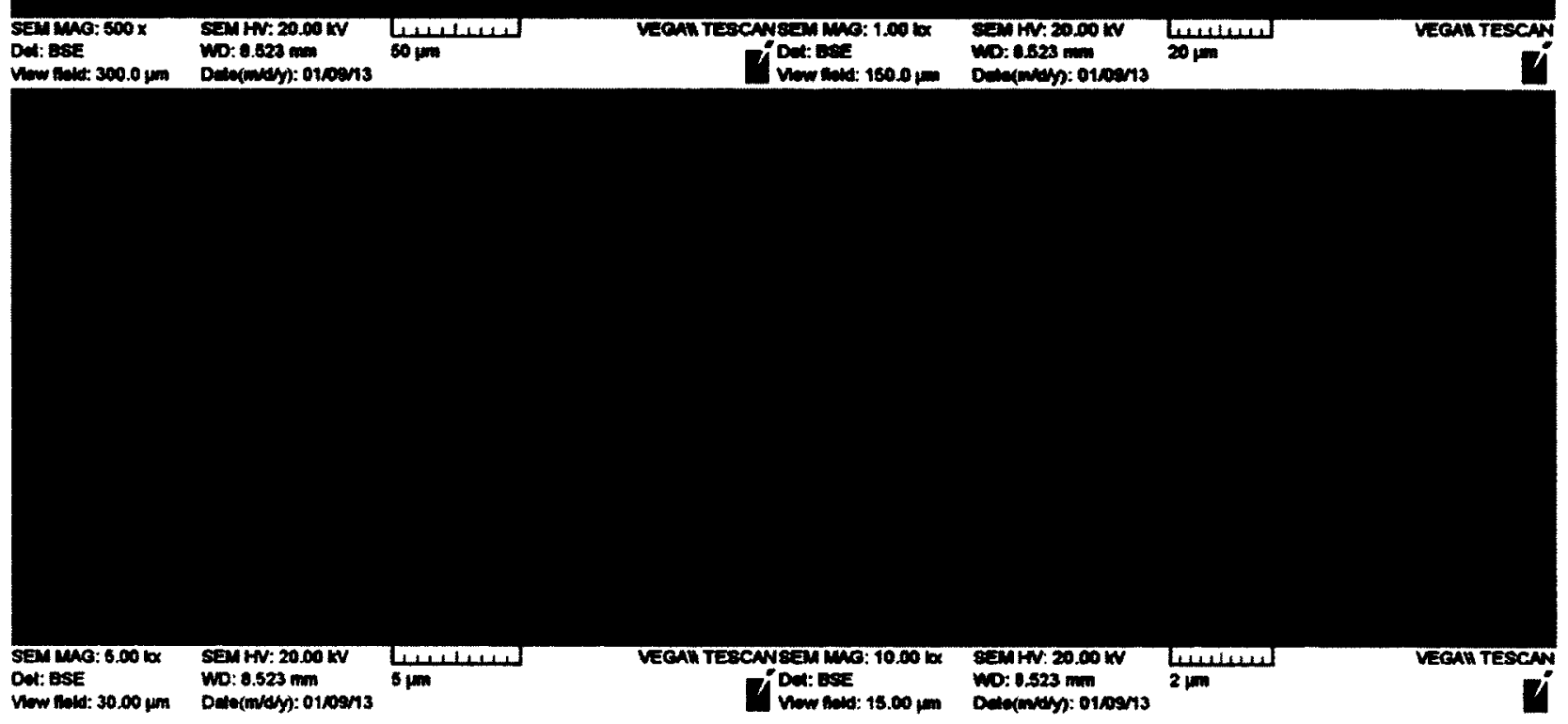

Figure 43 - SEM images of IN625 exposed to SCW $\left(600^{\circ} \mathrm{C}, 29 \mathrm{MPa}, 100 \mathrm{hrs}\right)$

SEM images of the surface of IN625 after 100 hours exposure to supercritical water show little has changed from the base material. At very high magnifications the evidence of oxide scale formation can be seen as minute particles. Figure 44 shows SEM images of the sample exposed to supercritical water for 200 hours. 


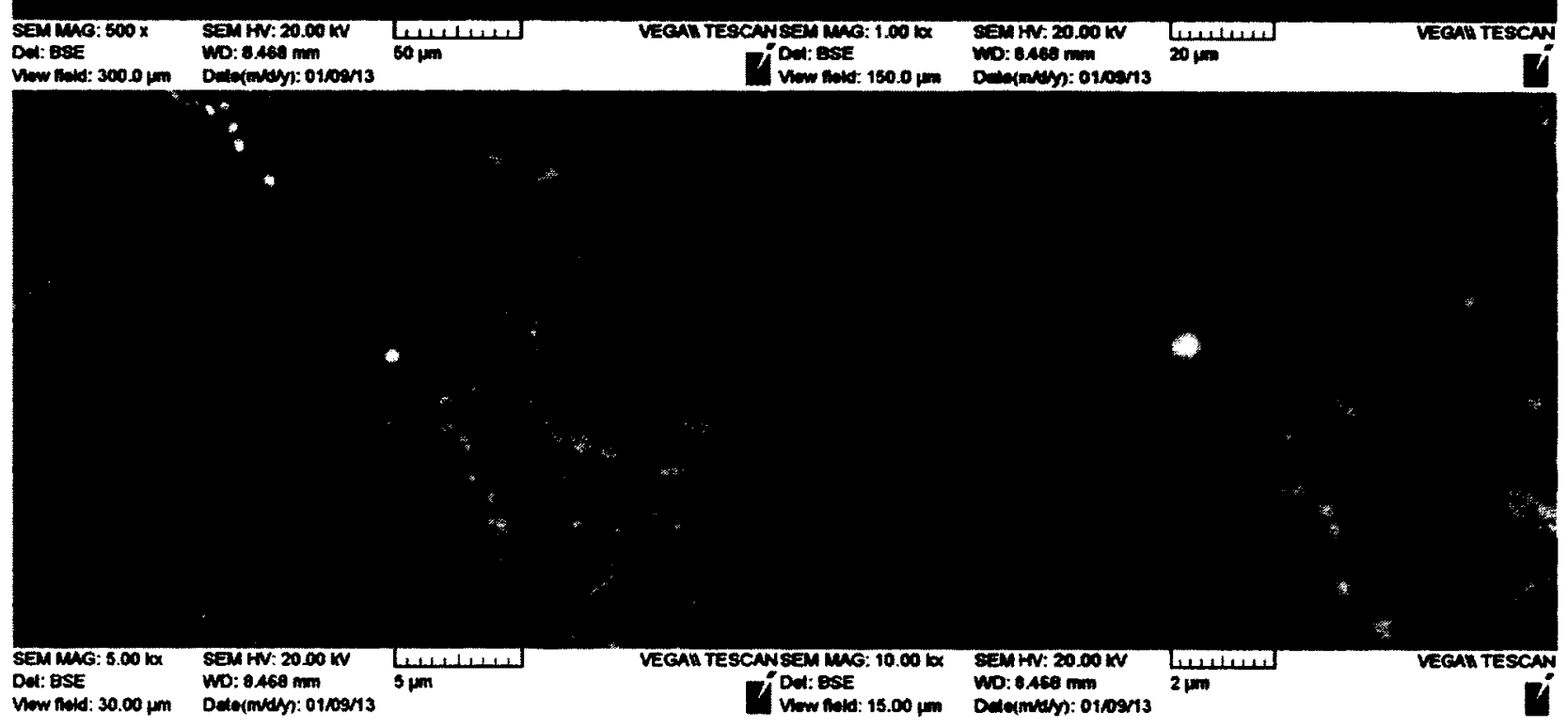

Figure 44 - SEM images of IN625 exposed to SCW $\left(600^{\circ} \mathrm{C}, 29 \mathrm{MPa}, 200 \mathrm{hrs}\right)$

After 200 hours of exposure to supercritical water, evidence of oxide scale formation becomes more evident in the presence of small modules across the material's surface. The dark depression (Figure 44), however, shows signs of possible grain boundary cracking, which may be a concern for long term use. Intergranular cracking in IN625 after SCW exposure was also observed by Selvig, Huang, et al [37]. Was, Ampornrat et al [23] determined that in supercritical water the $\mathrm{Cr}$ in IN625 migrates preferentially to the 
surface, leading to depletion and cracking [23]. Figure 45 shows SEM images for IN625 exposed to supercritical water for 300 hours.

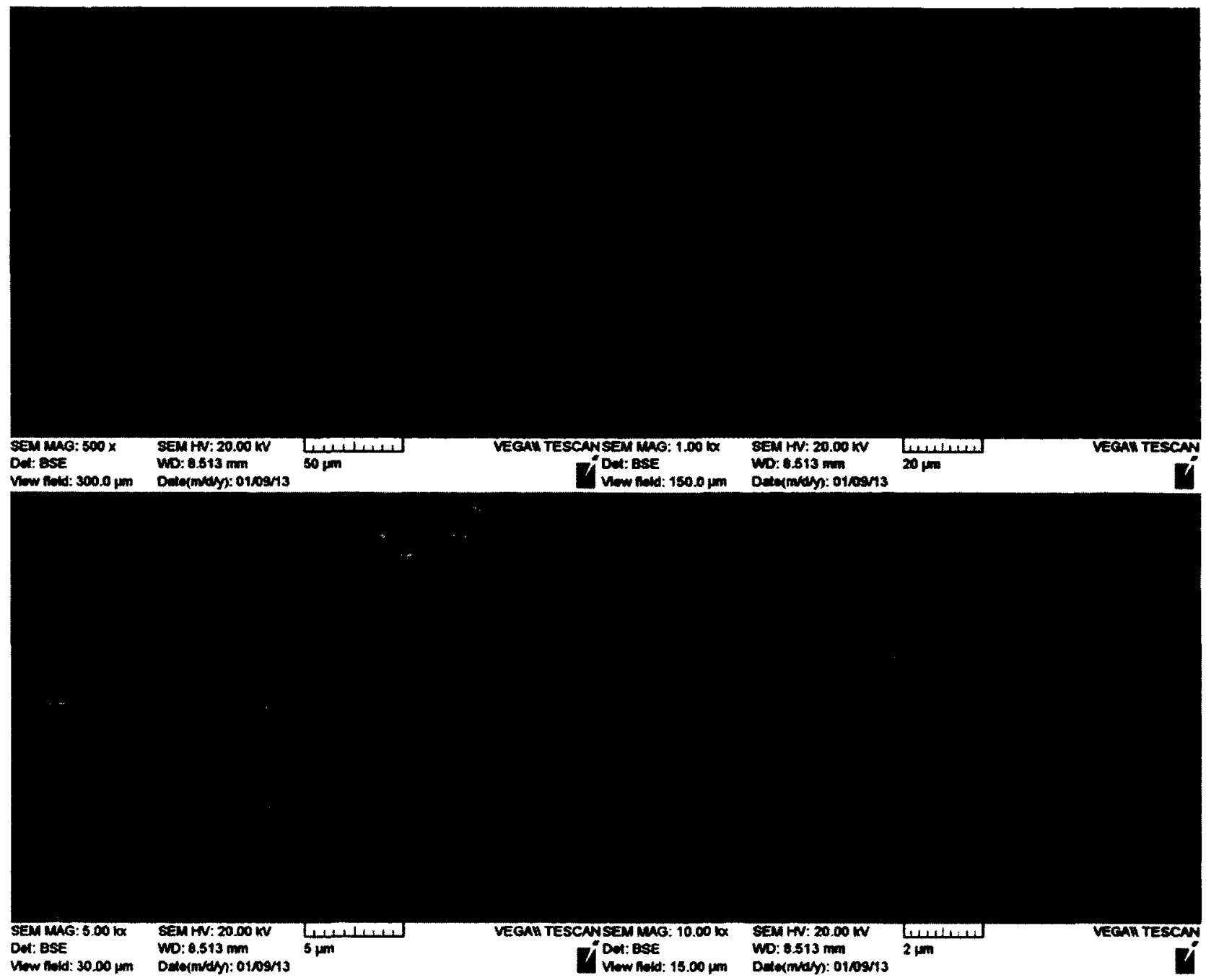

Figure 45 - SEM images of IN625 exposed to SCW $\left(600^{\circ} \mathrm{C}, 29 \mathrm{MPa}, 300 \mathrm{hrs}\right)$

Definite signs of oxide scale formation are seen on the surface of the sample exposed to supercritical water for 300 hours. This suggests a stable oxide layer has been formed, however, dark spots across the surface suggest blistering or microcracking is occurring, which would limit usage of IN625 for long term applications. 
The compositions of the IN625 samples after exposure to supercritical water, as determined through EDS analysis, are given in Table 13. For each exposure interval two sets of EDS results are given. The first shows the composition at an area showing signs of cracking, while the second shows the composition at an area of oxide formation. Overall, higher Mo and $\mathrm{Ni}$ contents seem to be associated with regions with cracking. And lower oxygen level, suggesting lack of oxide formation, is also observed in the cracked region.

Table 13 - EDS compositions of IN625 exposed to SCW $\left(600^{\circ} \mathrm{C}, 29 \mathrm{MPa}\right)$

\begin{tabular}{|c|c|c|c|c|c|c|c|}
\hline \multirow{2}{*}{$\begin{array}{c}\text { Exposure } \\
\text { (hours) }\end{array}$} & \multicolumn{6}{|c|}{ Composition by Element (Weight Percent) } \\
\cline { 2 - 8 } & $\mathbf{O}$ & $\mathbf{S i}$ & $\mathbf{C r}$ & $\mathrm{Fe}$ & $\mathrm{Ni}$ & $\mathrm{Nb}$ & Mo \\
\hline $\mathbf{1 0 0}$ - Cracking & 7.82 & 0.00 & 16.32 & 3.40 & 61.85 & 2.59 & 8.01 \\
\hline $\mathbf{1 0 0}$ - Oxide & 23.55 & 0.00 & 18.57 & 3.79 & 48.34 & 0.00 & 5.74 \\
\hline $\mathbf{2 0 0}$ - Cracking & 27.04 & 0.41 & 17.56 & 4.10 & 41.61 & 3.05 & 6.24 \\
\hline $\mathbf{2 0 0}$ - Oxide & 34.12 & 0.36 & 27.80 & 6.76 & 21.94 & 3.43 & 5.59 \\
\hline 300 - Cracking & 25.04 & 0.43 & 19.23 & 4.14 & 41.93 & 2.51 & 6.72 \\
\hline 300 - Oxide & 35.01 & 0.00 & 25.47 & 7.93 & 25.25 & 3.37 & 2.98 \\
\hline
\end{tabular}

Higher oxygen and $\mathrm{Cr}$ levels are likely due to formation of chromium $\left(\mathrm{Cr}_{2} \mathrm{O}_{3}\right)$. Nickel oxides ( $\mathrm{NiO})$ also are likely to have formed during the early stage of exposure since higher $\mathrm{Ni}$ content is detected on the 100 hour sample. In the areas of oxide scale 
formation, the oxygen levels remain relatively consistent as exposure time increases, which is consistent with the findings of the visual inspection and weight gain analysis.

\subsubsection{Superheated Steam Samples}

SEM and EDS analysis was performed on samples exposed to supercritical water $\left(600^{\circ} \mathrm{C}\right.$, $29 \mathrm{MPa}$ ) for varying durations. The results are shown below.

\section{A286}

A286 samples were exposed to supercritical water $\left(600^{\circ} \mathrm{C}, 0.1 \mathrm{MPa}\right)$ for durations of 100,200 , and 300 hours. Samples were cleaned according to the procedure described in the Methods section, and SEM and EDS analysis was performed. Figure 46 shows the SEM images of A286 exposed for 100 hours. 


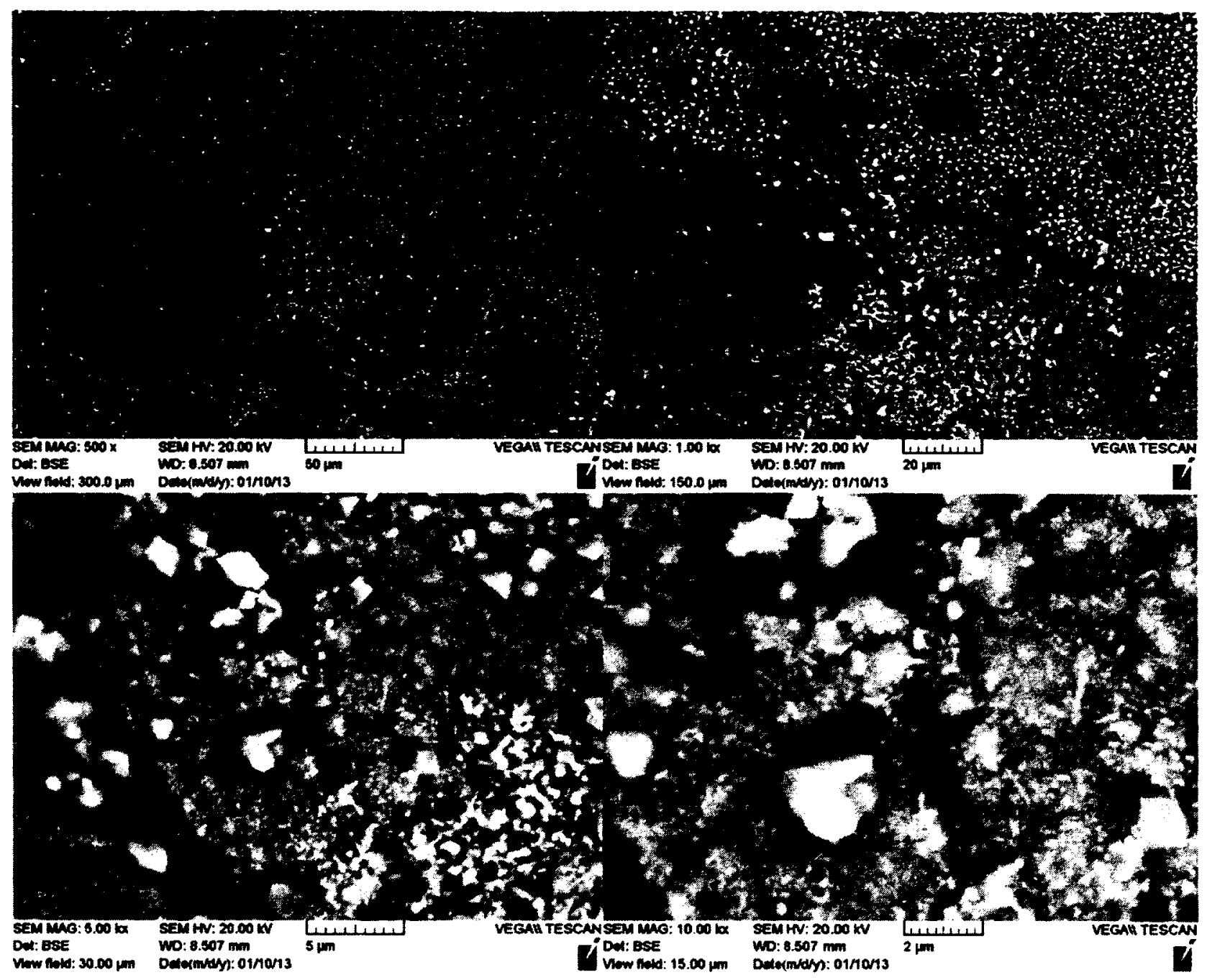

Figure 46 - SEM images of A286 exposed to SHS $\left(600^{\circ} \mathrm{C}, 0.1 \mathrm{MPa}, 100 \mathrm{hrs}\right)$

The weight gain data showed that in superheated steam A286 shows the highest weight gain after initial exposure, with decreasing gains as exposure time increased. SEM images of the sample exposed for 100 hours show some evidence of the formation of oxide scales at several surface locations. These scales appear to be intermittent and are not uniform across the surface of the sample, consistent with the small amount of weight gain observed. Figure 47 shows SEM images of the sample exposed to superheated steam for 200 hours. 


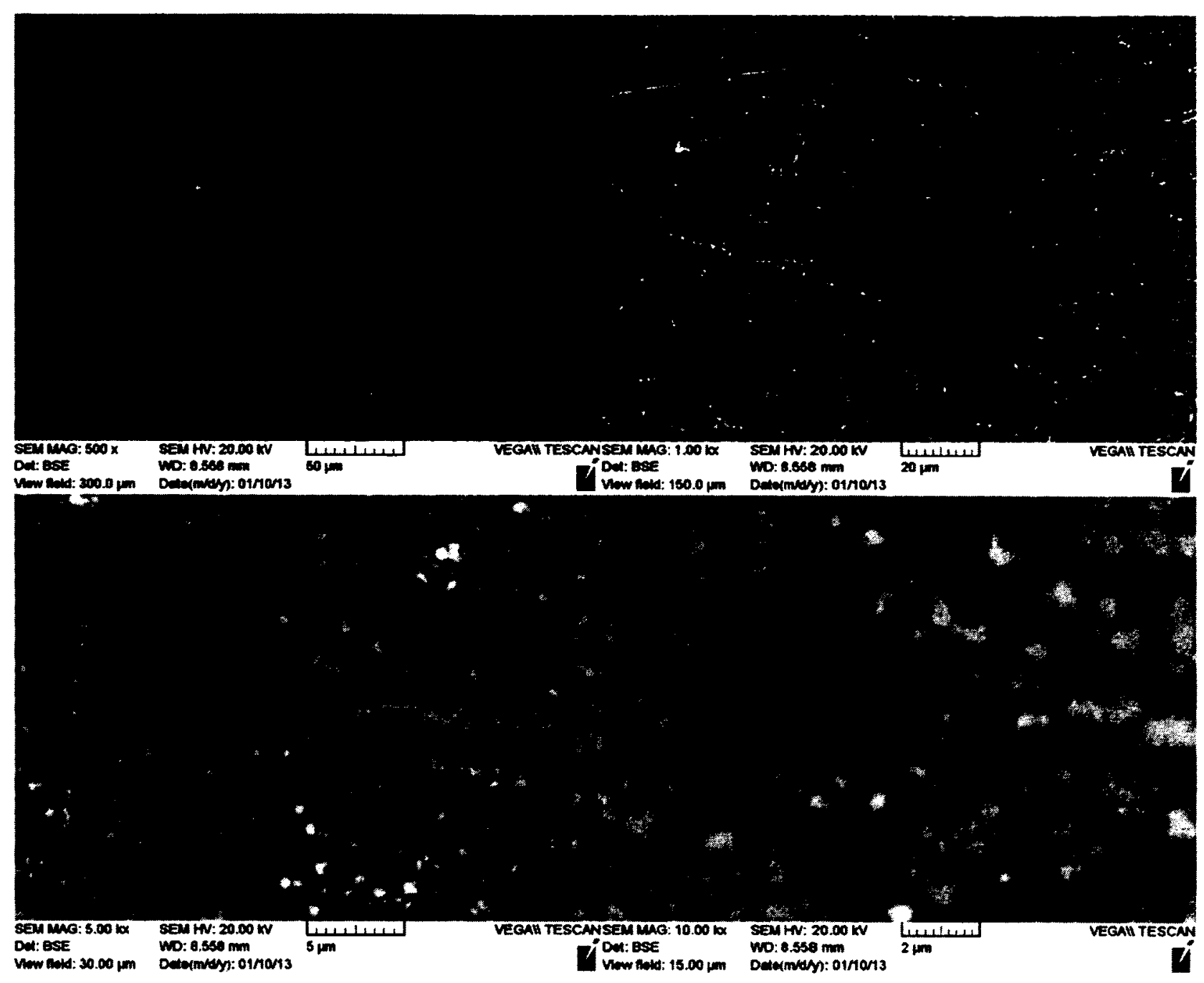

Figure 47 - SEM images of A286 exposed to SHS $\left(600^{\circ} \mathrm{C}, 0.1 \mathrm{MPa}, 200 \mathrm{hrs}\right)$

After 200 hours of exposure to superheated steam there is still evidence of some oxide formation on the surface sample, but less so than on the 100 hours exposure sample. This fits with the weight gain data, which shows that after a small initial gain, further exposure led to decreasing gains. However, unlike that seen on the surface after SCW exposure, clear polishing lines are still visible after 200 hours of exposure in SHS, suggesting limited oxide formation on the surface. SEM images of the sample exposed for 300 hours are shown in Figure 48. 


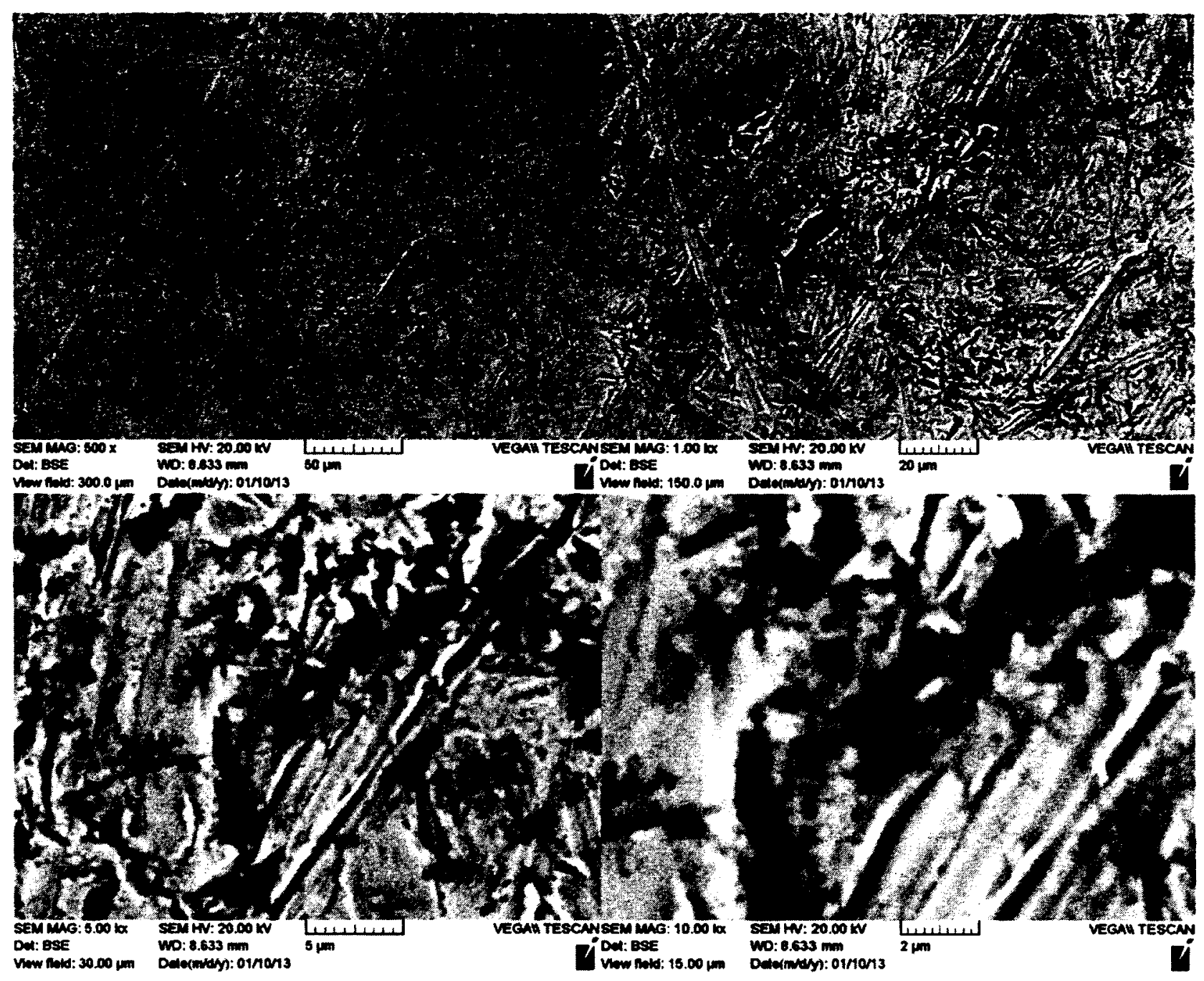

Figure 48 - SEM images of A286 exposed to SHS $\left(600^{\circ} \mathrm{C}, 0.1 \mathrm{MPa}, 300 \mathrm{hrs}\right)$

As expected, after 300 hours of exposure to superheated steam there is almost no evidence of oxide growth on the surface of the A286 sample. These results, considered along with the weight gain data, indicate that A286 forms a small oxide layer after initial exposure to superheated steam, which is then lost as exposure duration increases. This is likely due to the oxide dissolution in steam or spalling to continuous steam flow creating "erosion" action. For long-term applications in SCWR where constant steam or 
SCW flow exists, a lack of oxide layer exposes the base metal to the steam and could lead to continuous oxidation.

The compositions of the A286 samples after exposure to superheated steam, as determined through EDS analysis, are given in Table 14 below.

Table 14 - EDS compositions of A286 exposed to SHS $\left(600^{\circ} \mathrm{C}, 0.1 \mathrm{MPa}\right)$

\begin{tabular}{|c|c|c|c|c|c|c|c|c|c|}
\hline \multirow{2}{*}{ Exposure } & \multicolumn{7}{|c|}{ Composition by Element (Weight Percent) } \\
\cline { 2 - 10 } & $\mathbf{O}$ & $\mathrm{Al}$ & $\mathrm{Si}$ & $\mathrm{Ti}$ & $\mathrm{Cr}$ & $\mathrm{Mn}$ & $\mathrm{Fe}$ & $\mathrm{Ni}$ & Mo \\
\hline 100 & 31.52 & 0.00 & 0.00 & 3.71 & 19.65 & 0.69 & 38.27 & 6.16 & 0.00 \\
\hline 200 & 26.24 & 0.42 & 2.33 & 4.02 & 17.19 & 0.00 & 35.95 & 13.86 & 0.00 \\
\hline 300 & 13.90 & 0.00 & 3.22 & 1.96 & 13.10 & 0.00 & 47.05 & 19.47 & 1.30 \\
\hline
\end{tabular}

The 100 hour sample showed the highest level of oxygen at the sample surface, which decreases as exposure time increased. Chromium levels were also highest after 100 hours exposure, suggesting the oxides formed were chromium oxide $\left(\mathrm{Cr}_{2} \mathrm{O}_{3}\right)$. The $\mathrm{Cr}$ level on the surface steadily reduces with exposure time. Long term tests in thousands of hours will provide more insight into the repeated oxide formation and removal process.

\section{AISI 310}

AISI 310 samples were exposed to superheated steam $\left(600^{\circ} \mathrm{C}, 0.1 \mathrm{MPa}\right)$ for durations of 100,200 , and 300 hours. Samples were cleaned according to the procedure described in 
the Methods section, and SEM and EDS analysis was performed. Figure 49 shows the SEM images of AISI 310 exposed for 100 hours.

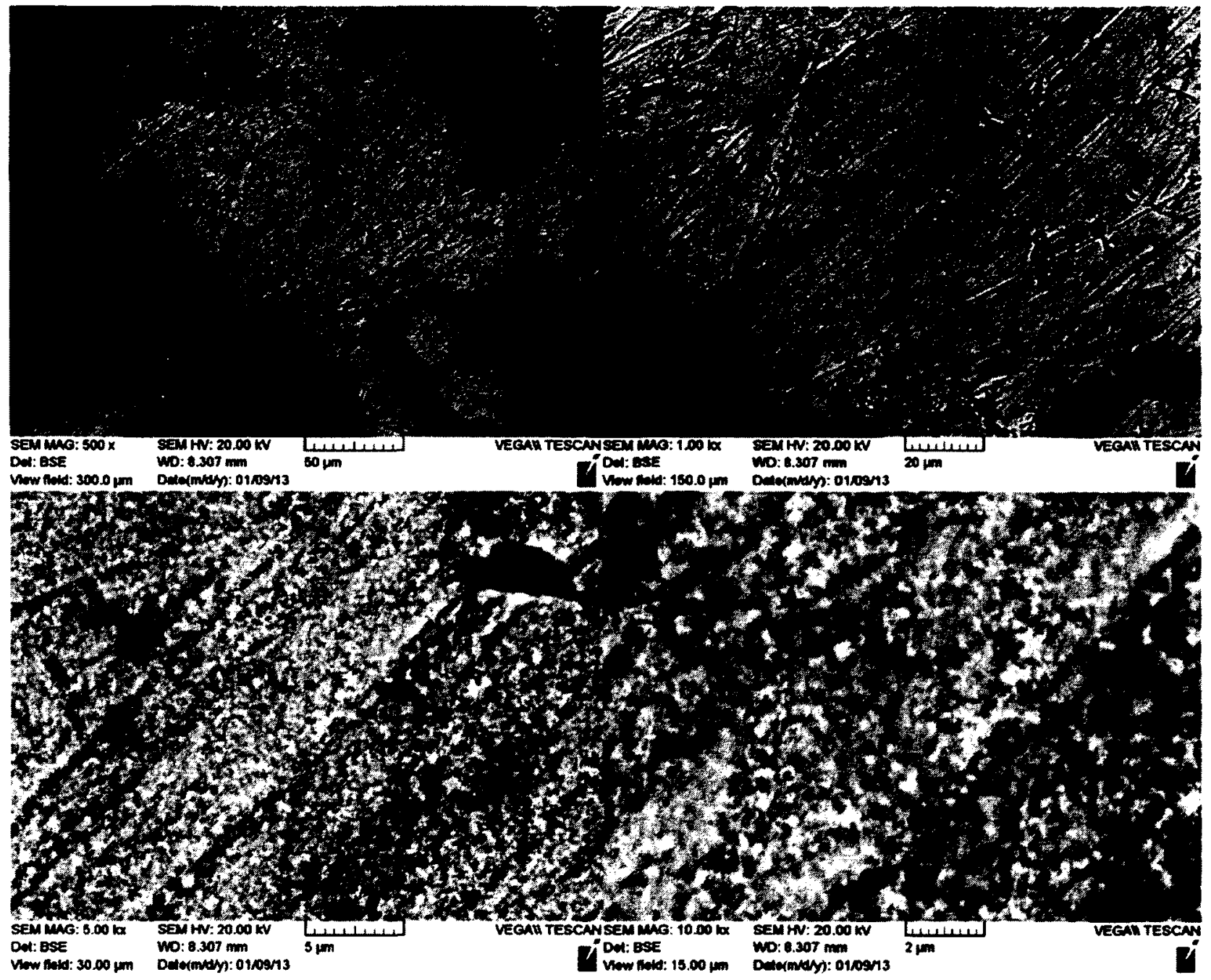

Figure 49 - SEM images of AISI 310 exposed to SHS $\left(600^{\circ} \mathrm{C}, 0.1 \mathrm{MPa}, 100 \mathrm{hrs}\right)$

After 100 hours of exposure to superheated steam, some evidence of oxide scale formation is visible, however less so than the sample exposed to supercritical water. Figure 50 shows the SEM images of AISI 310 exposed to superheated steam for 200 hours. 


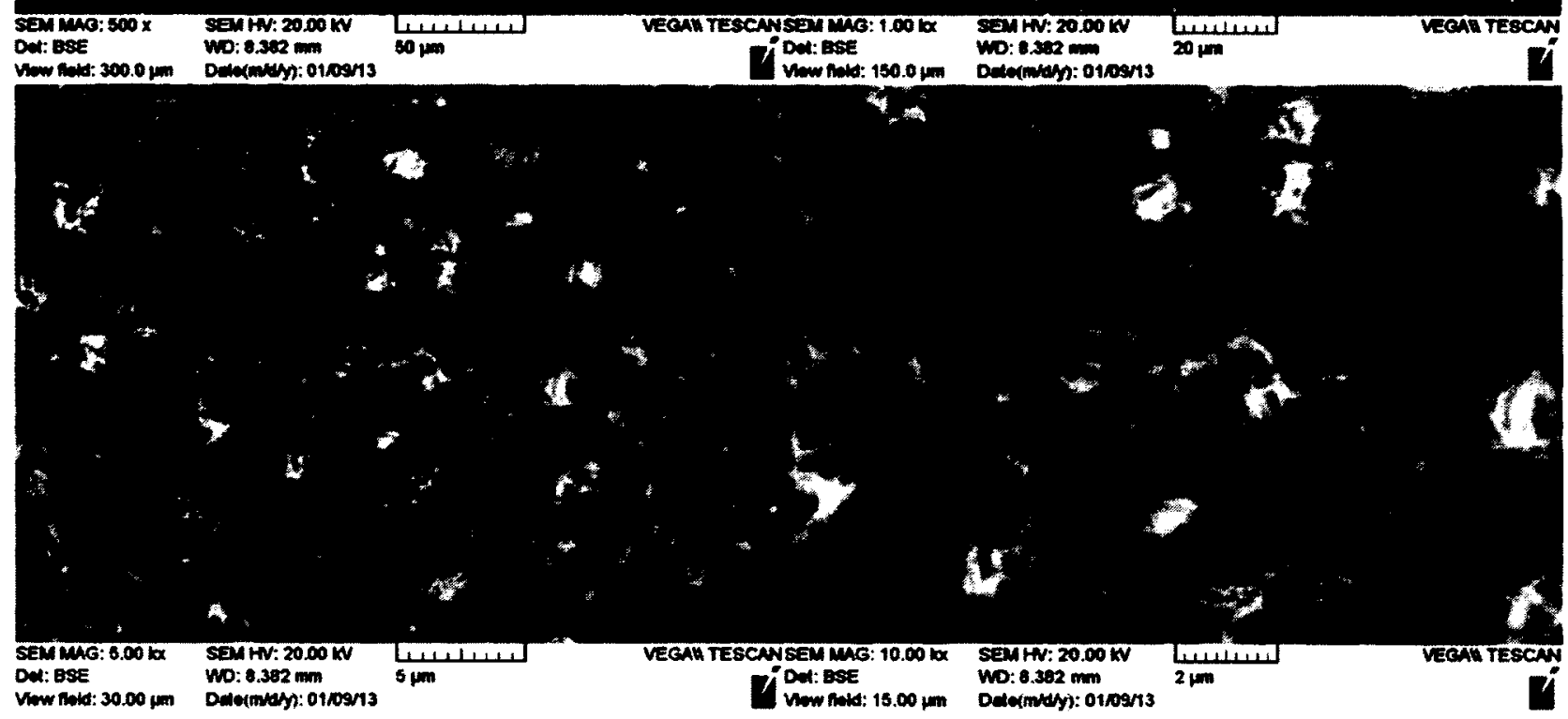

Figure 50 - SEM images of AISI 310 exposed to SHS $\left(600^{\circ} \mathrm{C}, 0.1 \mathrm{MPa}, 200 \mathrm{hrs}\right)$

After 200 hours of exposure to superheated steam, signs of oxide scale formation are clearly present. This is consistent with the weight gain results, which suggest that significant oxide formation occurs after 200 hours of exposure. Figure 51 shows the SEM images of the sample exposed to superheated steam for 300 hours. 


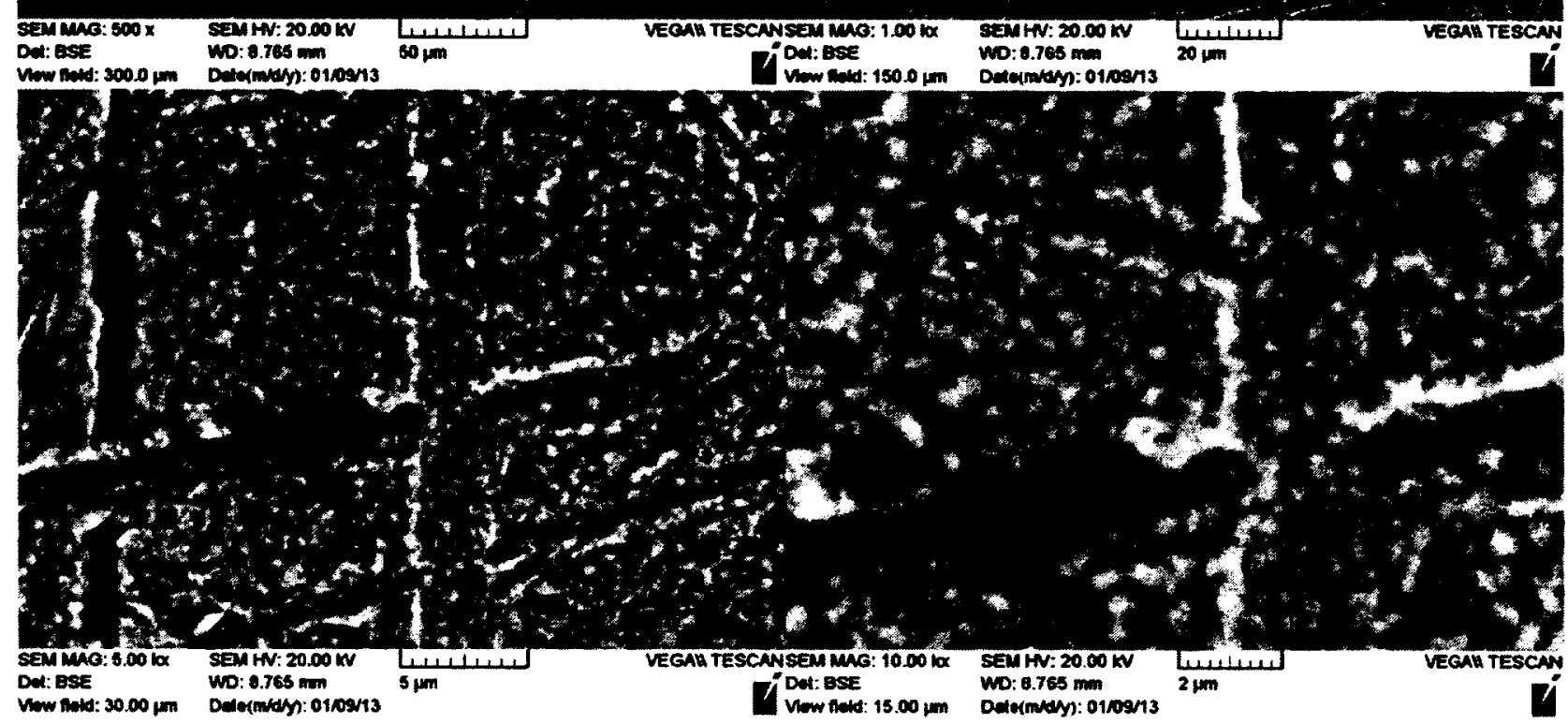

Figure 51 - SEM images of AISI 310 exposed to SHS $\left(600^{\circ} \mathrm{C}, 0.1 \mathrm{MPa}, 300 \mathrm{hrs}\right)$

The SEM images of AISI 310 exposed to superheated steam are much lighter than those of the sample exposed for 200 hours. This is consistent with the weight change results, which suggest that after 300 hours the oxide layer has been largely lost. These results suggest that an oxide layer formed after 200 hours has been removed by steam as exposure duration increases.

The compositions of the AISI 310 samples after exposure to superheated steam, as determined through EDS analysis, are given in Table 15. 
Table 15 - EDS compositions of AlSI 310 exposed to SHS $\left(600^{\circ} \mathrm{C}, 0.1 \mathrm{MPa}\right)$

\begin{tabular}{|c|c|c|c|c|c|c|c|}
\hline \multirow{2}{*}{ Exposure } & \multicolumn{6}{|c|}{ Composition by Element (Weight Percent) } \\
\cline { 2 - 8 } & $\mathrm{O}$ & $\mathrm{Al}$ & $\mathrm{Si}$ & $\mathrm{Cr}$ & $\mathrm{Mn}$ & $\mathrm{Fe}$ & $\mathrm{Ni}$ \\
\hline 100 & 9.97 & 0.59 & 2.39 & 24.47 & 1.69 & 44.64 & 16.24 \\
\hline 200 & 28.80 & 0.31 & 4.27 & 26.98 & 4.46 & 26.91 & 8.27 \\
\hline 300 & 5.98 & 0.00 & 2.13 & 24.05 & 1.44 & 48.16 & 18.24 \\
\hline
\end{tabular}

The oxygen level at the surface of the material is low after 100 hours, suggesting oxidation did not progress at the early stage; however, elevated oxygen is found in the sample exposed for 200 hours. The chromium level after 200 hours is elevated as well, suggesting the oxide layer formed is composed mainly of chromium oxide $\left(\mathrm{Cr}_{2} \mathrm{O}_{3}\right)$. This oxide was likely removed by steam after 300 hours. If the test continues for extended periods of time, the surface oxide formation and removal process will continue, depleting oxide forming elements from the material.

\section{IN625}

IN625 samples were exposed to superheated steam $\left(600^{\circ} \mathrm{C}, 0.1 \mathrm{MPa}\right)$ for durations of 100,200 , and 300 hours. Samples were cleaned according to the procedure described in the Methods section, and SEM and EDS analysis was performed. Figure 52 shows the SEM images of IN625 exposed for 100 hours. 


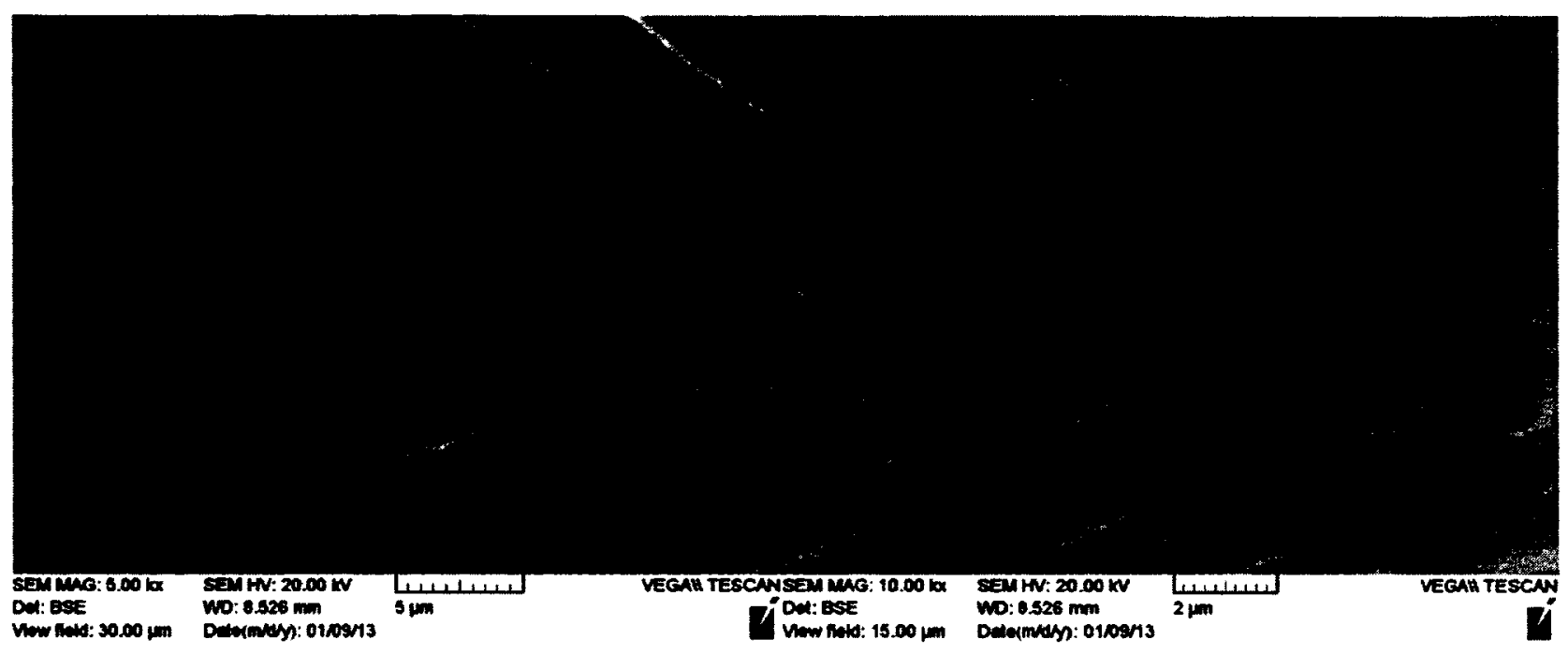

Figure 52 - SEM images of IN625 exposed to SHS $\left(600^{\circ} \mathrm{C}, 0.1 \mathrm{MPa}, 100 \mathrm{hrs}\right)$

After 100 hours of exposure to superheated steam, little change is observed on the surface of the IN625 sample. This suggests a significant oxide layer has not been formed. At some areas, however, signs of grain boundary cracking can be seen, shown in Figure 53. Cracking is detrimental to the integrity of the component for long term use. Coating of IN625 with NiCrALY has shown beneficial effect in preventing intergranular cracking [37]. 


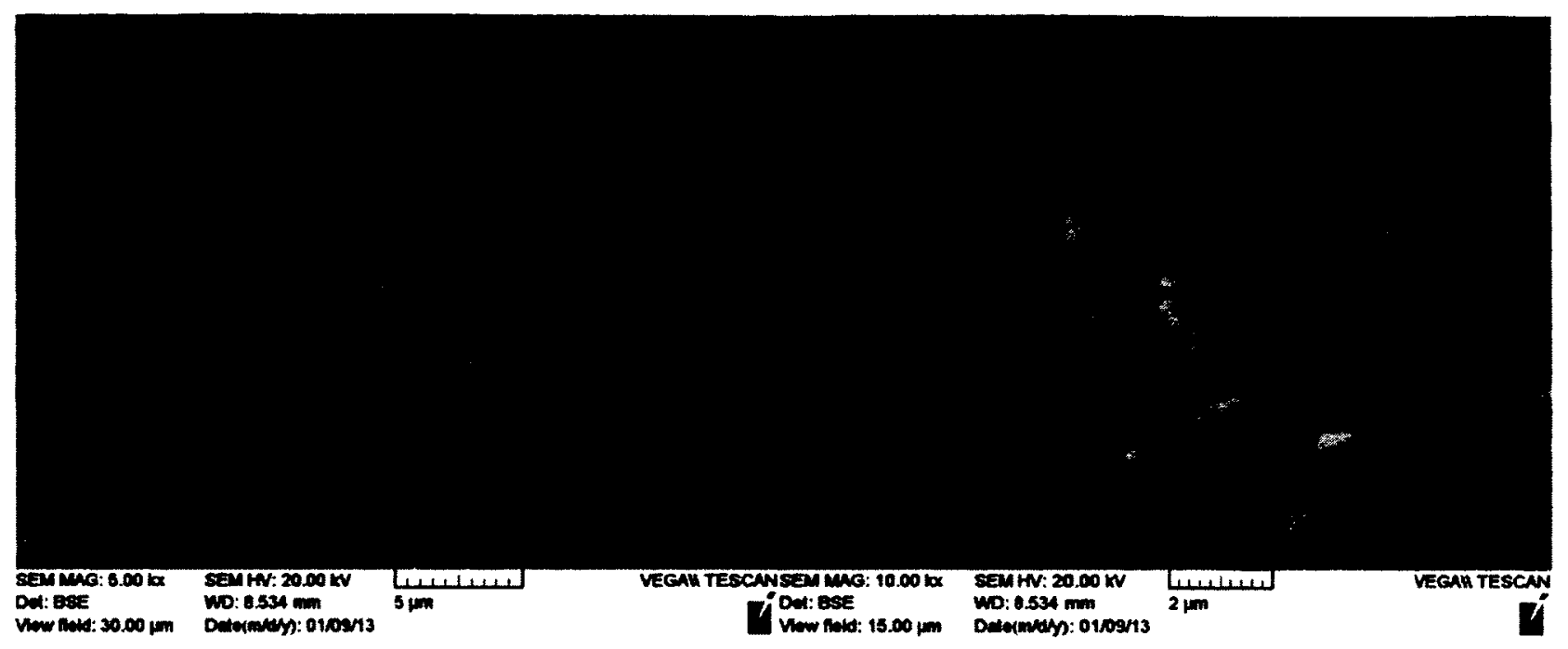

Figure 53 - SEM images of IN625 exposed to SHS $\left(600^{\circ} \mathrm{C}, 0.1 \mathrm{MPa}, 100 \mathrm{hrs}\right)$. Evidence of localized cracking.

Figure 54 shows the SEM images of IN625 exposed to superheated steam for 200 hours.

After 200 hours of exposure, some oxide scale can be seen, consistent with the increase in weight. This observation suggests that a protective oxide layer is not fully formed until 200 hours of exposure. Figure 55 shows the SEM images of the IN625 sample exposed to superheated steam for 300 hours.

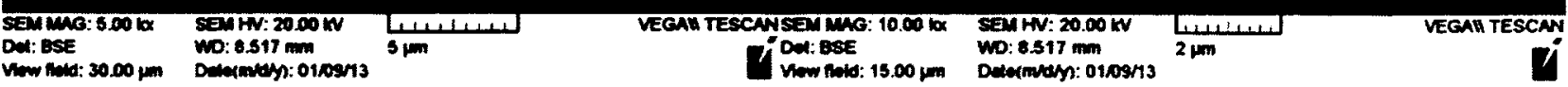

Figure 54 - SEM images of IN625 exposed to SHS $\left(600^{\circ} \mathrm{C}, 0.1 \mathrm{MPa}, 200 \mathrm{hrs}\right)$ 
After 300 hours of exposure signs of oxide scale formation have decreased, consistent with the decreased weight gain shown in Figure 32. This suggests the oxide layer formed after 200 hours has been removed after 300 hours of exposure. Signs of grain boundary cracking are still present, which could limit usefulness of IN625 for long term applications.

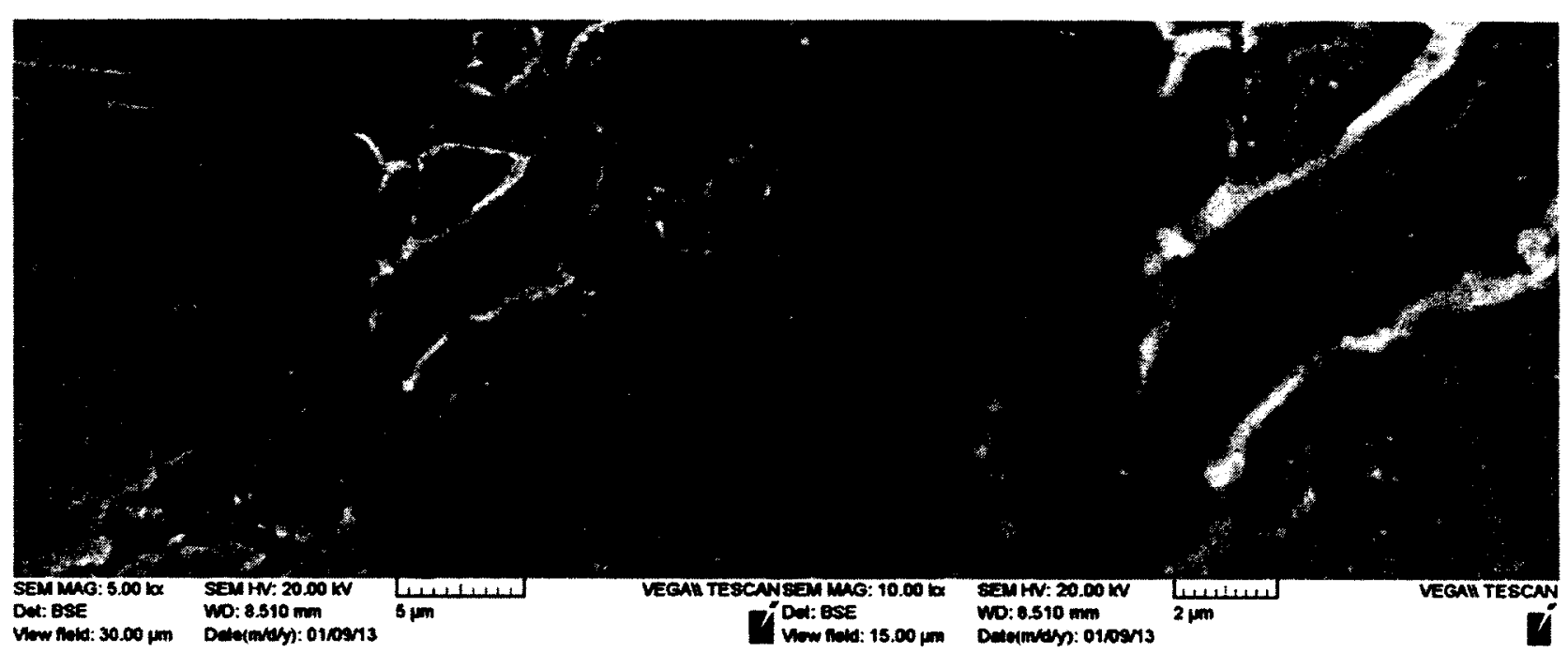

Figure 55 - SEM images of IN625 exposed to SHS $\left(600^{\circ} \mathrm{C}, 0.1 \mathrm{MPa}, 300 \mathrm{hrs}\right)$

The compositions of the IN625 samples after exposure to superheated steam, as determined through EDS analysis, are given in Table 16. The oxygen level on the surface of the sample is highly elevated after 200 hours of exposure. Chromium levels are also elevated, suggesting the formation of chromium oxide $\left(\mathrm{Cr}_{2} \mathrm{O}_{3}\right)$ as a protective oxide layer. After 300 hours, however, the levels have decreased significantly, suggesting this oxide layer has been removed. 
Table 16 - EDS compositions of IN625 exposed to SHS $\left(600^{\circ} \mathrm{C}, 0.1 \mathrm{MPa}\right)$

\begin{tabular}{|c|c|c|c|c|c|c|c|}
\hline \multirow{2}{*}{ (hours) } & \multicolumn{6}{|c|}{ Composition by Element (Weight Percent) } \\
\cline { 2 - 8 } & $\mathbf{O}$ & $\mathrm{Si}$ & $\mathrm{Cr}$ & $\mathrm{Fe}$ & $\mathrm{Ni}$ & $\mathrm{Nb}$ & Mo \\
\hline 100 & 5.48 & 0.68 & 19.10 & 4.20 & 61.61 & 0.93 & 8.00 \\
\hline 200 & 36.88 & 1.54 & 36.02 & 3.26 & 20.20 & 0.00 & 2.10 \\
\hline 300 & 10.26 & 1.27 & 17.03 & 4.02 & 60.26 & 0.00 & 7.16 \\
\hline
\end{tabular}

\subsection{Discussion}

After completing tests of all materials, the results can be compared. In supercritical water, the A286 showed higher weight gain than the others and the weight gain continues to increase for the duration of the test. The AISI 310 and the IN625 behave nearly identically, showing lower and steady weight gain for the duration of the testing. The AISI 310 showed signs of possible grain etching, and the IN625 showed some evidence of pitting or microcracking. However, these observations will need to be further confirmed with long term tests and cross sectional analysis. The difference in performance between the A286, and AISI 310 and IN625 is likely due to the $\mathrm{Cr}$ level in the materials. A286 contains 16 wt\% Cr, while AISI 310 and IN625 have 26 and 23 wt\% of $\mathrm{Cr}$, respectively. In SCW the oxide layer formed on AISI 31 and IN625 was seen to be composed of stable, protective $\mathrm{Cr}_{2} \mathrm{O}_{3}$, while on the $\mathrm{A} 286$ the oxide layer is largely $\mathrm{FeO}$, which is less protective and allows more corrosive species reaching the substrate thus degrading the integrity of the base material with increased exposure time. Based on these results, A286 appears inappropriate for use in a SCWR. AISI 310 and IN625, 
however, both perform well in terms of weight change (although the likelihood of selective surface etching and attacking will need to be further evaluated). Since AISI 310 is much less expensive and more commonly available than IN625, it would be preferable for SCWR use.

In superheated steam the corrosion behaviour was very different. Overall weight gains in SHS were all within $<0.6 \mathrm{mg} / \mathrm{cm}^{2}$ after 200 hours. However, A286 showed some initial oxide growth, which was immediately lost as exposure time increased (Figure 56). Both AISI 310 and IN625 showed the highest oxide growth after 200 hours, but by 300 hours weight loss started to occur. Some evidence of cracking was present on the IN625 samples. The difference in behaviour between the A286, AISI 310 and IN625 can be attributed to the difference in $\mathrm{Cr}$ levels. While some $\mathrm{Cr}_{2} \mathrm{O}_{3}$ growth was evident on the A286 samples, most of the oxide layer was still FeO, which led to faster oxide growth and potential spallation in longer term testing. Both the AISI 310 and IN625 formed $\mathrm{Cr}_{2} \mathrm{O}_{3}$ layers; however, the dynamic nature of the steam led to the oxide layer being stripped from the surface. No material showed strong corrosion resistance in superheated steam. This is consistent with work done by Ruther and Greenberg, who found corrosion in dynamic tests, such as these superheated steam tests, was 1.5 times higher than that in the static tests, such as the supercritical water tests [28]. 


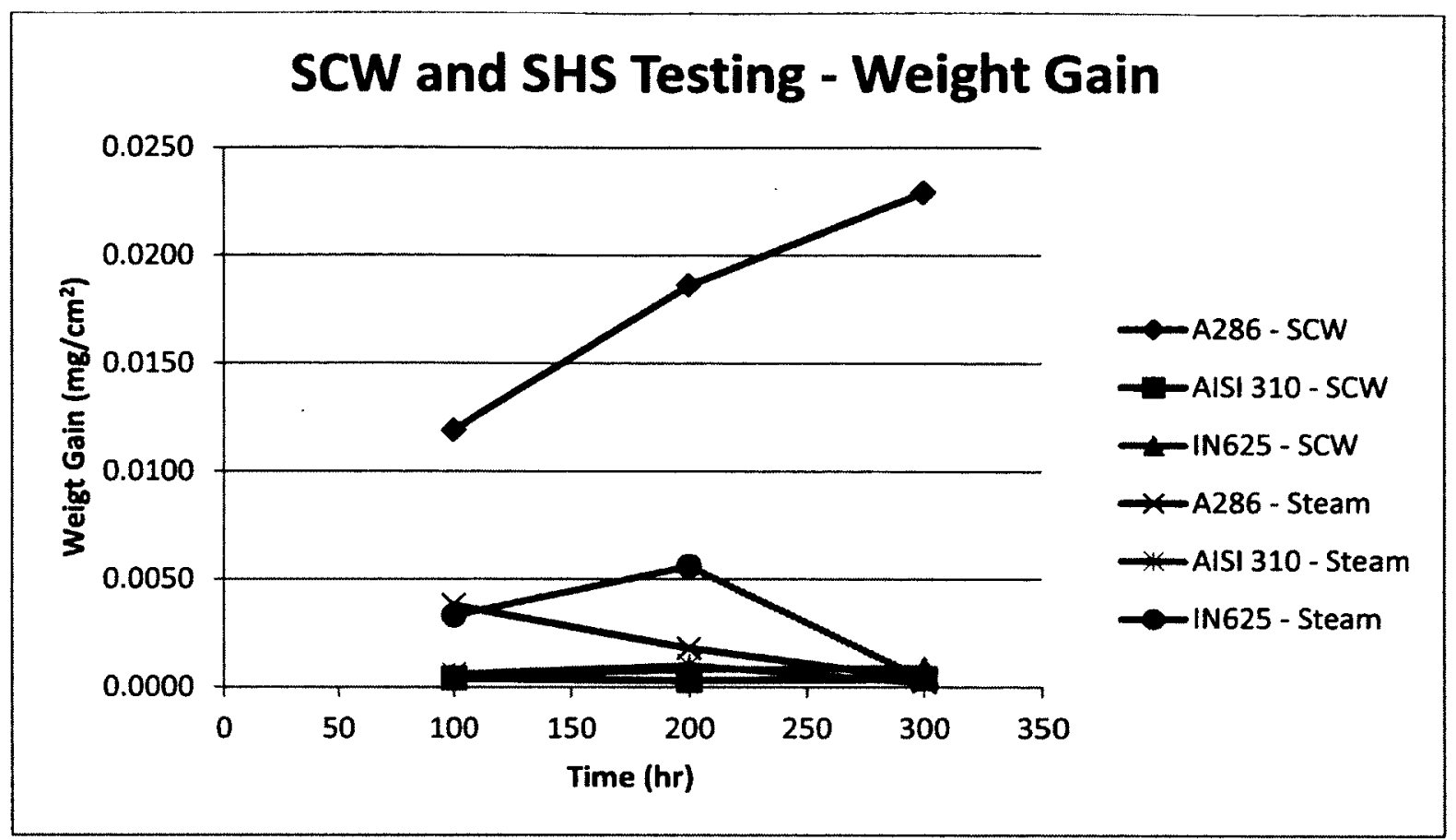

Figure 56 - Weight gain comparison (solid lines represent SCW and dashed lines SHS). The difference in oxidation behaviour for samples exposed to the supercritical water and to the superheated steam also suggests that one cannot be used as a testing proxy for the other. This can be seen when the weight gain data is compared between the two sets of tests, shown in Figure 56.

The dynamic nature of the superheated steam led to oxide spallation on all three samples, an effect not present during the static supercritical water testing. While AISI 310 and IN625 appeared corrosion resistant when exposed to supercritical water, the effect of flowing superheated steam in removing protective scale must be taken into consideration when selecting suitable materials for SCWR. 


\section{Conclusions}

A286 shows poor corrosion resistance in both supercritical water and superheated steam due to its relatively low chromium content. This material is not appropriate for use in a supercritical water cooled nuclear reactor where corrosion in supercritical water would be a serious concern.

IN625 has a high chromium content and showed strong corrosion resistance, in terms of weight change, when exposed to supercritical water, but suffered loss of its protective oxide layer in superheated steam. The possible grain boundary cracking must be further evaluated.

AISI 310 has higher chromium content and performed nearly identically to the IN625. It showed strong corrosion resistance in supercritical water, but lost its oxide layer in superheated steam testing. This material is much more commonly used than IN625, and significantly less expensive, and should be considered as a possible candidate material for supercritical water cooled reactor applications if the temperature is below $650^{\circ} \mathrm{C}$. In addition nickel is less desirable than iron for nuclear reactor applications due to its larger neutron cross section, so the lower nickel content of AISI 310 makes it preferable to IN625. The preferential grain etching, however, should be examined with long term testing.

The corrosion behaviour of the samples exposed to supercritical water was dramatically different than that of the samples exposed to superheated steam at the same temperatures. The static supercritical water test rig causes a very different effect than 
the dynamic superheated steam test rig due to the difference in pressure and fluid dynamics between the two. High temperature tests in superheated steam cannot be used as a substitute for testing in supercritical water, and a method of testing materials in high temperature flowing supercritical water (in a circulation loop) must be conducted. 


\section{Future Work}

To gain a better understanding of the degree of corrosion each material experienced, the test samples should be etched to remove oxides from the surface and reweighed. This was desired for this round of testing, but the necessary etching compounds could not be acquired in time. The following descaling procedure is suggested for etching $\mathrm{Fe}$ based alloys.

1. Mix descaling solution 1 and 2 according to Table 17.

Table 17 - Etching solution compositions

\begin{tabular}{|l|l|}
\hline Solution 1 & Composition (\%) \\
\hline Citric Acid & 2 \\
\hline Dibasic Ammonium Citrate & 5 \\
\hline Disodium EDTA & 0.5 \\
\hline Solution 2 & Composition (\%) \\
\hline Potassium Permanganate & 10 \\
\hline Caustic Soda & 4 \\
\hline
\end{tabular}

2. Expose samples to $1 \mathrm{~L}$ of stirred solution 1 at $90^{\circ} \mathrm{C}$ for 60 minutes.

3. Expose samples to $1 \mathrm{~L}$ of stirred solution 2 at $90^{\circ} \mathrm{C}$ for 60 minutes.

4. Expose samples to $1 \mathrm{~L}$ of fresh stirred solution 1 at $90^{\circ} \mathrm{C}$ for 30 minutes. 
5. Remove samples, wash in methanol in an ultrasonic cleaner for $\mathbf{1 5}$ minutes, dry, and weigh.

6. Repeat steps 4 and 5 until samples reach a constant weight.

To remove the oxide from the IN625 samples, solution 2 in Table 17 can be used. The preceding procedure, removing steps 2 and 4 , should be used.

Long term tests for the promising materials, AISI 310 and IN625, should be performed. Samples of these materials should be exposed to supercritical water and superheated steam for durations in the thousands of hours to gain a better understanding of corrosion behaviour.

Some contamination of the samples was seen during these tests. Samples exposed to supercritical water appeared to be contaminated by the lubricating grease used on the autoclave seal assembly. Great care should be taken during future testing to ensure the minimum amount of lubricant is used, and no lubricant is present on the inside of the autoclave test chamber. In the superheated steam testing, some samples were contaminated from the alumina insulation on which they were placed. A rack to hang samples, similar to that used in the autoclave, should be designed and built for future testing. 


\section{Bibliography}

[1] International Energy Agency, "2012 Key World Energy Statistics," International Energy Agency, Paris, 2012.

[2] GEN IV International Forum, "The Generation IV International Forum," 3 September 2012. [Online]. Available: www.gen-4.org.

[3] Gen IV International Forum, "GIF and Generation-IV," Gen IV International Forum.

[4] National Sciences and Engineering Research Council of Canada, "Canada's National Program on Generation IV Energy Technologies - Research and Development Priorities for 2012-16," National Sciences and Engineering Research Council of Canada, 11 July 2012. [Online]. Available: http://www.nserc-crsng.gc.ca/professorsprofesseurs/rpp-pp/GENIV0809Priorities-GENIV0809Priorites_eng.asp.

[5] Gen IV International Forum, "Supercritical Water-Cooled Reactor," Gen IV International Forum, [Online]. Available: http://www.gen4.org/Technology/systems/scwr.htm.

[6] L. Leung, "Canada's Super-Critical Water-cooled Reactor Design Concept," AECL, Saskatoon, 2012.

[7] A. S. Leyzerovich, Steam Turbines for Modern Fossil-Fuel Power Plants, Fairmont 
Pres, Inc., 2008.

[8] M. Kutz, "Supercritical Water Oxidation," in Environmentally Conscious Materials and Chemical Processing, John Wiley \& Sons, 2007.

[9] D. Guzonas, J. Wills, H. Dole, J. Michel, S. Jang, M. Haycock and M. Chutumstid, "Steel Corrosion in Supercritical Water: An Assessment of the Key Parameters," in The 2nd Canada-China Joint Workshop On Supercritical Water-Cooled Reactors (CCSC-2010), Toronto, 2010.

[10] P. Kritzer, "Corrosion in High-Temperature and Supercritical Water and Aqueous Solutions: A Review," Journal of Supercritical Fluids, vol. 29, pp. 1-29, 2004.

[11] Department of Biochemistry and Molecular Biophysic, "Chemistry Tutorial - The Chemistry of Water," University of Arizona, 2003. [Online]. Available: http://www.biology.arizona.edu/biochemistry/tutorials/chemistry/page3/html.

[12] P. Kritzer, N. Boukis and E. Dinjus, "Factors Controlling Corrosion in HighTemperature Aqueous Solutions: A Contribution to the Dissociation and Solubility Data Influencing Corrosion Processes," Journal of Supercritical Fluids, vol. 15, pp. 205-227, 1999.

[13] Č. Václav, V. Múčka and V. Viliam, "Radiation Induced Corrosion of Nuclear Fuel and Materials," in Advances in Nuclear Fuel, S. T. Revankar, Ed., InTech, 2012. 
[14] W. G. Cook and R. Olive, "Pourbaix Diagrams for Iron, Nickel and Chromium in SubCritical and Supercritical Water," in The 2nd Canada-China Joint Workshop on Supercritical Water-Cooled Reactors (CSC-2010), Toronto, 2010.

[15] A. Roine and K. Antilla, "Eh-pH-Diagrams (Pourbaix Diagrams)," HSC Chemistry, 10 August 2006. [Online]. Available: http://www.outotec.com/39483.epibrw.

[16] A. R. a. K. Antilla, "Eh-pH-Diagrams (Pourbaix Diagrams)," HSC Chemistry, 10 August 2006. [Online]. Available: http://www.outotec.com/39483.epibrw.

[17] Y. Chen, K. Sridharan and T. Allen, "Corrosion Behavior of Ferritic-Martensitic Steel T91 in Supercritical Water," Corrosion Science, vol. 48, pp. 2843-2854, 2006.

[18] Spirax Sparco, "Superheated Steam," 2012. [Online]. Available: http://www.spiraxsarco.com/resources/steam-engineering-tutorials/steamengineering-principles-and-heat-transfer/superheated-steam.asp. [Accessed 7 August 2012].

[19] F. Hajabdollahi, Z. Hajabdollahi and H. Hajabdollahi, "Soft computing based multiobjective optimization of steam cycle power plant using NSGA-II and ANN," Applied Soft Computing, vol. 12, no. 11, pp. 3648-3655, 2012.

[20] A. Fry, S. Osgerby and M. Wright, "Oxidation of Alloys in Steam Environments - A Review," National Physical Laboratory, Middlesex, 2002. 
[21] N. Otsuka and H. Fujikawa, "Scaling of Austenitic Stainless Steels and Nickel-Base Alloys in High-Temperature Steam at 973 K," Corrosion, vol. 47, no. 4, pp. 240-248, 1991.

[22] J. F. Shackelford, Introduction to Materials Science for Engineers, 6th ed., Upper Saddle River, New Jersey: Pearson Prentice Hall, 200.

[23] G. Was, P. Ampornrat, G. Gupta, S. Teysseyre, E. West, T. Allen, K. Sridharan, L. Tan, Y. Chen, X. Ren and C. Pister, "Corrosion and Stress Corrosion Cracking in Supercritical Water," Journal of Nuclear Materials, vol. 371, pp. 176-201, 2007.

[24] L. Zhang, F. Zhu, Y. Bao and R. Tang, "Corrosion Tests of Candidate Fuel Cladding and Reactor Internal Structural Materials," in The 2nd Canada-China Joint Workshop on Supercritical Water-Cooled Reactors (CCSC-2010), 2010, 2010.

[25] J. E. Croll and G. R. Wallwork, "The High-Temperature Oxidation of Iron-ChromiumNickel Alloys Containing 0-30\% Chromium," Oxidation of Metals, vol. 4, no. 3, pp. $121-140,1972$.

[26] Y. Otoguro, M. Sakakibara, T. Saito, H. Ito and Y. Inoue, "Oxidation Behaviour of Austenitic Heat-resisting Steels in a High Temperature and High Pressure Steam Enironment," Transactions ISIJ, vol. 28, pp. 761-768, 1988.

[27] T. Maekawa, M. Kagawa and N. Nakajima, "Corrosion Behaviours of Stainless Steel in High-Temperature Water and Superheated Steam," Translated Journal of the 
Japan Institute of Metals, vol. 9, pp. 130-136, 1968.

[28] W. E. Ruther and S. Greenberg, "Corrosion of Steels and Nickel Alloys in Superheated Steam," Journal of the Electrochemical Society, vol. 111, no. 10, pp. 1116-1121, 1964.

[29] S. Cisse, L. Laffont, B. Tanguy, M.-C. Lafont and E. Andrieu, "Effect of surface preparation on the corrosion of austenitic stainless steel 304L in high temperature steam and simulated PWR primary water," Corrosion Science, vol. 56, pp. 209-216, 2012.

[30] N. J. Cory and T. M. Herrington, "Kinetics of Oxidation of Ferrous Alloys by SuperHeated Steam," Oxidation of Metals, vol. 28, no. 5/6, pp. 237-257, 1987.

[31] J. C. Griess and W. A. Maxwell, "The Long-Term Oxidation of Selected Alloys in SUperheated Steam at 482 and 538oC," Oak Ridge National Laboratory, Oak Ridge, 1981.

[32] M. Warzee, J. Hennaut, M. Maurice, C. Sonnen, J. Waty and P. Berge, "Effect of Surface Treatment on the Corrosion of Stainless Steels in High-Temperature Water and Steam," Journal of the Electrochemical Society, vol. 112, no. 7, pp. 670-674, 1965.

[33] Atomic Energy of Canada Limited, AECL Internal Communication, 2012. 
[34] "A-286 High Strength Iron-Based Superalloy - Properties, Composition, Heat Treatments and Specifications from Super Alloys," AZoM.com, 13 May 2008. [Online]. Available: http://www.azom.com/article.aspx?ArticlelD=4221.

[35] "Alloy 625 - Inconel 625 Properties and Applications," AZoM.com, 29 June 2011. [Online]. Available: http://www.azom.com/article.aspx?ArticlelD=5738.

[36] "Stainless Steel - Grade 310," AZoM.com, 23 October 2001. [Online]. Available: http://www.azom.com/article.aspx?ArticlelD=966.

[37] A. Selvig, X. Huang, D. Kim and D. Guzonas, "Oxide Formation on IN 625 and Plasma Sprayed NiCrAlY after High Density and Low Density Supercritical Water Testing," Journal of Materials and Corrosion, 2012. 